\title{
Investigation of Pallet Stacking Pattern on Unit Load Bridging
}

\author{
Eduardo Molina Montoya
}

Thesis submitted to the faculty of the Virginia Polytechnic Institute and State University in partial fulfillment of the requirements for the degree of

Master of Science

In

Forest Products

Laszlo Horvath, Committee Chair

Marshall S. White

Brad A. Gething

\author{
May $4^{\text {th }}, 2017$ \\ Blacksburg, VA
}

Keywords: pallets, stacking patterns, packaging, unit load, unit load interactions 


\title{
Investigation of Pallet Stacking Pattern on Unit Load Bridging
}

\author{
Eduardo Molina Montoya
}

\section{ACADEMIC ABSTRACT}

The optimization of pallet design in today's competitive supply chain is imperative to reduce costs and improve sustainability. With over two billion pallets in circulation in the United States, most packaged products are handled using unit loads and the interactions between the unit load components are not being considered in the pallet design process. This study aims to investigate the effect of the interlocking of layers and the pallet stacking patterns on pallet bending. This effect is part of a greater encompassing observed behavior known as load bridging, where a redistribution of the stresses on the pallet dependent on the characteristics of the load is generated.

The bending of the unit load was measured under four common support conditions, warehouse racked across the width and length, fork tine support across the width and floor stacking. Five different pallet stacking patterns were then analyzed, comparing different interlocking levels, from column stacking to fully interlocking.

It was identified that interlocking the layers causes a reduction in pallet deflection of up to $53 \%$ versus column stacking, and is more significant on lower stiffness pallets. The stacking patterns and interlocking levels also presented an effect on pallet deflection, albeit only for very low stiffness pallets when supported on its weakest components.

A relationship between the observed results and a ratio of load and pallet stiffness was conducted, suggesting that when the load on the pallet is not significantly high in relation to the stiffness, load bridging won't be observed. These results provide a guideline on improving pallet design and help furthering the understanding of the load bridging effect. 


\title{
Investigation of Pallet Stacking Pattern on Unit Load Bridging
}

\author{
Eduardo Molina Montoya
}

\section{GENERAL AUDIENCE ABSTRACT}

The optimization of pallet design in today's competitive supply chain is imperative to reduce costs and improve sustainability. With over two billion pallets in circulation in the United States, most packaged products are handled using unit loads and the interactions between the unit load components are not being considered in the pallet design process. This study aims to investigate the effect of the interlocking of layers and the pallet stacking patterns on pallet bending. This effect is part of a greater encompassing observed behavior known as load bridging, where a redistribution of the stresses on the pallet dependent on the characteristics of the load is generated.

Tests were conducted to measure the pallet bending performance under common scenarios, evaluating the effect of five different pallet stacking patterns. It was identified that when the layers of a unit load are interlocked, the pallet presents lower deflection (up to $53 \%$ ).

A relationship between the observed results and a ratio of load and pallet stiffness was conducted, suggesting that when the load on the pallet is not significantly high in relation to the stiffness, load bridging won't be observed.

These results provide a guideline on improving pallet design and help furthering the understanding of the load bridging effect. 


\section{TABLE OF CONTENTS}

Chapter 1: Introduction .............................................................................................................. 1

Chapter 2: Literature Review............................................................................................ 5

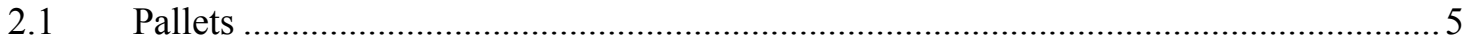

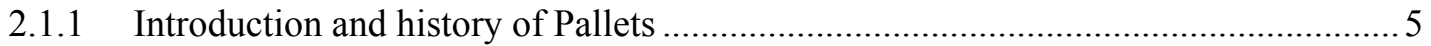

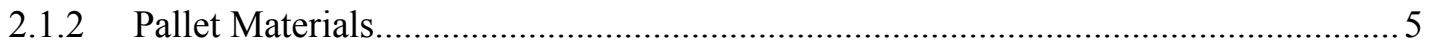

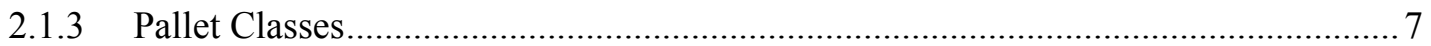

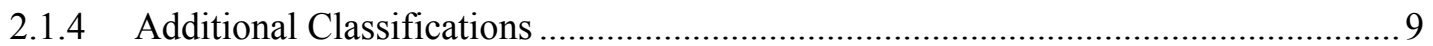

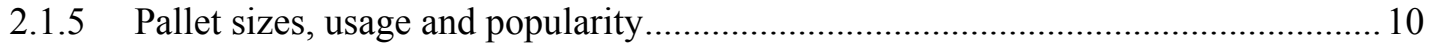

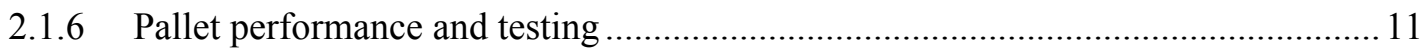

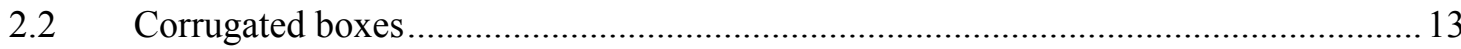

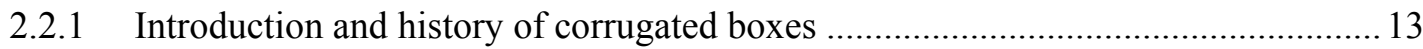

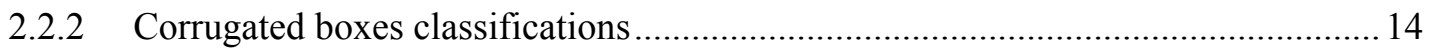

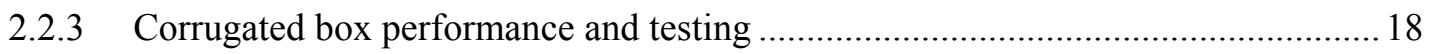

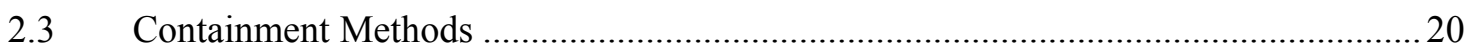

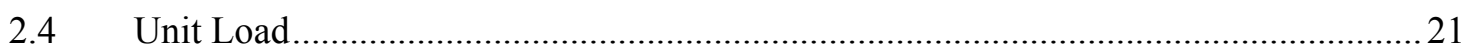

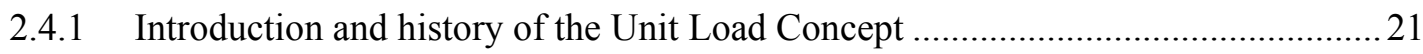

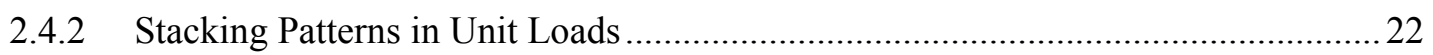

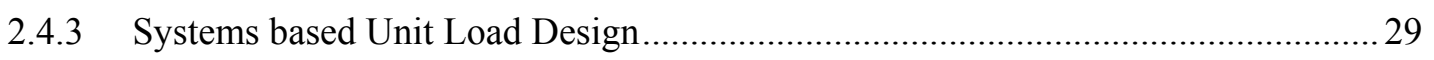

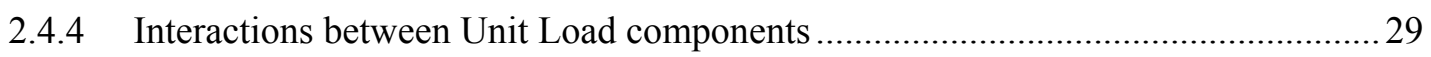

Chapter 3: Materials, Methods and Experimental Design ............................................... 35

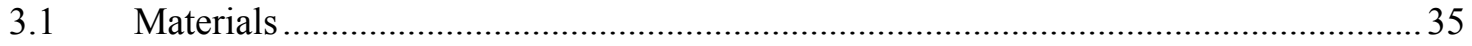

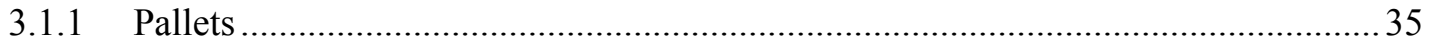

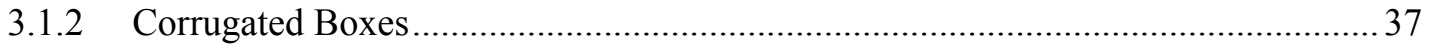

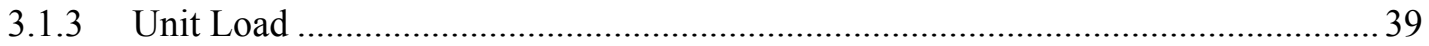

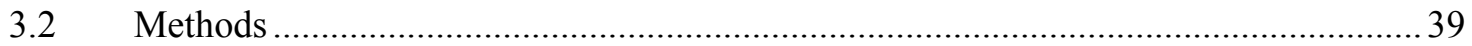

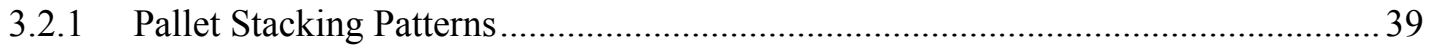

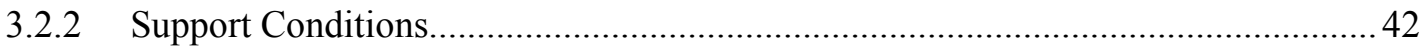

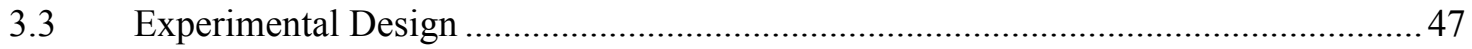

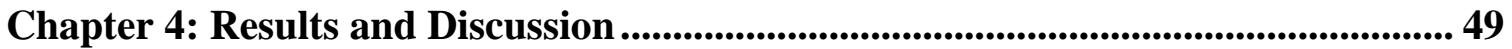

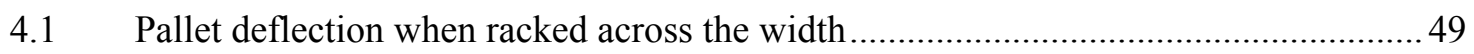


4.2 Pallet deflection when racked across the length .................................................... 51

4.3 Pallet deflection when supported on fork tines across the width................................53

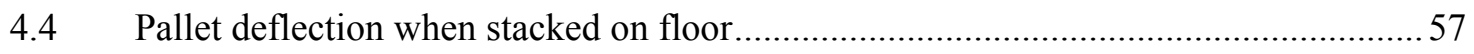

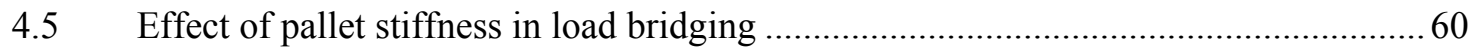

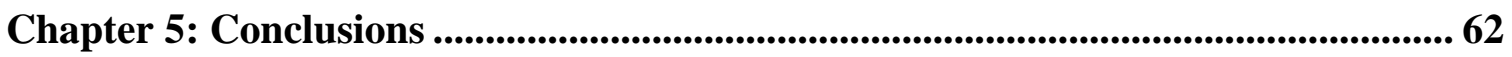

Chapter 6: Recommendations for future research .............................................. 64

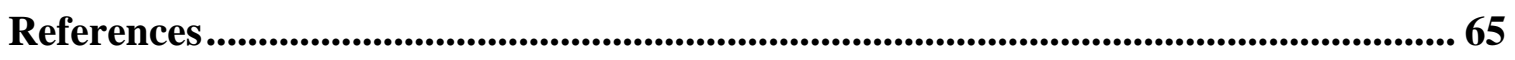

Appendix A: Modulus of Elasticity (MOE) measurements for pallet components .. 71

Appendix B: Statistical analysis results for the effect of pallet stacking patterns on

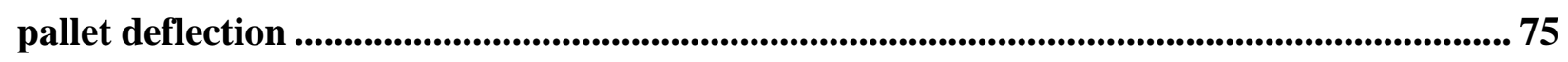

Appendix C: Data collected for the evaluation of the effect of pallet stacking

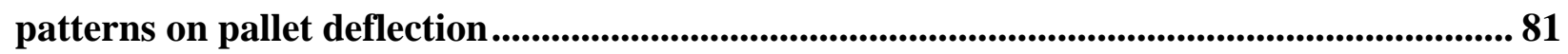




\section{List of Figures}

Figure 1. Schematic Diagram of Typical Stringer Class Pallet, with Principal Parts Labeled (MH1 Committee, 2016)

Figure 2. Schematic Diagram of Typical Block Class Pallet, with Principal Parts Labeled (MH1 Committee, 2016) ……................................................................................................... 9

Figure 3. Possible corrugated configurations (from Foster 2010), ............................................. 15

Figure 4. (a) Guillotinable and (b) non-guillotinable stacking patterns (From (Silva et al., 2016)).

Figure 5. Examples of possible pallet patterns (From (Heskett et al., 1964)) .............................. 24

Figure 6. Five basic stacking pattern forms. (From (Peleg \& Peleg, 1976)) ................................. 25

Figure 7. Example of a column stacked unit load supported on a forklift................................... 28

Figure 8. Pallet racked across the width under uniformly distributed loading with an airbag. .... 30

Figure 9. Experimentally observed load redistribution of a four-layer unit load on a racked across

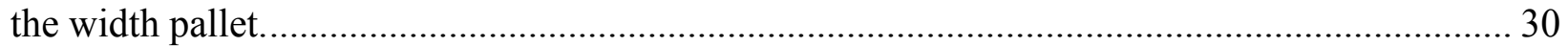

Figure 10. Experimental setup for the warehouse rack support across the width......................... 42

Figure 11. Identification of the pallet locations for the deflection measurements of the warehouse

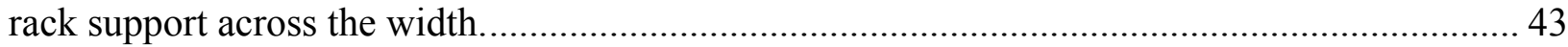

Figure 12. Experimental setup for the warehouse rack support across the length........................ 44

Figure 13. Identification of the pallet locations for the deflection measurements of the warehouse

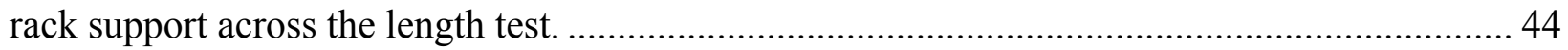

Figure 14. Experimental setup for the fork tine support across the width................................... 45

Figure 15. Identification of the pallet locations for the deflection measurements of the fork tine

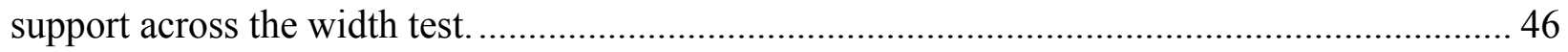

Figure 16. Experimental setup for the floor support.................................................................. 46 Figure 17. Identification of the pallet locations for the deflection measurements of the floor support

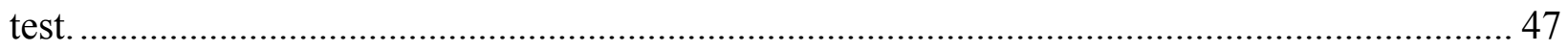

Figure 18. Average racked across the width pallet center deflection by stacking pattern and pallet design. 50

Figure 19. Average racked across the length pallet center deflection by stacking pattern and pallet design. 53 
Figure 20. Average fork tine support racked across the width pallet deflection by stacking pattern

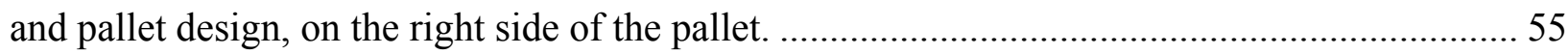
Figure 21. Load transfer schematic of a column stacked Unit Load on a fork lift support across the width. 56

Figure 22. Average floor stacking pallet top deckboard deflection by stacking pattern and pallet

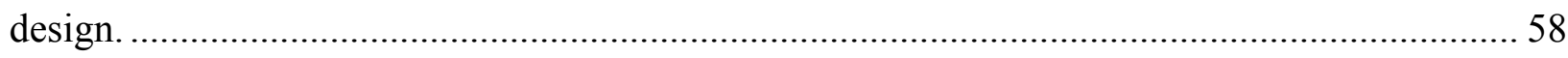

Figure 23. Schematic of load transfer in the floor stacking mode ..............................................59

Figure 24. Top deckboard deflection measurement locations. ..................................................... 59 


\section{List of Tables}

Table 1. Common materials used for pallet manufacturing, advantages, disadvantages and uses (adapted from (Clarke, 2004; Lacefield, 2015)).

Table 2. Market share estimate and usage of pallets by different materials (adapted from (McCrea, 2016; The Freedonia Group, 2008)). 7

Table 3. ISO Standard Pallet Dimensions (Adapted from ISO 6780: 2003) .......................... 11

Table 4. Most common flute styles and characteristics (adapted from Dekker, n.d.; Foster 2010).

Table 5. Common nominal basis weights for linerboard and medium in the U.S. and similar international grades (adapted from Steadman 2002) . ...................................................... 17

Table 6. Dimensions for the components of the pallets.................................................... 35

Table 7. Modulus of Elasticity (MOE) and Moisture Content (M.C.) for the pallet components.36 Table 8. Pallet stiffness for the low, medium and high stiffness designs under uniform loading. 36 Table 9. Performance estimation for the low, medium and high stiffness pallets based on The Pallet

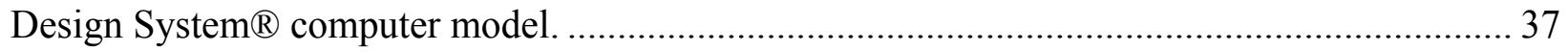

Table 10. Performance characteristics of the corrugated fiberboard used in the experimentation

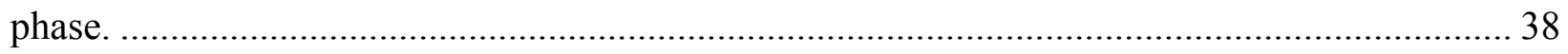

Table 11. Stacking Patterns developed for the study (Images generated using BestLoad $®$ )....... 41 Table 12. Experimental Designs for the Unit Load Deflection. ............................................. 48 Table 13. Average racked across the width pallet center deflection by stacking pattern and pallet design.

Table 14. Average racked across the width pallet ends deflection by stacking pattern and pallet design.

Table 15. Average racked across the length pallet center deflection by stacking pattern and pallet design. 52

Table 16. Average racked across the length pallet ends deflection by stacking pattern and pallet design. 52

Table 17. Average fork tine support racked across the width pallet deflection by stacking pattern and pallet design, on the right side (A) of the pallet. . 54 Table 18. Average fork tine support racked across the width pallet deflection by stacking pattern and pallet design, on the left side (B) of the pallet. 54 
Table 19. Diagrams of pallet patterns for the bottom layers.............................................. 56 Table 20. Average floor stacking pallet top deckboard deflection by stacking pattern and pallet

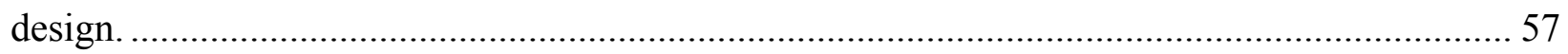

Table 21. Deflection of top deckboards under a floor stacking support at four locations........... 60 Table 22. Load-stiffness ratio for every pallet design under common support conditions with a

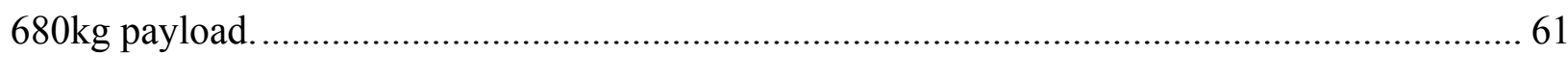




\section{Chapter 1: Introduction}

Given the current design of global distribution and transportation of goods, pallets can be characterized as the backbone of the supply chain. Although there are over 2 billion pallets in circulation in the United States (McGinley, 2016), its importance has been understated.

Today most handling of packaged goods is conducted using unit loads, which consists of a pallet and packages that are commonly secured together through various containment methods such as stretch wrapping, strapping and/or interlocking the packages, among others. The design of these unit load components involved in material handling operations, historically have been performed separately, without considering how certain changes in the characteristics of one component might affect the performance of the other components. To address this, White (2005) proposed a "Systems-based Design" methodology, where the unit load interactions are key to the design optimization process.

The most ubiquitous package material in the unit load is the corrugated fiberboard box, which is used for the transportation of over 95\% of North America's consumer goods (Fibre Box Association, 2015) and represents more than $80 \%$ of the volume of shipping materials used (Twede, Selke, Kamdem, \& Shires, 2014). Extensive research has been carried out to predict and model the mechanical behavior of corrugated boxes (Frank, 2014; Thomas J Urbanik \& Frank, 2006). In the early studies conducted by McKee (1957; 1963), a formula was developed for the calculation of box compression strength and has been the basis for modeling box performance. Kellicut $(1963 ; 1951)$, began the investigation to understand the effects of the various factors on box compression strength, such as moisture content, time under load, contents, and the load bearing surface. But only a limited number of studies focused more extensively on the effect of support conditions (pallet gap, overhang) on compression strength (Baker, Horvath, \& White, 2016a, 2016b; DiSalvo, 1999; Ievans, 1975; Kellicut, 1963; Monaghan \& Marcondes, 1992). Most of these studies assumed that the boxes are supported on a rigid, uniform surface, not fully considering the effect of the pallet itself (Frank, 2014). Baker (2016a) was the first one who unambiguously considered the effect of pallet stiffness on the compression strength of the box.

On the other hand, an assumption of a uniformly distributed flexible load on top of a pallet has been the usual technique for predicting or measuring the load capacity of pallets, and this has 
been conducted commonly using an airbag as load applicator in laboratory environments. Lofersky et. al (1988) developed a reliability based method for the design of wooden pallets. Wooden pallets are used by $96 \%$ of companies in the U.S. (McCrea, 2016). Additional research has been conducted to improve the modeling capabilities of wooden pallets using the assumption of uniformly distributed loading (Samarasinghe, 1987; T J Urbanik, 1985a, 1985b; B. S. White, 2008). This technique provides a safe baseline and is necessary for a replicable modeling method but it was proven to underestimate the load capacity of pallets carrying packages such as bags, boxes, pails, etc. (Collie, 1984; Fagan, 1982). The underestimation is due to a phenomenon known as the load bridging effect, that reduces stresses in the pallet because of a redistribution of the pressure along the packages.

In order to characterize the load bridging effect, multiple studies have been conducted to account for different compositions of the packages on top of a pallet, taking also into consideration the available support conditions. Fagan (1982) conducted the first investigation on the subject comparing four different load types (an airbag, two interlocked box loads and a platen-type load) and concluded that the load type has a significant effect on the pallet stiffness and the magnitude of the effect is dependent on the stiffness of pallet, being less for high stiffness pallets. This study did not identify a significant difference between the two interlocking patterns used.

Collie (1984) further analyzed this load bridging effect. It was identified that when multiple unit loads are stacked on the top of each other, the deflection of the top deckboards of the bottom pallet does not increase proportionally to the amount of unit loads stacked. It was concluded that only $80 \%$ of the weight of the second unit load and $66 \%$ of the third unit load contributed to the bending of the top deckboard of the bottom pallet. Regarding the racking condition, an experiment with seven load types was conducted, concluding that a significant difference exists on pallet deflection when the rigidity of the load changes. Collie found differences among two interlocking pattern of boxes when racked across the deckboards on a low stiffness pallet, but not on the higher stiffness treatments or when racked across the stringers.

Park et al. (2017) confirmed that the size of the boxes and the flute type have a significant effect on load bridging, increasing pallet deflection when box size decreases or when flute type is less stiff. The type of containment method and force applied also has a significant effect on the rigidity of the load, affecting unit load deflection(M. S. White, Dibling, Rupert, \& Mcleod, 1999). Yoo (2011), based on the principle of a beam on an elastic foundation, developed a model to 
predict compressive stress distributions at the interface between the packages and the pallet, which depends on deckboard stiffness, package stiffness and pallet joint fixity. Empirical data of these studies showed that load bridging decreases pallet deflection for certain conditions, but its effect on ultimate pallet strength has not been evaluated due to the fact that most packages fail at a lower load than the necessary load to reach pallet failure.

The pallet stacking pattern, one of the factors affecting load bridging, has also been widely investigated from different perspectives and multiple disciplines. Extensive literature and multiple software packages can be found on solving the "Manufacturer's Pallet Loading Problem", which focuses on finding the optimal or most efficient arrangement of a set of rectangular boxes on a pallet, mainly to maximize volume utilization in transport(Silva, Oliveira, \& Wäscher, 2016). From the standpoint of the performance of corrugated boxes, research has been conducted to measure the reduction in compression strength when using an interlocking pattern instead of a columnar stacking pattern (DiSalvo, 1999; Frank, Gilgenbach, \& Maltenfort, 2010; Ievans, 1975; Kellicut, 1963; Monaghan \& Marcondes, 1992). Additional investigations focused on investigating how stacking pattern affects the stability of unit loads, taking advantage of it as an alternative form of unit load containment method (Carpenter \& Dowsland, 1985; Kocjan \& Holmström, 2010). Regarding the stacking pattern and its effect on pallet strength and stiffness, it was identified that it has an effect on the bending resistance of the pallet but additional research is required to further generalize the effect (Center for Unit-Load Design, 1997; Collie, 1984; Fagan, 1982; M. S. White et al., 1999). If, by interlocking the packages or varying the stacking pattern, the deflection of the pallet can be reduced and load carrying capacity increased. Knowing its effect can provide a useful tool for unit load designers to optimize material consumption.

Given the relevance of the stacking pattern in material handling and in the interactions between the unit load components, the objective of this research is to investigate the effect of the different pallet stacking patterns on the bending stiffness of the pallet. 


\section{Objectives}

The main objective of the project is to investigate the effect of pallet stacking pattern on the bending stiffness of the pallet.

Specific objectives of the project are

1) To investigate the effect of interlocking the layers of a unit load on the bending resistance of the pallet, comparable to column stacking.

2) To investigate the effect of different stacking patterns on the bending resistance of the pallet. 


\section{Chapter 2: Literature Review}

\subsection{Pallets}

\subsubsection{Introduction and history of Pallets}

Currently in the United States, there are over 2 billion pallets in circulation (McGinley, 2016) and is expected to grow to around 2.6 billion by the year 2019 (The Freedonia Group, 2015), conforming an industry with total revenues of over $\$ 7.9$ billion dollars (McGinley, 2016). In 2011, more than 416 million wooden pallets were produced and over 326 million were recovered, remanufactured or repaired (Bush \& Araman, 2014).

The development of the pallet was closely related to the invention and advance of the forklifts. Between the years 1887 and 1909, the first low lift trucks where developed, which were able to carry skids inside the factories, facilitating the material handling. Fork lift design improvements continued until around the year 1925, when forklifts began to be constructed with a cantilever fork design and were able to carry higher loads. This flexibility in the forklift added pressure to the design of the skids, changing the appearance of the pallet to roughly how we know it today. In the next years, although the benefits where evident, the utilization expanded very slowly, mostly due to the high costs of the handling equipment (LeBlanc \& Richardson, 2003).

As the United States entered World War II, an urgency to optimize the logistics appeared. The pallet was seen as an alternative to reduce the manual labor requirements by mechanizing the material handling processes and reducing the time of the operations involved. By that time, a specialized industry developed around the pallet manufacturing. When the war ended, pallet demand contracted dramatically, but it had been now widely demonstrated the benefits of unitizing the products (LeBlanc \& Richardson, 2003). In the following years, different industries began adopting the use of pallets, up to the point now, where around $80 \%$ of U.S. trade moves on one of them (Mazeika Bilbao, Carrano, Hewitt, \& Thorn, 2011).

In order to properly identify pallets, the ANSI MH1:2016 standard, recommends specifying the class, use, type, style, bottom deck, size, and design (MH1 Committee, 2016).

\subsubsection{Pallet Materials}

The first material for the production of pallets was wood and its dominance did not change significantly since the introduction of the first units. Projections conducted for pallet industry 
estimate that by 2019, an 84 percent of the available units will be in the form of wooden pallets, and it will represent a 93\% of total sales (The Freedonia Group, 2015). In the last years, different alternatives were developed for the production of pallets, but their market share still remains small. Table 1 summarizes the most commonly used materials in pallet manufacturing, including their advantages and disadvantages and lastly the preferred use for each one. Table 2 shows the market share estimate for each of the different materials and the percentage of the companies that use either entirely or partially, each type of pallet.

Table 1. Common materials used for pallet manufacturing, advantages, disadvantages and uses (adapted from (Clarke, 2004; Lacefield, 2015)).

\begin{tabular}{|c|c|c|c|}
\hline Material & Advantages & Disadvantages & Preferred Uses \\
\hline Wood & $\begin{array}{l}\text { Most research and design } \\
\text { parameters developed for } \\
\text { wood. } \\
\text { Easy to prototype. } \\
\text { Best cost/performance ratio. }\end{array}$ & $\begin{array}{l}\text { Product damage by fasteners. } \\
\text { Variability inherent to a } \\
\text { natural material. } \\
\text { Moisture desorption can } \\
\text { affect packaging. } \\
\text { Can harbor insects. }\end{array}$ & $\begin{array}{l}\text { Extended use across } \\
\text { almost all type of } \\
\text { industries. }\end{array}$ \\
\hline $\begin{array}{l}\text { Plastic } \\
\text { (mainly PP, } \\
\text { HDPE, PVC, } \\
\text { PC) }\end{array}$ & $\begin{array}{l}\text { Durability. } \\
\text { Sanitation. } \\
\text { No fasteners. } \\
\text { Broad design alternatives. } \\
\text { Lightweight. }\end{array}$ & $\begin{array}{l}\text { Higher initial cost. } \\
\text { Low stiffness. } \\
\text { Difficult to prototype and } \\
\text { analyze. } \\
\text { No remanufacturing } \\
\text { possibility. } \\
\text { Fire hazards. }\end{array}$ & $\begin{array}{l}\text { Closed loop supply } \\
\text { chains, high sanitation } \\
\text { requirements }\end{array}$ \\
\hline $\begin{array}{l}\text { Composite } \\
\text { Wood (OSB, } \\
\text { plywood) }\end{array}$ & $\begin{array}{l}\text { Lower cost than plastic or } \\
\text { metal. } \\
\text { Can be used when pest } \\
\text { regulations forbid wood pallets. } \\
\text { Easy to prototype. }\end{array}$ & $\begin{array}{l}\text { Require fasteners. } \\
\text { Low weather resistance. } \\
\text { Expensive to repair. }\end{array}$ & $\begin{array}{l}\text { Industries with pest } \\
\text { regulations and at } \\
\text { import/export } \\
\text { operations. }\end{array}$ \\
\hline $\begin{array}{l}\text { Paper Based } \\
\text { (corrugated, } \\
\text { honeycomb, } \\
\text { etc.) }\end{array}$ & $\begin{array}{l}\text { Lightweight. } \\
\text { Easily recyclable. } \\
\text { Can be used when pest } \\
\text { regulations forbid wood pallets. }\end{array}$ & $\begin{array}{l}\text { Could be more expensive } \\
\text { than wood. } \\
\text { Performance dependent on } \\
\text { moisture. }\end{array}$ & $\begin{array}{l}\text { Industries with pest } \\
\text { regulations. } \\
\text { Airfreight with weight } \\
\text { dependent costs. }\end{array}$ \\
\hline $\begin{array}{l}\text { Metal } \\
\text { (mainly } \\
\text { steel, } \\
\text { aluminum) }\end{array}$ & $\begin{array}{l}\text { Excellent durability, strength } \\
\text { and stiffness. } \\
\text { Sanitary. } \\
\text { Recyclable. }\end{array}$ & High cost. & $\begin{array}{l}\text { Closed loop supply } \\
\text { chains with heavy } \\
\text { weight requirements. }\end{array}$ \\
\hline
\end{tabular}


Table 2. Market share estimate and usage of pallets made of different materials (adapted from (McCrea, 2016; The Freedonia Group, 2008)).

\begin{tabular}{ccc}
\hline Material & $\begin{array}{c}\text { Pallet Material } \\
\text { Demand }\end{array}$ & $\begin{array}{c}\text { Percent of Companies } \\
\text { Using each Pallet Type }\end{array}$ \\
\hline Wood & $80 \%$ & $96 \%$ \\
\hline $\begin{array}{c}\text { Plastic (mainly } \\
\text { PP, HDPE, PVC, } \\
\text { PC) }\end{array}$ & $11 \%$ & $37 \%$ \\
\hline $\begin{array}{c}\text { Composite Wood } \\
\text { (OSB, plywood) }\end{array}$ & $\mathrm{NA}$ & $15 \%$ \\
\hline $\begin{array}{c}\text { Paper Based } \\
\text { (corrugated, } \\
\text { honeycomb, etc.) }\end{array}$ & $8 \%$ & $\mathrm{NA}$ \\
\hline $\begin{array}{c}\text { Metal (mainly } \\
\text { steel, aluminum) }\end{array}$ & $1 \%$ & $5 \%$ \\
\hline
\end{tabular}

\subsubsection{Pallet Classes}

Although many pallet designs were developed in the industry, almost all the pallets are manufactured using the same components. It could be either a stringer or block pallet. The stringers are solid wooden beams used to provide structural support and spacing between the top and bottom deckboards. The blocks are used instead of the stringers as spacers, but require an additional stringerboard to link the pallet components. Blocks are distributed across the pallet. Besides the stringers or the blocks, the other main components of the pallets are the top deck or deckboard which could be composed of multiple deck boards or a single whole board, the bottom deckboards and the fasteners to hold these components together. If there are no bottom decks or deckboards present, it is not called a pallet, but a skid or a single-face pallet.

\section{$\underline{\text { Stringer Pallets }}$}

This class of pallets are easier and therefore cheaper to manufacture than the alternative block pallets, making them the most common type in the United States (Clarke, 2004). In the year $2011,86 \%$ of all new wooden pallets manufactured in the U.S. where limited and multiple use stringer pallets (Bush \& Araman, 2014). Stringer pallets have at least two stringers, commonly three, as the main identifier, but the quantity depends on the specific use of each pallet design. The stringers are commonly one single piece of wood and can have notches to allow handling by forklifts from all sides of the pallets (LeBlanc \& Richardson, 2003). Figure 1 shows a schematic for a stringer pallet and the common parts labeled. 


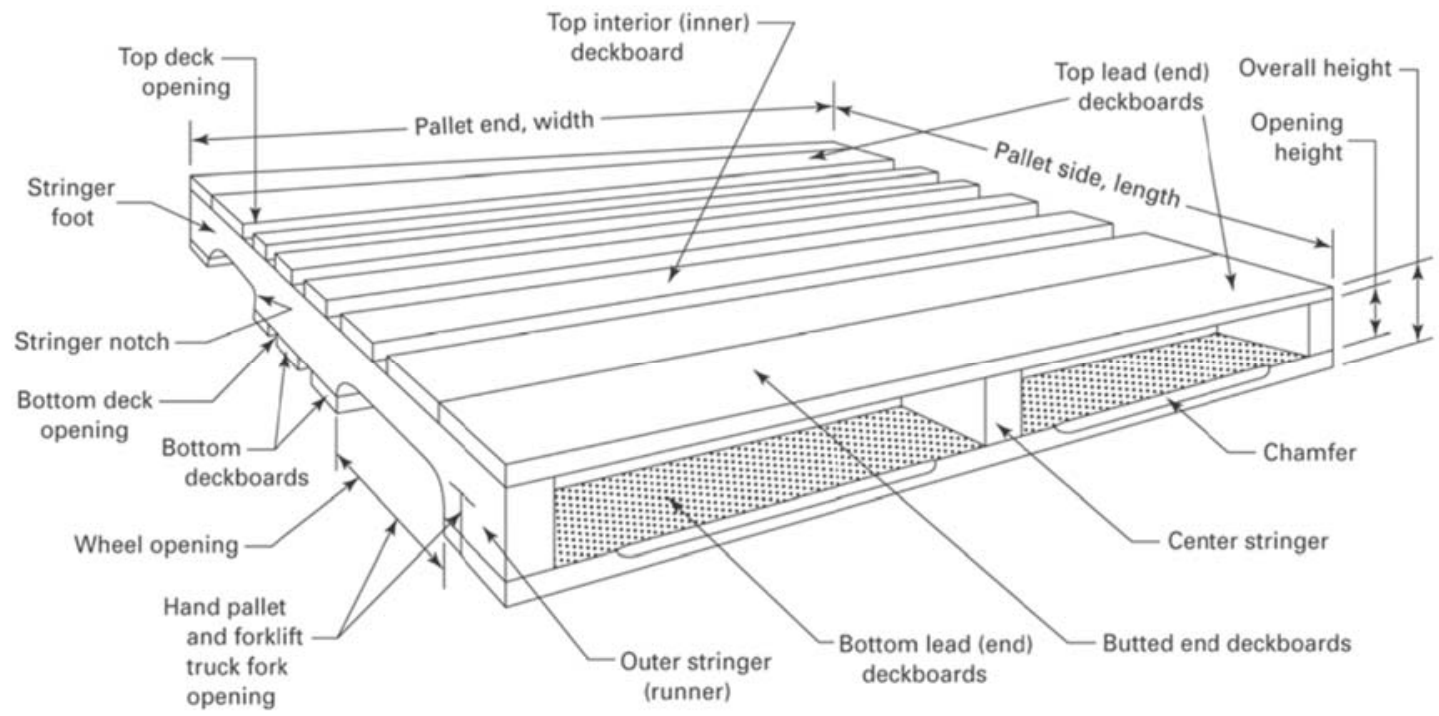

Figure 1. Schematic Diagram of Typical Stringer Class Pallet, with Principal Parts Labeled (MH1 Committee, 2016)

\section{$\underline{\text { Block Pallets }}$}

Block pallets are manufactured using wooden blocks, typically nine located at the corners, center of the sides and the center of the pallet. These blocks function as spacers between top and bottom decks. Additionally, a stringerboard is used to link the components at the top of the pallet. The block pallet design allows for material handling equipment to access the pallet from all four directions in most cases, helping the improvement of cube utilization and reducing the time of the handling, increasing the popularity of this type of pallet (LeBlanc \& Richardson, 2003). Block pallets represented a $6 \%$ of new wooden pallets produced in the U.S. in 2011(Bush \& Araman, 2014). Figure 2 shows a schematic for a block pallet and the common parts labeled. 


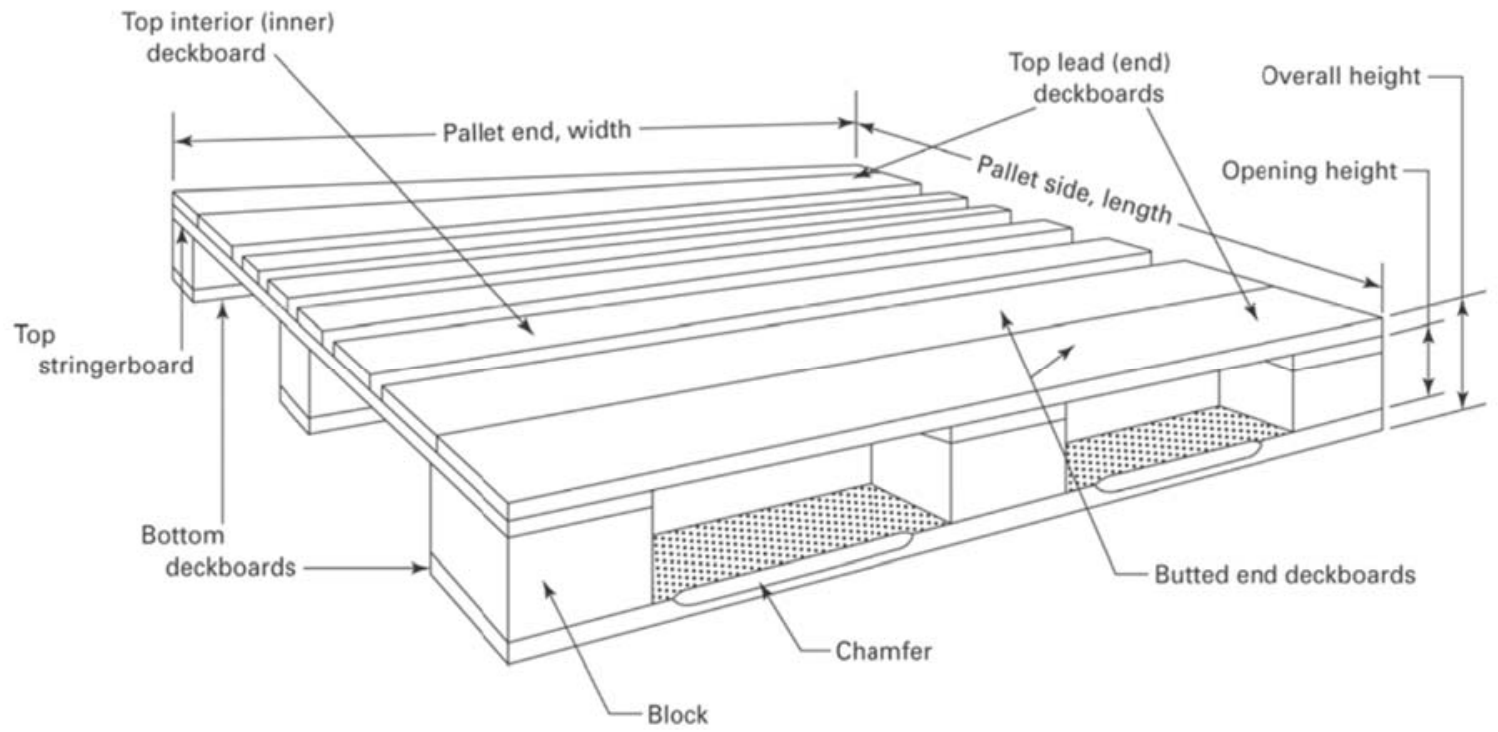

Figure 2. Schematic Diagram of Typical Block Class Pallet, with Principal Parts Labeled (MH1 Committee, 2016)

Although the two classes of a pallet are stringer and block, multiple sub categories exist to classify a pallet based on different functionality and design variations.

\subsubsection{Additional Classifications}

Following the Material Handling Institute's (2016) and the National Wooden Pallet and Container Association (2014) standards for identifying a pallet, besides the pallet class, the next classification is regarding the use intended for it. A reusable pallet is one which is intended for multiple uses with one or more different unit loads. If the pallet is intended for a single use with one specific load type, then it is classified as a single-use, one-way, or expendable pallet. This classification will determine important characteristics of the final product, such as quality and specifications of the components.

The following classification of a pallet would be by the type of access. A pallet that can only be accessed from the ends is called a 2-way pallet and it, typically, has stringers without notches. If the stringers are notched or it is a block pallet with overlapping bottom stringer boards it is called a partial 4-way pallet, since it can be accessed from all ends and sides by forklifts but only form the two ends when using an electrical pallet jack. If the pallet is accessible from the sides and ends with no limitation regarding the material handling equipment, then it is known as a full 4-way pallet. If the pallet can be used flipping the top and bottom deckboard interchangeably, 
it is a reversible pallet, otherwise it is a non-reversible pallet that has specific bottom and top deckboards.

The design of the base of the block pallet can be identified as three types. First, the unidirectional base that consists of deckboards positioned all parallel in one direction. If the pallet instead has deckboards in both directions and contains butted and endboards is known as a perimeter base. Lastly, a cruciform base is similar to the perimeter base but including connector boards in the center of the pallet.

One additional classification for the pallet design is the alignment of the stringers on the sides with the ends of the deckboards or panel. If the ends of the deckboards are flush with the stringer, it is called a flush pallet. Meanwhile, if the ends of the deckboards overhang the stringer forming a cantilever at the end, it is called a wing pallet. Pallets with only top decks overhanging are called single wing pallets. Pallets with both the top and bottom decks overhanging the stringers are called double winged pallets.

\subsubsection{Pallet sizes, usage and popularity}

Pallet dimensions are usually specified as length by width, where the length of a pallet is the length of the stringers or stringer boards while the width of the pallet is the length of the length of the top deck boards (ISO, 2003). When pallet utilization began expanding, different sizes emerged to fulfill specific needs. The most common dimensions were defined to optimize or at least match the dimensions of the vehicles used in the region and/or the rest of the material handling equipment used along the supply chain (Twede et al., 2014).

In an effort to standardize the pallet sizes the International Standard ISO 6780:2003 Flat Pallets for intercontinental materials handling - Principal dimensions and tolerances was developed, aiming to increase distribution efficiency. In this standard, six different plan

dimensions are proposed, three of which are rectangular and the other three square pallets. Additionally, they are classified according to the region where the usage is more common. 
Table 3. ISO Standard Pallet Dimensions (Adapted from ISO 6780: 2003)

\begin{tabular}{ll}
\hline Size, mm(in) & Region \\
\hline $1200 \times 800(47.2 \times 31.5)$ & Europe \\
$1200 \times 1000(47.2 \times 39.4)$ & Europe, China \\
$1219 \times 1016(48 \times 40)$ & North America \\
$1067 \times 1067(42 \times 42)$ & North America \\
$1100 \times 1100(43.3 \times 43.3)$ & Japan, Korea \\
$1140 \times 1140(44.9 \times 44.9)$ & Australia \\
\hline
\end{tabular}

It is very common for companies or groups of companies to develop their own pallet sizes to fit their needs better. The Grocery Manufacturers Association introduced what is now the most common pallet footprint in North America, 48 by 40 inches (1219 mm x $1016 \mathrm{~mm}$ ), representing a $24.4 \%$ of all the new wooden pallets manufactured in 2011 in the U.S (Bush \& Araman, 2014). Other industries also implemented common pallet dimensions along its members, for example 42 by 42 inches $(1067 \mathrm{~mm} \times 1067 \mathrm{~mm})$ which is the second most used pallet footprint in the U.S., mostly by the plastics industry. Multiple examples can be found in other industries.

It is hypothesized that all of these multiple sizes moving in the supply chains generate a negative impact in the productivity of the logistics operations, making it necessary for manual transfer of goods from one pallet to another in order to fit the handling equipment available at different facilities and increasing the number of pallets required. The negative impact of standardization is the reduction in transport containers volume utilization, but it is considered that the losses can be offset with the gains from the higher efficiencies in the supply chain (Raballand \& Aldaz-Carroll, 2007).

\subsubsection{Pallet performance and testing}

Knowing how a pallet is going to perform under the different conditions present in the distribution process is key for the correct operation of any supply chain. This helps in assuring the safety of the material handling process and the efficiency of the operations, these being manual or automatic.

In order to predict pallet performance, Fagan (1982) developed a testing apparatus to apply uniformly distributed load to the pallets using an airbag, which showed better results than the 
methods available at that time, which were based mostly on manually loading pallets with bags or boxes and measuring deflection. This new method provided a constant rate of uniform load application, providing greater testing capabilities.

Multiple standardized testing procedures have been developed to evaluate pallet performance by simulating different scenarios found in the logistics operations. These tests are designed to determine performance values such as the maximum safe load a pallet can carry under different support condition or the durability of the pallet or some of its components.

ISO 8611 - Pallets for material handling - Flat Pallets (2011) provides a framework of testing methods to simulate the normal use of a pallet in the material handling operations. It is composed of four parts. Part 1 describes the tests methods used to determine the nominal load capacity of the pallet. Part 2 describes the performance requirements for the various support conditions and the selection of the tests. The results of the tests provide the nominal load of the pallet, which corresponds to "the lowest safe load value for the specified support conditions, independent of the type of load"(ISO/FDIS, 2011) and is a comparative value for evaluating pallet performance, but not an actual payload. Part 3 describes the determination methodology of the maximum working load capacity of the pallet. The maximum working load is the "greatest payload that a pallet is permitted to carry in a specific loading and support condition" (ISO/FDIS, 2011) and can be lower or higher than the nominal load.

ASTM D 1185 Standard Test Methods for Pallets and Related Structures Employed in Materials Handling and Shipping (2009) includes two major types of testing procedures, static and dynamic tests. Static tests include compression and bending tests for estimation of stiffness, strength and safe working loads. The results of these tests are dependent on the type of support condition used and the load used. If the pallet designer is required to evaluate the durability and functionality of the pallet, data provided from the dynamic testing is to be used. These tests include corner and end drop tests, and a set of different incline impact tests. Overall, these standard tests can be used to predict the performance characteristics of a pallet under specific material handling and shipping environments, as well as classifying pallets as single or multiple use.

The MH1 - Pallets, Slip Sheets, and Other Bases for Unit Loads (2016) is a standard from the Materials Handling Industry which provides guidelines for the standardization of pallet dimensions, quality and characteristics for the different materials used in pallet manufacturing. It 
also includes a protocol for testing pallet nails and staples and makes reference to other standards for evaluating pallet performance, but does not includes testing protocols.

The National Wooden Pallet and Container Association (NWPCA) Uniform Standard for Wood Pallets (2014) contains minimum quality requirements for pallet production. It begins with a section covering the quality of materials used in the pallet, workmanship, tolerances and all the guidelines necessary. Part 2 encompasses the performance evaluation of the pallets. In this sections in makes reference to the two standards previously mentioned, as well as the evaluation of the pallet design using computerized models in the software The Pallet Design System (PDS) ${ }^{\odot}$. Part 3 covers the phytosanitation of wood pallets.

Besides running physical tests to evaluate the performance of a pallet, predictive mathematical models have been developed, using finite element analysis. These models are the backbone of the current pallet design software packages in the market and accurately predict pallet deformation of the simulated pallets when compared with field testing (Han, White, \& Hamner, 2007).

\subsection{Corrugated boxes}

\subsubsection{Introduction and history of corrugated boxes}

Corrugated boxes are the most common shipping containers made from corrugated fiberboard. The corrugated fiberboard is usually conformed of two outside papers, known as liners, and a corrugated paper in the middle, known as the medium. Different arrangements can be made by changing the medium design (flute) or adding additional layers and combinations of fiberboard in order to adjust the container for each specific use (Dekker, 2013).

Corrugated boxes have been for more than a hundred years, the preferred shipping containers for transporting almost every type of goods and currently represent $80 \%$ of the volume of shipping materials used in the US (Twede, 2007). The development process began in the second half of the nineteenth century, until reaching a wide usage of the corrugated boxes in the early 1900's, supporting the need for moving the ever increasing amount of consumer goods being manufactured (Twede, 2007).

In the year 1856, a patent was issued for the first corrugated material used for lining in tall hats of Victorian Englishmen (Fibre Box Association, 2005). The material was further improved and in 1871 Albert Jones of New York City received the patent for single face corrugated board, being the first patent specifically granted for use as a packaging material (Jones, 1871; Twede, 
2007). By 1894 in New York City, the first double-faced corrugated box was manufactured by Thompson and Norris in order to be used for light express shipping by Wells Fargo (Twede, 2007). In 1903, certain cereal manufacturers were allowed to ship their product on corrugated boxes and by 1906 most carriers authorized the general use of fiber boxes, although charging a premium versus wood packaging (Browder, 1935). After a long debate, railroad companies accepted the transportation of goods packaged in corrugated boxes without charging any additional tariff. In the year 1914 the Interstate Commerce Commission defined in the Prindham Decision that there were no transportation differences between the corrugated boxes and the primary packaging product of the time, wooden crates, prohibiting the railroads to charge any additional amount for the use of corrugated containers (Twede, 2007).

Paper and paperboard packaging is currently the main material used for packaging in the U.S., and is tied with plastics in worldwide usage. Of the different package forms produced from paper and paperboard, the corrugated fiberboard packaging represented a $64 \%$ of the total value of the shipments in the year 2011, and a total production for the industry of $\$ 26.1$ billion in the United States (Twede et al., 2014).

\subsubsection{Corrugated boxes classifications}

\subsubsection{Corrugated board}

The corrugated fiberboard, from which corrugated boxes are made from, is composed of two structural elements, the linerboard and the medium. The facings of the corrugated board are the linerboards and the medium is the fluting structure adhered to the liners (Fibre Box Association, 2005). These two elements are glued together using most commonly starch-base adhesive, which allows to form a good bond at high manufacturing speeds (Twede et al., 2014).

Linerboards can be of several types, the most common being Kraft liner. This type of facing is made from softwood fibers and can be mixed with recycled fibers. In the United States it is consider "virgin" if at least $80 \%$ is new fiber (Maltenfort, 1988).

The corrugated medium is made by a similar process as the linerboards but from a different type of pulp. It is normally made from recycled corrugated board or from virgin hardwood fibers. This type of medium is known as semi chemical, due to the process of defibering by mechanical and chemical processes. Although most packaging applications wouldn't consider this type of fiber 
acceptable, in the production of medium, it is beneficial to facilitate the corrugating process without breaking the paper (Maltenfort, 1988; Twede et al., 2014).

These components are used together in different configurations. When only one layer of liner is attached to the medium, it is known as a single face corrugated board, mostly used as a wrapping material and shipped and sold in rolls. When two liners are attached, one on the inside and other on the outside of the board it is called a double face board or single wall. Double or triple wall corrugated boards are extensions of the arrangements possible between liners and mediums (Twede et al., 2014). Figure 3 shows drawings for these configurations.

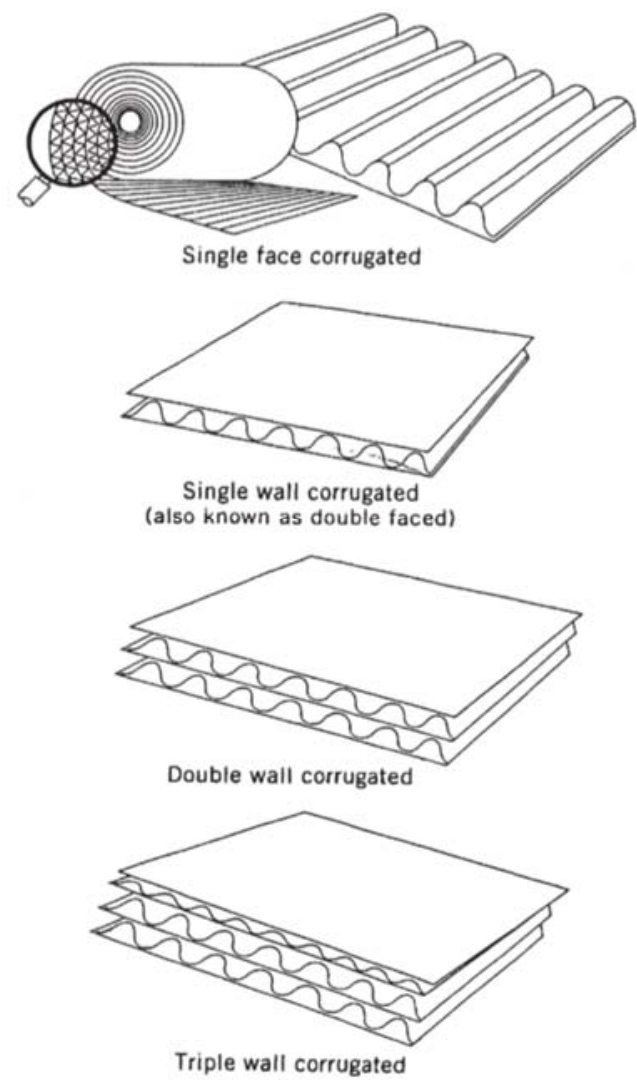

Figure 3. Possible corrugated configurations (from Foster 2010).

\subsubsection{Flute types}

The flutes or medium can be made in several different common standard sizes. These sizes are characterized by the flute height and the number of flutes per linear distance (feet or meters) and identified with letters. The thickest flute type is A and the most popular type is C-flute. The sizes are not ordered correspondingly to the alphabet order but as they appeared historically, being 
A-flute the first to be produced, followed by B-flute (Twede et al., 2014). Table 4 presents the four most common flute styles in the market, the number of flutes per meter or inch and the usual range height of the flute. It must be noted that it is common to have variations in factors such as the flutes per meter, since these values are not completely standardized and depend on the manufacturing characteristics (Twede et al., 2014). It also includes a take-up factor, which is the ratio of the length of the medium divided by the length of the linerboard (Koning, 1983).

Table 4. Most common flute styles and characteristics (adapted from Dekker, n.d.; Foster 2010).

\begin{tabular}{ccccc}
\hline $\begin{array}{c}\text { Flute } \\
\text { Type }\end{array}$ & \multicolumn{1}{c}{$\begin{array}{c}\text { Flutes per } \\
\text { meter }\end{array}$} & $\begin{array}{c}\text { Flutes } \\
\text { per foot }\end{array}$ & $\begin{array}{c}\text { Flute } \\
\text { Thickness, } \\
\text { mm (in.) }\end{array}$ & $\begin{array}{c}\text { Take-up } \\
\text { factor }\end{array}$ \\
\hline A & $108 \pm 10$ & $33 \pm 3$ & $4.8(3 / 16)$ & 1.5 \\
C & $128 \pm 10$ & $39 \pm 3$ & $4.0(5 / 32)$ & 1.45 \\
B & $154 \pm 10$ & $47 \pm 3$ & $3.2(1 / 8)$ & 1.35 \\
E & $295 \pm 13$ & $90 \pm 4$ & $1.6(1 / 16)$ & 1.25 \\
\hline
\end{tabular}

\subsubsection{Board grades}

Corrugated board grades are usually specified by the basis weight (BW), which is the weight per unit of area and is also known as grammage, and the flute type. In the S.I. metric system, the BW is defined as the weight in grams of a square meter of the component (linerboard or medium) and in the U.S. customary system is the weight in pounds of $1000 \mathrm{ft}^{2}$ (Steadman, 2002).

A sample of the most common grammages is shown on Table 5, including the U.S. basis weight, the exact equivalent in metric units and the corresponding similar metric grade. Additional values can be found on the market. It is a common practice to match a low grammage medium with low grammage linerboards so a balanced structure can be obtained (Steadman, 2002). Due to the modifications of the materials used for the manufacturing of corrugated board, such as the increased use of recycled fibers that reduce the strength, the basis weight is no longer enough to predict the physical capabilities of the board and additional information is required, such as the results from the edge crush test or the Mullen burst test (see Section 2.2.3 Corrugated box performance and testing). 
Table 5. Common nominal basis weights for linerboard and medium in the U.S. and similar international grades (adapted from Steadman 2002) .

\begin{tabular}{cccc}
\hline \multicolumn{3}{c}{ Common Basis Weight or Grammage } \\
\hline \multicolumn{2}{c}{ Linerboard } & \multicolumn{2}{c}{ Medium } \\
\hline U.S. customary & Metric & U.S. customary & Metric \\
$\left(\mathrm{lb} / 1000 \mathrm{ft}^{2}\right)$ & System & $\left(\mathrm{lb} / 1000 \mathrm{ft}^{2}\right)$ & System \\
& $\left(\mathrm{g} / \mathrm{m}^{2}\right)$ & & $\left(\mathrm{g} / \mathrm{m}^{2}\right)$ \\
\hline 26 & 125 & 26 & 125 \\
33 & 150 & 28 & 140 \\
38 & 175 & 30 & 150 \\
42 & 200 & 36 & 175 \\
47 & 225 & 40 & 200 \\
69 & 339 & 42 & 200 \\
\hline
\end{tabular}

Note: Relation between the common basis weights is not equivalent to the mathematical conversion of the units.

\subsubsection{Corrugated box styles}

In order to be able to identify the different box styles, a collaboration between the European Federation of Corrugated Board Manufacturers (FEFCO) and the European Solid Board Association (ESBO), developed a classification method, assigning numerical codes to the different styles of boxes according to their designs (Fibre Box Association, 2005).

The FEFCO classification groups all box styles in nine basic categories. The first two digits of the four digit FEFCO code represent the different categories while the last two digits identify the specific design with the category (FEFCO-ESBO, 2007). The different categories are listed next. 
01 - Commercial rolls and sheets

02 - Slotted-type boxes

03 - Telescope-type boxes

04 - Folder-type boxes and trays

05 - Slide-type boxes

06 - Rigid-type boxes

07 - Ready-glued cases

09 - Interior fitments

The most common type of box is the Regular Slotted Container (RSC), code 0201. It is made from a single piece of corrugated and normally the lengthwise flaps meet at the center when folded. It is a very efficient design with little material waste when manufacturing (Fibre Box Association, 2005).

Regarding the sizes of the boxes, although any design can be sized as needed to better fit the product, the standard ISO 3394 Packaging - Complete, filled transport packages and unit loads - Dimensions of rigid rectangular packages has been published to facilitate the material handling operations by limiting the dimensions of packages to modular sizes, based on the proposed dimensions for pallets, and therefore having better utilization of the available space (ISO, 2012). Three different modules are proposed, 600x400mm, 600x500mm and 550x366mm, and for each of them, the corresponding pallet sizes. Submultiples of the modules are given for the users to make the decision according to their needs.

\subsubsection{Corrugated box performance and testing}

Edge Crush Test (ECT) (TAPPI T 811:2002 Edgewise compressive strength of corrugated fiberboard (short column test), TAPPI T 839:1995 Edgewise compressive strength of corrugated fiberboard using the clamp method (short column test) and ISO 13821:2002 Corrugated fibreboard -- Determination of edgewise crush resistance -- Waxed edge method) is probably the most common and important test performed on corrugated boards. Since the ECT results are used to predict the compression strength of a box and therefore the performance of it, it is commonly used as the main value when specifying corrugated board, instead of grammage or thickness (Twede et al., 2014). The test consists of applying constant force to a sample of corrugated board 
standing on its edge with its flutes parallel to the force until the board is crushed. The amount of force when the failure occurs divided by the length of the sample gives the ECT value (lb-force/in or kilonewtons/meter).

Using the simplified McKee Formula (Equation 1), the ECT value can be used to predict the compression strength of the box (BCT). This formula relates the perimeter of the box and the caliper of the board to estimate the box compression strength (McKee et al., 1963).

$$
B C T=5.87 * E C T * \sqrt{P * Z} \quad \text { [Equation 1] }
$$

with,

ECT: Edge Compression test (lbf/in)

P: Perimeter of the box (in)

$\mathrm{Z}$ : Caliper of combined corrugated board (in)

Besides estimating the BCT from the ECT value, testing can be performed to determine the box compression strength. TAPPI T804:2002 Compression test of fiberboard shipping containers, ISO12048:1994 Complete, filled transport packages - Compression and stacking tests using a compression tester or ASTM D642:2000 Determining Compressive Resistance of Shipping Containers, Components, and Unit Loads are three testing standards that can be followed. ISO and TAPPI methods follow similar procedures of conditioning and testing, but the ISO standard is limited to filled packages, while TAPPI T 804:2002 recommends the usage of empty containers. The ASTM test provides the option of testing the containers with floating platens and in general a wider scope of possibilities for the type of containers that can be tested.

Another important performance characteristic of corrugated board is the bursting strength. The testing method for performing this test is the TAPPI T 810:1998 Bursting strength of corrugated and solid fiberboard, which is specifically for single and double wall corrugated fiberboard. After conditioning circular corrugated test specimens, they are clamped on the edges in the bursting tester and pressure is applied with a piston inflating a diaphragm underneath the sample until it bursts. The pressure at the moment of bursting is an important measure of board performance. 
Flat crush testing (FCT) is a measure of the compression strength of the flutes of corrugated when a force is applied perpendicular to the board surface. TAPPI T808:2001 Flat crush test of corrugated board (flexible beam method) is description of this test.

\subsection{Containment Methods}

To protect the product as it moves through the supply chain in unit load form, packages are secured on the pallet with one of several load stabilizers (Singh, Cernokus, Saha, \& Roy, 2014).. One option is to organize the product or packages on the pallet in an interlocked pattern instead of column stacking, so each layer stabilizes the boxes on the bottom of it by applying force in an opposite direction. Additional to this, a containment force can be applied to the unit load, which can be achieved by the utilization of any of various methods such as stretch wrapping, stretch hooding, strapping or shrink wrap, among others. The most common type of containment method is the stretch wrap (Singh et al., 2014).

The stretch wrapping of a unit load is commonly made using Linear-Low Density Polyethylene polymer (LLDPE) due to its elastic properties, puncture resistance and market acceptance (Rogers, 2011). There are three methods of applying the stretch wrap to the unit load. The manual method is labor intensive and results in an uneven load along the unit load, generally with low containment force. Semi-automatic systems apply the stretch wrap by itself, but they are manually loaded. Automatic machines receive the product via an automated mechanism such as a conveyor, and wrap the load automatically. The stretch wrapping machines can be identified by the mechanism they use to apply the containment force to the load. This can be a turntable, a rotary arm or an orbital stretch wrapping system. Each one has different characteristics and is best suited for different operations depending on the weight, fragility and shape of the load (Singh et al., 2014).

Singh (2014) studied the effect of pre-stretching of the stretch wrap on the containment force experienced by the unit load and how it affects the unit load performance along the distribution. It was concluded that the magnitude of pre-stretching has no direct effect on the containment of the load, either before or after the simulated distribution, so higher pre-stretching values can be used to save costs. Additionally, it was validated that the containment force is proportional to the number of layers applied. 
Bisha (2008) compared the effect of different load stabilizers when the unit load is under vibration and when it is impacted. By measuring the displacement of the load from the pallet and the shift of the load between each layer of boxes, it was concluded that the best load containment method, when under vibration is strapping, since it restricts vertical spring movement and the worst was the 400ga stretch hooding. The other two methods tested were 80 ga and 63 ga stretch wrap. When the unit load was impacted on one side, the stretch hooding yielded the best results for prevention of load shifting, while the stretch wrapping failed to secure the load as much as the other options, and the 63 ga performed worse than the 80ga. All of these results were specific to the amounts and techniques used, so the same type of stretch wrap, with different amounts and application patterns, could generate different results.

Methods have been developed to measure the applied containment force, specifically for stretch wrapping. The standard ASTM D4649-03 Selection and Use of Stretch Wrap Films provides guidelines to measure and compare the wrapping performance of the films, but it measures the containment load only at the faces and not at the corners, where higher pressure might exist, therefore generating a possible bias. This method performs the measurements after applying the film, so a trial and error process must be followed to reach specific containment forces. Efforts have been conducted in order to develop methods capable of predicting a containment force following standardized calculations, using film thickness and pre-stretch as inputs, but additional research is required to obtain more consistent results (Bisha, 2012).

Regarding the unit load stability, the effect of the containment method can be evaluated running standardized tests such as ASTM D4169:2009 Standard Practice for Performance Testing of Shipping Containers and Systems or ISTA 3E (2009) Unitized Loads of the Same Product but it can't be accurately predicted.

\subsection{Unit Load}

\subsubsection{Introduction and history of the Unit Load Concept}

Unitizing product shipments using a pallet as a platform helps reduce product damage as much as an $80 \%$ when compared to shipping loose items. This reduction in damage enables shippers to reduce packaging costs (Goertz, 1976). Another benefit is the time to complete a distribution cycle. Unitizing product and the proper material handling equipment will generate significant reductions in time and therefore overall savings and better inventory control. Internal 
and external theft can be reduced, minimizing inventory shrinkage. The main drawback identified from palletizing instead of break bulk shipping is the reduction on the efficiency of the cargo space utilization. When using ISO standardized pallets, up to $30 \%$ of the otherwise available volume won't be used (Goertz, 1976), but the overall efficiencies gained make it the preferred shipping method, with an estimate of an $80 \%$ of the product transported in the United States being moved in the form of a unit load (Raballand \& Aldaz-Carroll, 2007).

\subsubsection{Stacking Patterns in Unit Loads}

Significant research has been conducted on the stacking patterns from mainly three perspectives. One, which relates to the design activities for the product containers, is how the strength of the packages, especially for corrugated fiberboard boxes, is affected when the box stacking pattern is interlocked versus column. Studies have shown that interlocking boxes between layers significantly reduces the box resistance to compression (Ievans, 1975; Kellicut, 1963). Additional experimentation was conducted to further characterize the behavior, but most comparisons where between column stacks and one interlock stack configuration.

The second perspective has been conducted in the Mathematics and Operations Research fields. It focuses on maximizing the space utilization of a certain storage or shipping area, by developing algorithms capable of positioning the highest quantity of packages on the pallet. The emphasis of this research has been on the mathematical calculations for solving the "Pallet Loading Problem", but most of the investigations exclude considerations on the effect of the resulting stacking pattern on the strength of packages or the pallet (Carpenter \& Dowsland, 1985).

The last perspective of research related to stacking patterns is to increase unit load stability. Some of these investigations can be presented as part of the two previous classifications, where additional considerations were taken. Carpenter and Dowsland (Carpenter \& Dowsland, 1985) developed guidelines to improve the applicability of the "Pallet Loading Problem" solutions for real world cases. For it, they included certain constrains to assure the stability of the unit loads within the calculations performed.

Multiple classification options and development guidelines have been created to properly identify stacking patterns. To begin the classification, the problem must be identified as a manufacturer's problem, where all the packages are of the same size, or if it is dealing with the distributor's problem, where packages of non-identical sizes must be unitized. The main focus on 
the studies regarding the stacking patterns, is around the manufacturer's problem, since a single solution will be developed in the design stage and used repeatedly throughout the life of the product, therefore requiring better performance. Distributor's problem solutions require quick results to keep up with the operations pace, processing a new pallet each time. Given that the majority of products are shipped in rectangular shapes, most of the research has excluded any other types of geometries (Hodgson, 1982).

One of the most common classification of the patterns comes from the efforts to maximize material utilization in activities like metal, glass or paper cutting, where each cut was restricted to a guillotine cut from one end to the other (guillotinable pattern), so a non-guillotinable pattern is one that includes box arrangements where partial "cuts" must be made. This solution started due to the availability of acceptable algorithms already in use but it limited the optimization to a 2-D perspective and only guillotinable patterns (Ram, 1992). Figure 4 shows examples of guillotinable and non-guillotinable patterns.

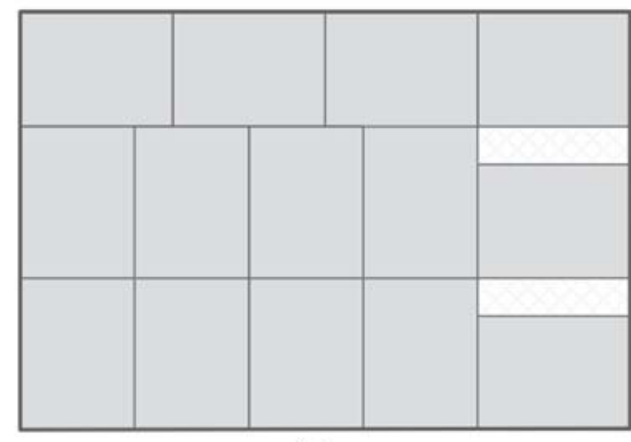

(a)

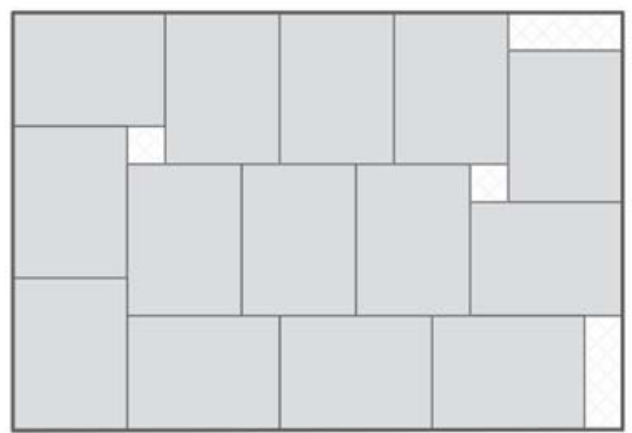

(b)

Figure 4. (a) Guillotinable and (b) non-guillotinable stacking patterns (From (Silva et al., 2016)).

With the progress in the algorithms developing loading patterns, it is complicated to classify all of them depending on the direction that boxes are arranged, since custom solutions with optimal or near optimal space utilization are commonplace in manufacturing environments. Efforts for classification can be traced back to the 1950's and 1960's. One example from 1964 (Heskett, Ivie, \& Glaskowsky, 1964) can be seen in Figure 5. Different classifications are available in literature and commercially available palletization software use their own nomenclature and grouping method of the loading patterns. 


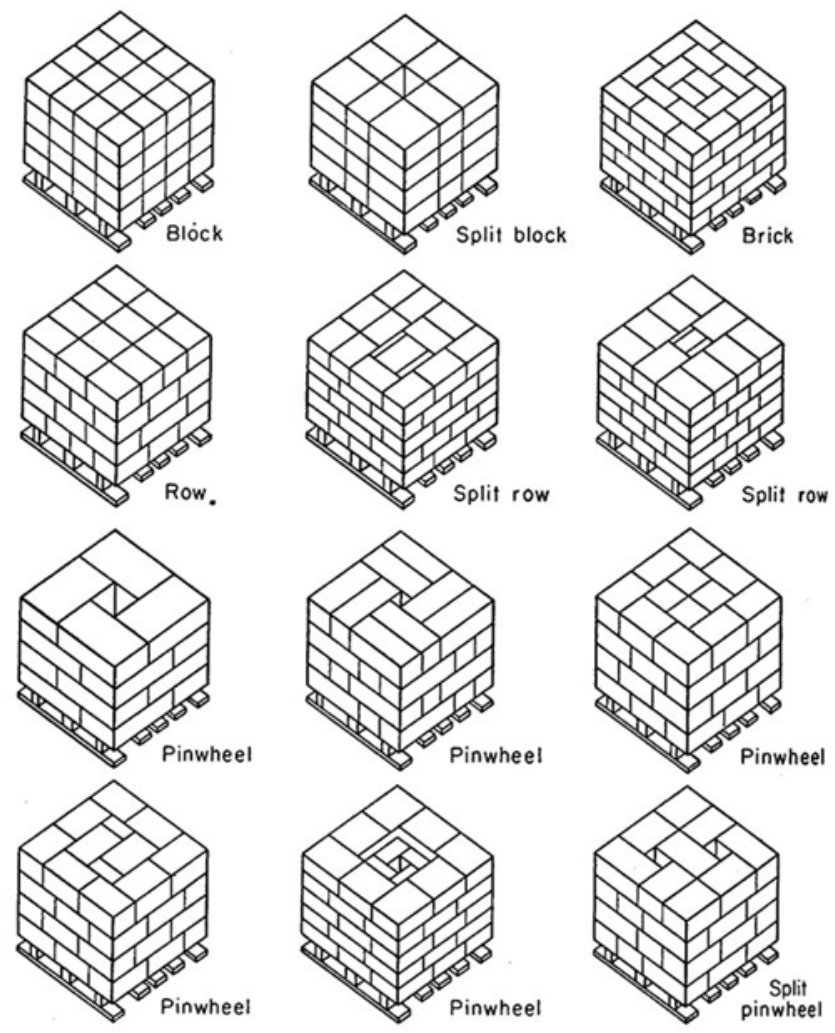

Figure 5. Examples of possible pallet patterns (From (Heskett et al., 1964)).

Peleg (1976) identified five basic stacking pattern forms and the variations are combinations of these forms. They are row patterns (Figure 6a) which have parallel and perpendicular rows, trivial patterns (Figure 6b) where all rows have the same orientation, peripheral patterns (Figure 6c) characterize for arranging the boxes around a center hole, staggered patterns (Figure 6d) which show a diagonal row of holes along the pattern and the singular dimension ratio patterns (Figure 6e), that present a proportionality between length and width of the packages and allow an arrangement where an almost diagonal line separates boxes in perpendicular orientation. 


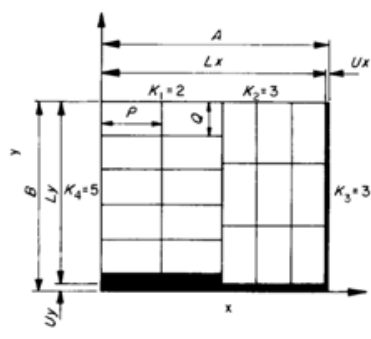

(a) Row pattern

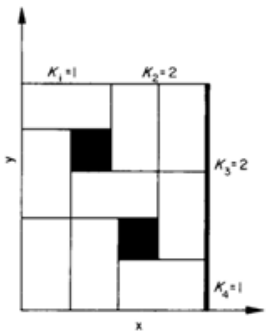

(d) Staggered pattern

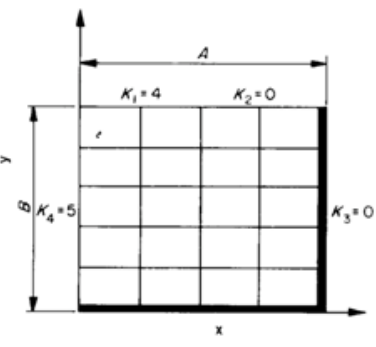

(b) Trivial pattern

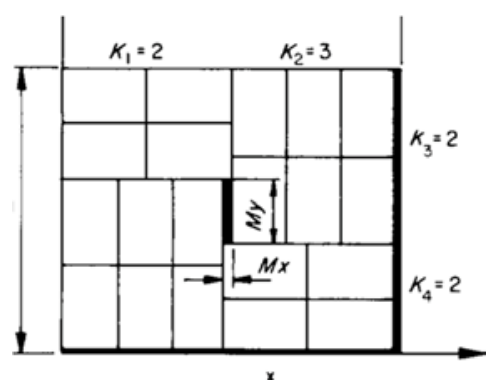

(c) Peripheral pattern

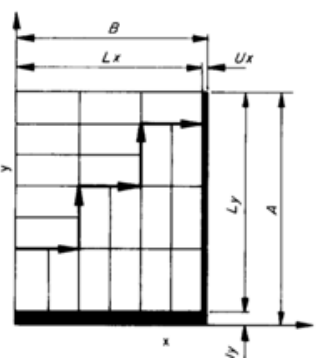

(e) Singular dimension ratio pattern

Figure 6. Five basic stacking pattern forms. (From (Peleg \& Peleg, 1976)).

One important consideration to design an efficient unit load is considering all of its components from the beginning of the process. The design engineers should take into consideration the pallet footprint and the transportation modes to be used in the distribution operations. With this information, package size can be adjusted to optimize the different factors affecting the efficiency of the unit load, especially those related to the stacking pattern.

To evaluate a stacking pattern different variables should be considered and how much weight should be assigned to each one is going to depend on the specific requirements of use. The main objectives of the design process should be:

- Assure unit load stability

- Maximize volume utilization

- Maximize package and pallet performance

Additional considerations can be the time required to build a unit load when using robotic palletization, or when clamps are used, then smooth edges are required. If the boxes are the same size but contain different products, then it can be evaluated depending on the time to access each specific box or certain air circulation requirements (Peleg \& Peleg, 1976; Ram, 1992). 


\subsubsection{Stacking Patterns and Volume Utilization}

Since the introduction of pallets and the unitization of packages for distribution, one concern has been how to optimize the handling operations. Significant time and cost is saved when a product is no longer handled as individual packages but instead, as a unit load. The main drawback of this change is the reduction in the effective space utilization during transportation due to the unit load shape. To solve this, the main effort comes from the Operations Research discipline, who has been working the past 50 years with the "Manufacturer's Pallet Loading Problem (MPLP)" in order to develop optimal or near-optimal solutions to it, using different analytical methods.

Initial exact solutions can be traced back to Barnett and Kynch (Barnett \& Kynch, 1967) in 1967, for very limited cases. Research was moved forward using exact and heuristic algorithms and the application of multiple techniques such as simulation and exact, integer or linear programming. For most instances of the MPLP, optimal solutions were generated with reasonable computing times; however, for some specialized scenarios the models still cannot provide an optimal solution without the need for too much computational effort. These scenarios are currently being investigated (Silva et al., 2016).

The main measure in this subject is pallet utilization, which represents the percentage of volume is covered by product. The most popular commercial softwares for solving this palletization problem are CAPE and TOPS (Twede et al., 2014).

\subsubsection{Stacking Patterns and Unit Load Stability}

Stacking patterns affect unit load stability. Unstable unit loads are serious hazards in distribution operations, generating not only product damage but also putting at risk associates handling the product or customers in club stores walking by the rack storage.

Columnar stacks tend to generate unstable unit loads and require additional containment methods to hold the load in place. Common containment force applicators are stretch wrapping, stretch hooding, strapping or using tie-sheets among other alternatives. The quantity used and the force applied are going to depend on the geometry and stability of the unit load itself, but an excess of containment force can generate package damage. Interlocking the packages in addition to other containment methods is going to increase the overall stability and reduce the risk of collapse and could allow the cost allocated to material consumption from the load stabilizers to be reduced. 
Unit load stability can be evaluated in laboratory testing or using theoretical calculations related to the solution of the "Pallet Loading Problem". Laboratory testing, subjects the unit load to different distribution simulations to measure the shift of the load position on the pallet and also the movement between each layer.

Additional methods to measure the stability of the stacking pattern (without consideration of additional load stabilizers) have been defined by Carpenter and Dowsland (1985). They determined three main design criteria for evaluating the stability. These criteria are:

- Each box has to be supported by at least two boxes under it.

- Measure the percentage of the box that is in contact with the layer underneath.

- And the "non-guillotine cut" criterion, which intends to reduce the possibility of developing stacks that are completely dividable, as in two major columns of interlocked boxes.

More extensive literature on the stability of stacking patterns relates to the solution of the "Distributor's Pallet Loading Problem", due to the inherent instability issues generated by stacking boxes of different sizes. But the same three criteria are generally applied (Schuster, Bormann, Steidl, Reynolds-Haertle, \& Stilman, 2010).

\subsubsection{Stacking Patterns and Corrugated Box Strength}

When determining the strength of a corrugated box, it is critical to know whether a column or an interlocking stacking pattern is going to be used in the distribution environment. When stacked, a box supports most of the load at the corners(McKee \& Gander, 1957), so by interlocking, the load will transfer from corners to the less resistant walls, decreasing the overall load carrying capacity of the box. This reduction is be estimated to be between $35 \%$ and $55 \%$, depending on the specific conditions of the investigations conducted (Carstens \& Mina, 1988; Ievans, 1975; Kellicut, 1963; Singh \& Singh, 2011). Although it was previously mentioned that interlocked patterns are more stable, it is worth noting that if the reduction in box strength is enough to cause box failure, mainly at the bottom of the stack, the overall unit load could present stability issues and lead to product damage (Singh \& Singh, 2011). 


\subsubsection{Stacking Patterns and Pallet Deflection}

Limited research has been conducted with the objective to determine the effect of the stacking pattern in pallet deflection and ultimate load carrying capacity. The load configuration, which is affected by the specification of the stacking pattern, leads to significant changes in the bending behavior of the pallet.

Fagan (1982) and Collie (1984) conducted investigations where different load configurations where evaluated and a clear trend of relationship between load characteristics and pallet bending was found, but no specific evaluation was conducted to measure the effect of the stacking pattern by itself. White et al. (M. S. White et al., 1999) also evaluated the effect on pallet deflection due to the application of different load stabilizers, among which stacking pattern was included to compare column versus interlock. The results identified a significant effect of load stabilizers on pallet deflection but no conclusive results were obtained. Figure 7 shows an example of a unit load composed of a column stack pattern and a low stiffness pallet.

In general, it can be concluded that the different stacking patterns modify the pressure distribution of the load on the pallet, and therefore change the pallet performance but no specific knowledge is available to the exact effect of the stacking pattern. Identifying simple alternatives to improve the performance of the unit load can translate to cost and material reduction and a more efficient supply chain.

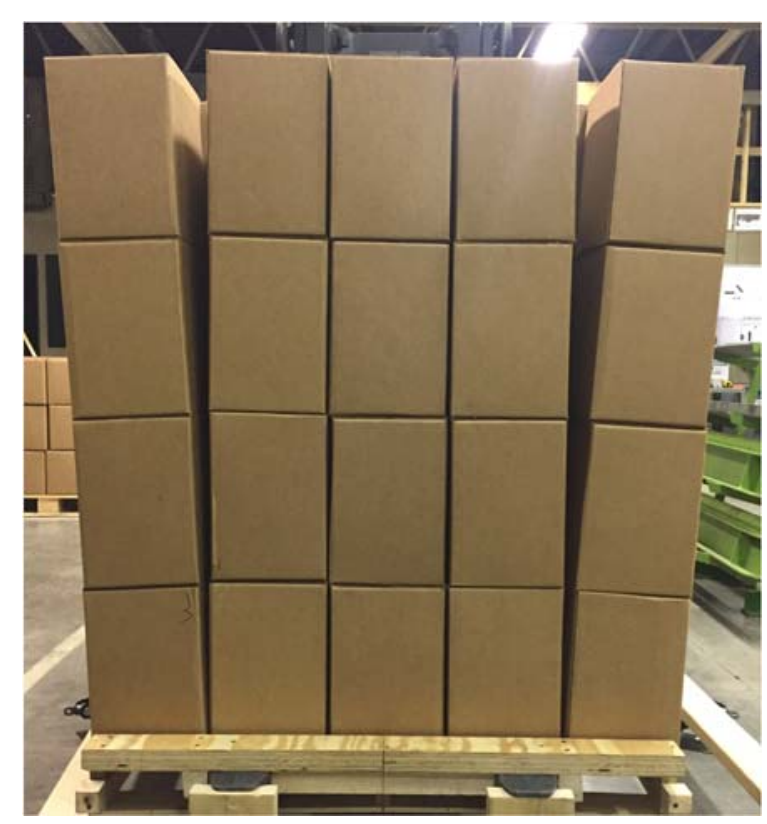

Figure 7. Example of a column stacked unit load supported on a forklift. 


\subsubsection{Systems based Unit Load Design}

The packaging supply chain is composed of three main components, the packages, usually bags, boxes, pails, etc., the pallet that works as a platform to support the product and the material handling equipment. Typically, these components have been developed as isolated units, where the goal is to reduce the costs of the individual components, but ignoring that when any of the components changes, it also affects the performance of the other components (M. S. White \& Hamner, 2005). This component based design methodology can generate an increase in the cost of the overall supply chain, because reducing pallet costs could result in lower pallet stiffness and as a consequence, higher compression stresses will be applied to the corrugated containers, possibly damaging them, increasing the overall costs. To eliminate the above mentioned issues in the supply chain, White and Hamner (2005) proposed using a "System-based Design System", where every component is designed taking into consideration the interaction between the different elements. The result of this system-based design methodology is reduced overall costs for final consumers, reduction on the environmental impact of logistics, and higher human health and safety levels due to better performing unit loads.

\subsubsection{Interactions between Unit Load components}

A unit load is composed of the product, which can be packed in boxes, bags or any other available method, the pallet supporting the packaged products and the stabilization methods such as shrink wrap and slip-sheets. All of these components interact in different ways with each other and with outside factors, such as the handling mechanisms or storage configurations available in the supply network.

\subsubsection{Load Bridging}

Current pallet design techniques assume a uniformly distributed loading on the pallets, and laboratory verification based on ASTM D1185 (ASTM International, 2009) is conducted under the same principle, commonly using airbags as load applicators (Figure 8). But the actual loads being shipped on pallets differ from airbags and don't distribute uniformly the load. The most common package type used is corrugated fiberboard boxes and based on previous investigations (McKee \& Gander, 1957) it is known that in a scenario where boxes are stacked in a column, most of the load distributes down along the perimeter of the box. McKee also showed 
that there is a load concentration at the corners of the boxes resulting in an uneven distribution of load along the box perimeter.

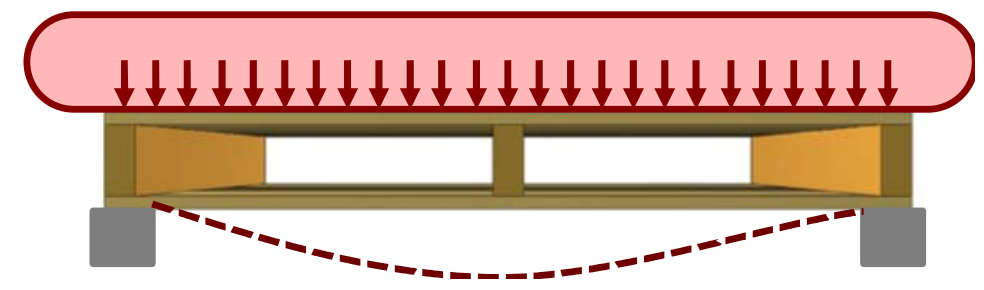

Figure 8. Pallet racked across the width under uniformly distributed loading with an airbag.

In a unitized scenario, where pallet bending is present, the boxes interact with each other, altering how the load is transferred down the stack to the pallet. As a result of this interaction, a certain percent of the compression stresses on the pallet is redistributed towards the supports, reducing the pallet deflection. This stress redistribution is called load bridging. Figure 9 shows a schematic of the experimentally observed unit load interaction and stress redistribution present in the load bridging effect in a racking support mode, but the specific mathematical behavior has not yet been characterized.

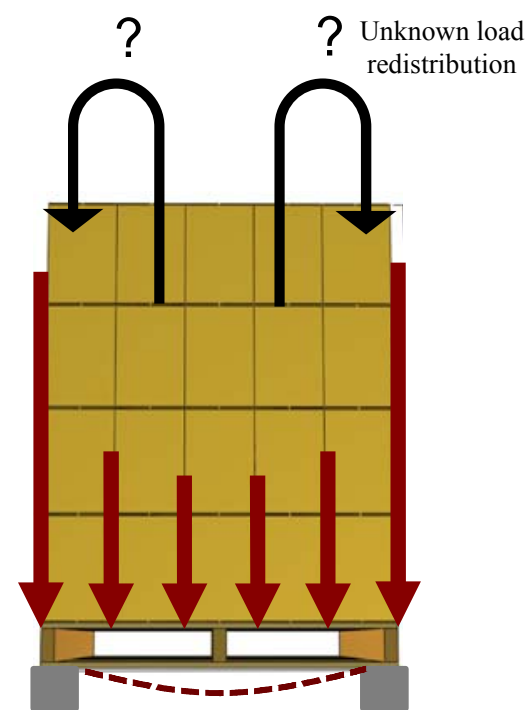

Figure 9. Experimentally observed load redistribution of a four-layer unit load on a racked across the width pallet. 
The factors that have been identified to affect the stiffness of the load and therefore the load bridging effect magnitude are (Center for Unit-Load Design, 1997; Collie, 1984; Fagan, 1982; Park, 2015; Park et al., 2017; M. S. White et al., 1999; Yoo, 2011):

- Package size

- Package and pallet stiffness

- Containment force

- Number of layers

- Unit Load height

- Coefficient of Friction between components

- Stacking Pattern

Fagan (1982) began characterizing the loads, supports and structural members of the unit loads in order to be able to gain an understanding on how the type of load affects the pallet performance. In this initial study, the author tested four different load types representing different expected load bridging effects and measured pallet deflection as the main response. The first one was uniform loading with an airbag (no load-bridging), then a symmetrical box pattern on the pallet (low load-bridging), next an asymmetrical box pattern (medium load-bridging) and the fourth a platen-type load (extreme load-bridging). Every load type was tested for four pallets with different stiffness, identified by the average MOE of the components of each pallet, and in the two racking directions, racked across the length and across the width. It was concluded that there is a significant effect on the deflection of the pallet depending on the load type and the stiffness of the pallet. The stiffness of the pallet what drives the magnitude of the effect of the other factors.

Collie (1984) continued with investigation of the load bridging effect on unit loads. One of the studies performed evaluated the effect of the stacking patterns and the amount of unit loads stacked on one another. All these tests were performed simulating floor stacking. No effect in deflection was identified for the different stacking patterns and adjustment factors were calculated for the effect due to the number of piled pallets.

In additional tests, Collie (1984) worked toward identifying and characterizing the factors causing the load-bridging effect when the unit load is in a racking support condition. For this experiment, five different loads where used as treatments with different levels of expected load bridging. For extreme load bridging, box goods of the size of half the pallet width where used. Two loads with the same boxes but different stacking pattern where used as estimated medium 
bridging. A stiffer load with minimal bridging was simulated with bagged goods and finally, an airbag was used as control, with no load bridging at all. Every type of load was tested on three different pallet types, of low, medium and high stiffness and each of these combinations was tested in racking across the width and racking across the length, being pallet deflection the main response measured. He identified, as Fagan (1982) had also concluded, that load bridging decreases significantly when the stiffness of the pallet increases, making the effect almost negligible on very stiff pallets. Also, the racking direction was demonstrated as a critical factor on the amount of resulting load bridging by the unit loads. Bridging is greater on pallets spanning pallet width because pallets are less stiff in this mode of support. Regarding the differences in deflection due to the load type, only on the low stiffness pallets was possible to find any significant variation between them.

When the size of the package is increased, the load is distributed along less points and a higher percentage of the load is directly supported by the supports of the pallet, mainly in a racking support (Collie, 1984). To better understand and model the distribution of the stresses on pallet decks, Yoo (2011) developed research relating pallet stress distribution with the theory of a beam on an elastic foundation. It was identified that the compression stresses are higher near the supports and diminish towards the middle of the free span. The magnitude of the stress redistribution depends on the pallet stiffness and the stiffness of the load itself.

In order to quantify the effect of the size of the corrugated box on the performance of the unit load, Park (2017) measured pallet deformation while varying box sizes and flute types, finding that up to a $76 \%$ reduction in the unit load deflection can be achieved by increasing the package dimensions.

Park (2015) conducted an experiment to identify the effect of the containment force of stretch wrap on the load bridging of the unit loads. The tests were conducted using two plywood boards as simulated pallets with low and high stiffness, three different packaging sizes and three levels of containment force (0 lbs., $30 \mathrm{lbs}$. and $60 \mathrm{lbs}$.). The effect was measured by the deformation of the simulated pallet and deflection was compared to the one of the same simulated pallets but with the load applied using an airbag. It was concluded that pallet deformation decreases significantly with changes in the size of the box. An interaction was present when varying box size and containment force. Using a pressure mat it was also identified that the stress distribution on the board changes with the increase in the containment force. With little or no containment force, 
the stresses are more evenly distributed along the pallet, but as the applied containment force increases, the stresses move towards the edges, applying more pressure to the packages and increasing the load bridging effect.

\subsubsection{Effect of pallet design on compression stresses on packaged product}

Multiple studies have been performed in order to characterize the interaction between a product, mainly corrugated boxes, and the different pallet design characteristics. One critical characteristic identified are the gaps between deckboards in the pallet. Kellicut (1963) addressed this from the perspective of the strength of the corrugated boxes and how they are affected by the pallet gaps, showing a reduction in strength when the box was not fully supported. Monaghan and Marcondes (1992) worked towards quantifying the effect of the overhang and the pallet gap size on the compression strength of the corrugated boxes. They determined an exponential and decreasing relationship between the compression strength and the pallet gap size. Regarding the overhang, a reduction was identified although not quantified.

More extensive research was conducted by Baker et al. (Baker et al., 2016a) where different pallet gaps where analyzed in combination with different stiffness of deckboards to identify the changes in the compression strength of the corrugated box.

Packages stacked in a unit load are subjected to compression stresses of variable magnitudes. For an effective package design, these forces must be known and besides the common factors in determining compressive stresses such as force applied and the effective bearing area, it has been identified that in the case of unitized product, the stiffness of the pallet is a significant factor with a direct effect on the bearing area. If the stiffness of the pallets decks is increased, the deflection of the deckboards is minimized, resulting in increased effective bearing area, which reduces the compressive stresses on the packages (M. S. White, 2015).

\subsubsection{Stress distribution during stacking in Unit Loads}

In a study conducted by Collie (1984) it was identified that when multiple unit loads are stacked on the top of each other, the deflection of the top deckboards of the bottom pallet does not increase proportionally to the amount of unit loads stacked. It was concluded that only $80 \%$ of the weight of the second unit load and $66 \%$ of the third unit load contributed to the bending of the top 
deckboard of the bottom pallet, which is the critical pallet component during the floor stacking mode.

\subsubsection{Vibration Transmissibility}

The design of the pallet and the characteristics of the components from which it was built, have a significant effect on the magnification of the vibratory movement and its acceleration experienced by packages in a unit load while it is being transported. The pallet essentially acts as a spring between the transportation mode and the product. A pallet can be redesigned in order to control and reduce the transmissibility (ratio of output to input acceleration) from the transportation mode vibration to the vibration the packages experience. If stiffer deckboards and stiffer joints are used, the transmissibility can be significantly decreased since the resonance frequency of the product package system will be modified. Overall, the magnification of the vibration hazard in distribution is dependent on the stiffness of the deckboards, the joint type between the components and the characteristics of the load (Weigel \& White, 1999). As an example of the findings of this research, a pallet with a deck stiffness of $202 \mathrm{~N} / \mathrm{m}^{2}$ produced a transmissibility of $2.4 \mathrm{G}$ 's of output for every $\mathrm{G}$ from the input acceleration, while a stiffer pallet $\left(2391 \mathrm{~N} / \mathrm{m}^{2}\right)$ had a transmissibility of only $1.6 \mathrm{G}$, reducing notably the hazards for the product. 


\section{Chapter 3: Materials, Methods and Experimental Design}

In order to characterize the behavior of the pallet under different types of load configurations, an experimental setup was developed.

\subsection{Materials}

\subsubsection{Pallets}

To simulate low, medium, and high stiffness pallets commonly used in the industry, 1200 mm x $1000 \mathrm{~mm}$, two-way stringer class wooden pallets were built. The pallets were composed of 3 stringers, 5 bottom deckboards and 7 top deckboards. The top and bottom deckboards were manufactured from Spruce-Pine-Fir (SPF) No. 2 and better and the stringers from defect free Poplar. All components were kiln dried to $19 \%$ moisture content. The fasteners used were 63.5 $\mathrm{mm}$ (2.5 in.) long structural screws. A total of 72 screws per pallet were used, 2 at each joint between a deckboard and a stringer. The nominal component dimensions of the pallets are listed in Table 6.

Table 6. Dimensions for the components of the pallets.

\begin{tabular}{lcccc}
\multicolumn{5}{c}{ Pallet Components Specifications } \\
Low Stiffness & Medium Stiffness & High Stiffness \\
\hline \multirow{4}{*}{ Top Deck } & Quantity & 7 & 7 & 7 \\
& Thickness (mm) & 10 & 16 & 22 \\
& Width (mm) & 90 & 90 & 90 \\
& Length (mm) & 1000 & 1000 & 1000 \\
\cline { 2 - 5 } Bottom Deck & Quantity & 5 & 5 & 5 \\
& Thickness (mm) & 10 & 16 & 22 \\
& Width (mm) & 90 & 90 & 90 \\
& Length (mm) & 1000 & 1000 & 1000 \\
\cline { 2 - 5 } Stringers & Quantity & 3 & 3 & 3 \\
& Width (mm) & 25 & 38 & 44 \\
& Height (mm) & 90 & 90 & 90 \\
& Length (mm) & 1200 & 1200 & 1200 \\
\hline \multirow{5}{*}{} & & & &
\end{tabular}

The Modulus of Elasticity (MOE) was determined for each wood component, following the procedures in ASTM D198 (ASTM, 2015) Static Tests of Lumber in Structural Sizes. With the load and bending data obtained, the MOE was calculated using Equation 2. The average MOE of the different pallet components for each pallet design are shown in Table 7. Components with 
low MOE were grouped and used for the low stiffness pallet in order to reduce stiffness variability within components of each pallet. The same was done for the medium and high stiffness pallets.

$$
\text { Modulus of Elasticity }(M O E)=\frac{P l^{3}}{4 b d^{3} \Delta} \quad \text { [Equation 2] }
$$

Where $P$ is the increment of applied load on flexure specimen below proportional limit, $(\mathrm{N}), l$ is the span of flexure $(\mathrm{mm}), b$ is the width of flexure specimen $(\mathrm{mm}), d$ is the depth of rectangular flexure specimen $(\mathrm{mm})$ and $\Delta$ is the increment of deflection of neutral axis of flexure specimen measured at midspan over distance $l$ and corresponding load $P(\mathrm{~mm})$.

Table 7. Modulus of Elasticity (MOE) and Moisture Content (M.C.) for the pallet components.

\begin{tabular}{llccc}
\hline \multicolumn{4}{c}{ Pallet Components Specifications } \\
\hline \multirow{5}{*}{ Deckboards } & Low Stiffness & Medium Stiffness & High Stiffness \\
\cline { 2 - 5 } & Average MOE, MPa & 7,155 & 9,662 & 10,627 \\
& (COV) & $(29 \%)$ & $(17 \%)$ & $(14 \%)$ \\
& Average M.C. (\%) & 12.68 & 14.38 & 14.86 \\
\cline { 2 - 5 } Stringers & Average MOE, MPa & 11,157 & 11,632 & 12,181 \\
& (COV) & $(2 \%)$ & $(7 \%)$ & $(9 \%)$ \\
& Average M.C. & $15 \%$ & $15 \%$ & $15 \%$ \\
\hline
\end{tabular}

The pallet stiffness under a uniformly distributed load was measured using an airbag as load applicator, following the standard ASTM D1185-98a(2009). This provides a comparison of the bending characteristics between pallet designs and are in Table 8.

Table 8. Pallet stiffness for the low, medium and high stiffness designs under uniform loading.

\begin{tabular}{cccc}
\hline & \multicolumn{3}{c}{ Pallet Stiffness (kg/mm) } \\
\hline & Low Stiffness & $\begin{array}{c}\text { Medium } \\
\text { Stiffness }\end{array}$ & High Stiffness \\
\cline { 2 - 4 } \begin{tabular}{c} 
Racked Across the \\
Length \\
Racked Across the \\
Width \\
\cline { 2 - 4 }
\end{tabular} & 165.63 & 283.48 & 295.74 \\
\cline { 2 - 4 } $\begin{array}{c}\text { Forklift Support } \\
\text { (RAW) } \\
\text { Floor Support }\end{array}$ & 17.44 & 84.59 & 175.24 \\
\cline { 2 - 4 } & 122.83 & 366.53 & 212.92 \\
\hline
\end{tabular}


Theoretical performance estimations of each pallet design were conducted using computer modeling using The Pallet Design System ${ }^{\circledR}$ (PDS). The values for each pallet on each support condition are shown in Table 9.

Table 9. Performance estimation for the low, medium and high stiffness pallets based on The Pallet Design System ${ }^{\circledR}$ computer model.

\begin{tabular}{|c|c|c|c|c|}
\hline \multicolumn{5}{|c|}{ Pallet Design Performance Estimation } \\
\hline \multirow{3}{*}{$\begin{array}{l}\text { Racked Across the } \\
\text { Length }\end{array}$} & & Low Stiffness & $\begin{array}{l}\text { Medium } \\
\text { Stiffness }\end{array}$ & High Stiffness \\
\hline & Safe Maximum Load (kg) & 535 & 1146 & 1671 \\
\hline & Deflection at Max Load (mm) & 7 & 7 & 7 \\
\hline \multirow{4}{*}{$\begin{array}{l}\text { Racked Across the } \\
\text { Width } \\
\text { Forklift Support } \\
\text { (RAW) }\end{array}$} & Safe Maximum Load (kg) & 218 & 555 & 1066 \\
\hline & Deflection at Max Load (mm) & 21 & 14 & 11 \\
\hline & Safe Maximum Load (kg) & 483 & 1191 & 2230 \\
\hline & Deflection at Max Load (mm) & 9 & 6 & 6 \\
\hline \multirow{2}{*}{ Floor Support } & Safe Maximum Load (kg) & 774 & 2032 & 4142 \\
\hline & Deflection at Max Load (mm) & 4 & 3 & 3 \\
\hline
\end{tabular}

\subsubsection{Corrugated Boxes}

Regular Slotted Container (RSC), single wall, C-flute, corrugated fiberboard boxes with nominal outer dimensions of $300 \mathrm{~mm}$ x $200 \mathrm{~mm}$ x $290 \mathrm{~mm}$ were used in the study. The corrugated boxes were built using a Data Technology Inc. Computer Aided Design cutting table Model DT11066.

The box dimensions were defined based on the modular carton dimensions recommended by the standard ISO 3394:2012 - Packaging- Complete, filled transport packages and unit loads Dimensions of rigid rectangular packages (ISO, 2012). Boxes where filled with Nation's Choice ${ }^{\circledR}$ premium wood pellets with a density of $610 \mathrm{~kg} / \mathrm{m}^{3}$ in order to reach a total load of $680 \mathrm{~kg}$ (1500 lbs.), so each box weighted $8.5 \mathrm{~kg}$. The box flaps were closed using two parallel beads of hot melt glue.

Edgewise compressive strength (ECT), flat crush strength (FCT), burst strength, coefficient of friction, and box compression strength were also determined for the corrugated boxes used(Table 10). 
Table 10. Performance characteristics of the corrugated fiberboard used in the experimentation phase.

\begin{tabular}{lll}
\hline Characteristic & Average Value & COV (\%) \\
\hline Edgewise Compressive Strength (ECT) & $4.52 \mathrm{kN} / \mathrm{m}$ & 3.26 \\
Flat Crush Strength (FCT) & $302 \mathrm{kPa}$ & 2.44 \\
Burst Strength & $1,170 \mathrm{kPa}$ & 10.04 \\
Coefficient of Friction & $0.50\left(26^{\circ}\right.$ Slide Angle) & 11.68 \\
& Outer: $178 \mathrm{~g} / \mathrm{m}^{2}$ & 0.69 \\
Grammage & Medium: $130 \mathrm{~g} / \mathrm{m}^{2}$ & 1.13 \\
& Inner: $178 \mathrm{~g} / \mathrm{m}^{2}$ & 1.88 \\
\hline
\end{tabular}

Details regarding each test performed were as follows.

Edge Crush Test (ECT)

Test performed according to TAPPI T 839 (2009) Edgewise compressive strength of corrugated fiberboard using the clamp method (short column test). Universal testing machine (Model: MTS Criterion 42) with a $5 \mathrm{kN}$ load cell was used. Ten replicate tests were conducted.

\section{Flat Crush Test (FCT)}

Test performed according to TAPPI T 808 (2013) Flat crush test of corrugated board. Universal testing machine (Model: MTS Criterion 42) with a $5 \mathrm{kN}$ load cell was used. Ten valid replicate tests were conducted.

\section{Bursting Strength}

Test performed according to TAPPI T 810 (2011) Bursting strength of corrugated and solid fiberboard. Mullen Burst Tester (Model AD) was used. Twenty replicate tests were conducted.

\section{Coefficient of Friction}

Test performed according to TAPPI T 815 (2001) Coefficient of static friction (slide angle) of packaging and packaging materials (including shipping sack papers, corrugated and solid fiberboard) (inclined plane method). Coefficient of Friction Tester (Model 32-25) from Testing Machines Inc. was used. Twenty replicate tests were conducted, with the orientation of the 
materials perpendicular to each other (Machine Direction against Cross Direction) and facing the outer side of the boxes (felt).

\section{Basis Weight}

Test performed according to ISO 536 (2012) Paper and board - Determination of Grammage. Five replicate tests were conducted.

\subsubsection{Unit Load}

Each unit load was built with 80 boxes arranged in four layers of 20 boxes each, with an overall height of $1160 \mathrm{~mm}$, covering $100 \%$ of the pallet with no under- or overhang, regardless of the stacking pattern. The total weight of the product was $680 \mathrm{~kg}$. The height and number of layers are based on the standard height required by different popular club stores in order to optimize the cubing out of a 53-foot trailer, which has an inner height of $2.67 \mathrm{~m}$. With the current dimensions, the unit load can be double stacked during transportation. It also works with the $1400 \mathrm{~mm}$ available vertical space in stores, so it can be racked and displayed without any modification to the unit load.

\subsection{Methods}

\subsubsection{Pallet Stacking Patterns}

In order to select the pallet stacking patterns for the investigation, multiple options were generated when running the commercial software solutions CAPE and BestLoad, for the pallet footprint and package dimension in use. The stacking patterns selected required a full deckboard coverage, so any pattern with under or overhang or inner gaps was discarded, assuring that every unit load design will have the same total weight and box quantity. The patterns were evaluated and compared following the criteria proposed by Carpenter and Dowsland (1985). They suggested three conditions to assure the stability of a unit load. The first criterion indicates that when a box is placed upon multiple boxes, the interlocking level is higher, therefore preferable, due to higher stability. For this evaluation, a direct proportionality between unit load stability and interlocking level is assumed. In the patterns selected, pattern P1, being it a column stack, any box in the three top layers is supported by a single box. For patterns $\mathrm{P} 2$ and $\mathrm{P} 3$, each box is supported by an average of 2.7 boxes underneath, ranging from 2 to 4 boxes depending on the box location. Patterns P4 and 
P5 have an average on 2.1 boxes placed upon each other, representing then a lower level of interlocking. The unit loads are shown in Table 11.

The second criterion is that each box must have a predetermined percent of the base supported by another box. For this study, only patterns where a $100 \%$ of the base of every box is supported were selected, discarding any patterns with gaps or boxes protruding on the sides.

The third criterion was the number of guillotine cuts along the whole unit load, which is, trying to minimize the number of independent columns in the stack, which would allow for movement and generate instability. Pattern P1 had 20 columns which generated 7 guillotine cuts across the unit load. The remaining patterns had a single cut across. It was not possible to develop a stacking pattern without guillotine cuts for the box and pallet dimensions being used, that also provided $100 \%$ of the pallet deck coverage and no overhang.

Although other options where available, these patterns make possible the evaluation between symmetric and asymmetric loading, where depending if boxes are facing the length or the width, different pallet behavior could be observed, due to higher load concentration in certain areas. Additionally, previous research identified that the box size is a significant factor in unit load deflection (Park et al., 2017). Although the box size is not varied in this investigation, the effect of the box direction could result in a variation in the effective box size for each of the pallet patterns. Here, the rectangular box could have the length or the width side parallel aligned with the free span on each of the support conditions, thus affecting the load application.

The bottom layer is the one that directly interacts with the pallet, so the effect of not only changing the interlocking level but also the design of the bottom layer changes the location where the edges and corners of the boxes are located, potentially changing how the compression stresses are distributed down to the pallet. Three designs were selected, one for P1, a second design for P2 and $\mathrm{P} 4$ and a final one for P3 and P5. Table 11 shows the diagrams for the bottom layers.

In summary, the stacking patterns selected were, pattern P1, which was a regular column stacking pattern, P2 was a split-row fully interlocked pattern, P3 followed a pinwheel fully interlocked design, P4 had the bottom two layers arranged in a column stacked and the top layers were interlocked, with every layer following a split-row design, and P5 used a pinwheel pattern with the bottom layers stacked in a column and the top layers interlocked. 
Table 11. Stacking Patterns developed for the study (Images generated using BestLoad®).

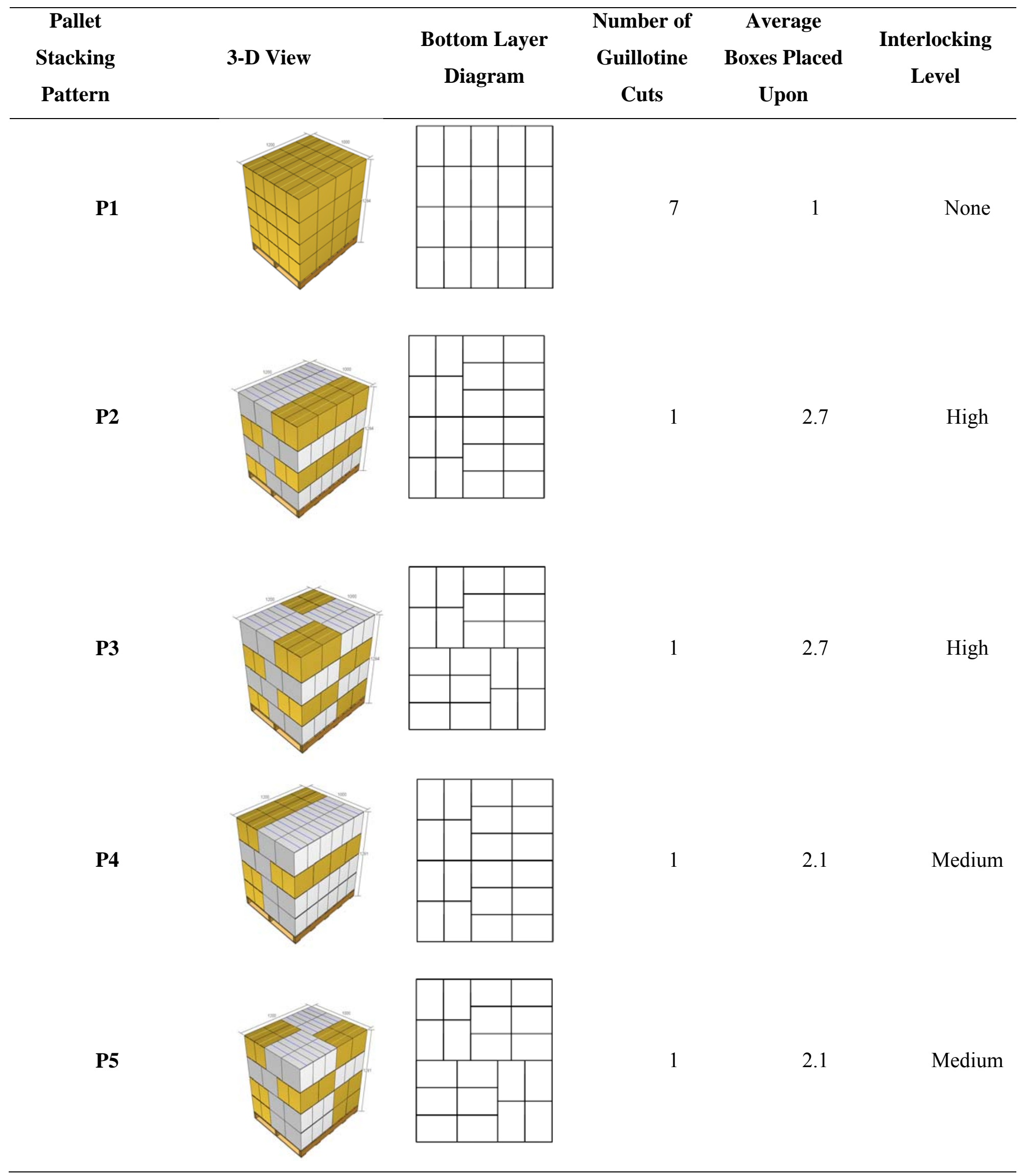




\subsubsection{Support Conditions}

Four support conditions were tested for each unit load assembled: floor support, pallet bending racked across the width, pallet bending racked across the length, and pallet bending using forklift support across the width. All materials were conditioned to laboratory environmental conditions and temperature and relative humidity was continuously recorded.

For each treatment factor combination, a unit load was assembled and raised with the forklift five times to allow for the load to settle. Afterwards, testing was conducted by placing the unit load on three of the four support conditions tested, racked across the width, racked across the length and forklift support across the width. Testing to measure bending of the top deckboards was performed separately.

\subsubsection{Warehouse rack support across the width (RAW)}

The simulated racking support was built using two I-beams $1500 \mathrm{~mm}$ long, $275 \mathrm{~mm}$ height and $150 \mathrm{~mm}$ wide with a circular beam of a $60 \mathrm{~mm}$ diameter welded on top and a $50.4 \times 12.7 \mathrm{~mm}$ steel plate placed on the circular beam with free rotational movement, fixed parallel to each other with a $962 \mathrm{~mm}$ free span. The unit load was centered on the supports with the width of the pallet spanning the supports (Figure 10).

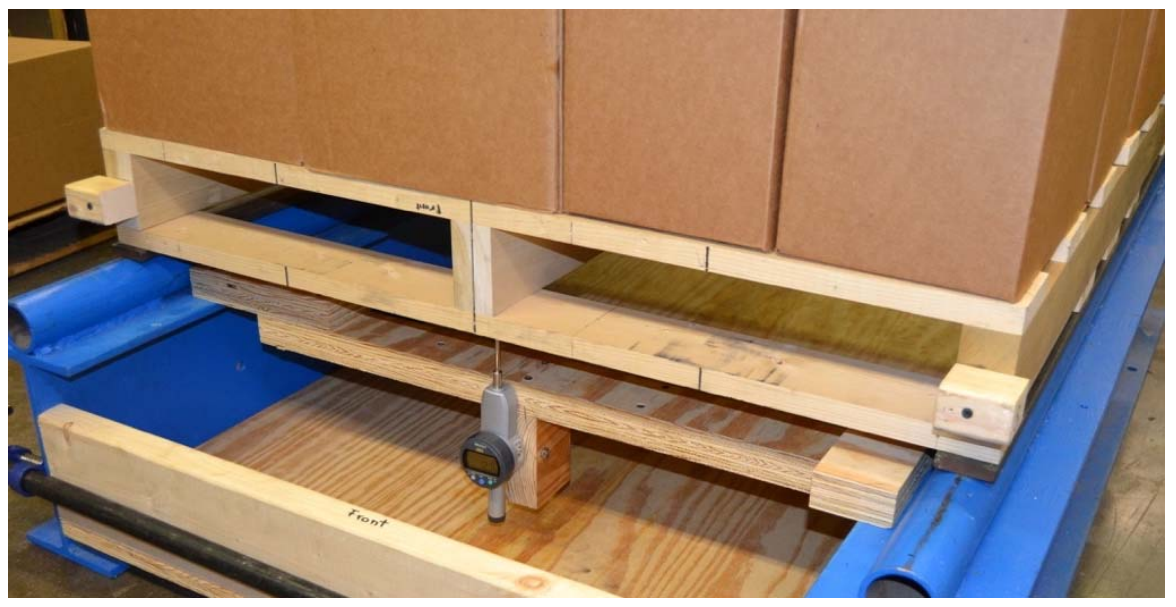

Figure 10. Experimental setup for the warehouse rack support across the width. 
After two minutes of the application of the payload the deflection was recorded at the points shown in Figure 11. Deflection was measured using a Mitutoyo Digimatic Indicator Series with a $50.8 \mathrm{~mm}$ range attached to a custom jig which was supported on the flanges of the I-beams.

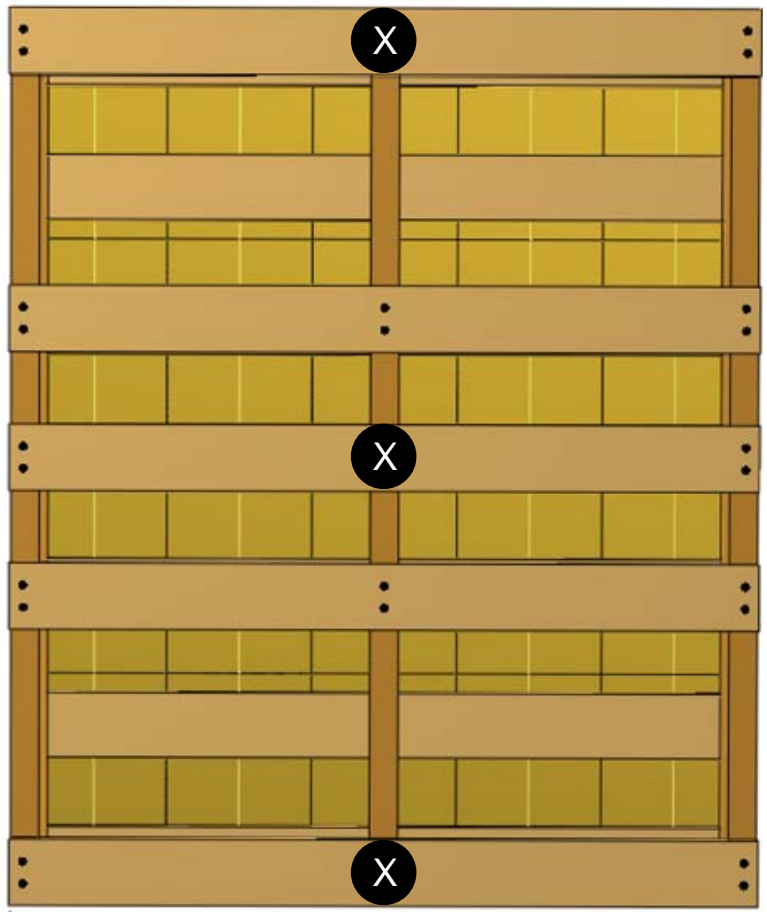

Figure 11. Identification of the pallet locations for the deflection measurements of the warehouse rack support across the width.

\subsubsection{Warehouse rack support across the length (RAL)}

The simulated racking support was built using two I-beams $1500 \mathrm{~mm}$ long, $275 \mathrm{~mm}$ height and $150 \mathrm{~mm}$ wide with a circular beam of a $60 \mathrm{~mm}$ diameter welded on top and a $50.4 \times 12.7 \mathrm{~mm}$ steel plate placed on the circular beam with free rotational movement, fixed parallel to each other with a $1150 \mathrm{~mm}$ free span. The unit load was centered on the supports with the length of the pallet spanning the supports (Figure 12). 


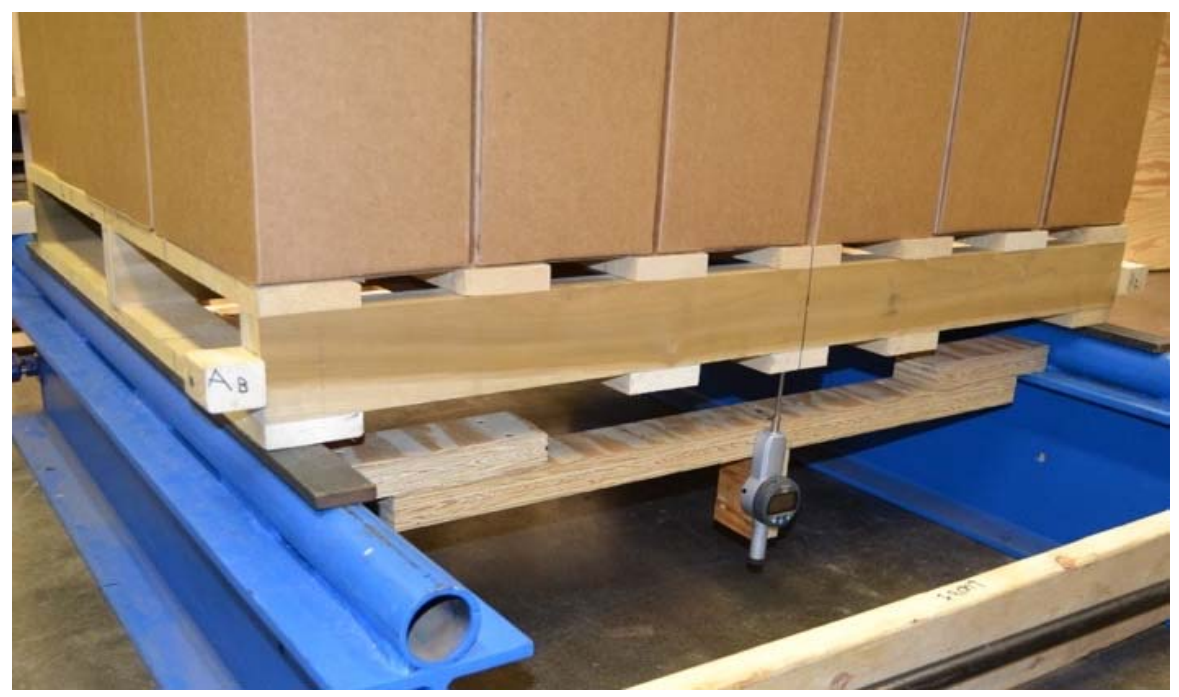

Figure 12. Experimental setup for the warehouse rack support across the length.

After two minutes of the application of the payload the deflection was recorded at the points shown in Figure 13. Deflection was measured using a Mitutoyo Digimatic Indicator Series 543 with a $50.8 \mathrm{~mm}$ range attached to a custom jig which was supported on the flanges of the I-beams.

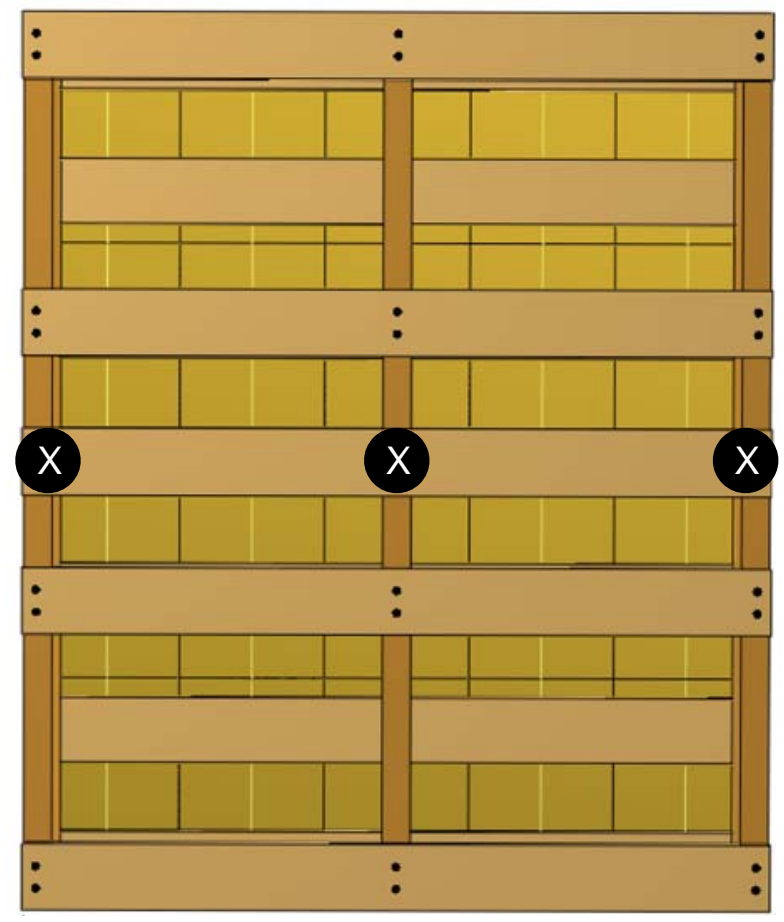

Figure 13. Identification of the pallet locations for the deflection measurements of the warehouse rack support across the length test. 


\subsubsection{Fork tine support across the width}

Using the actual tines of the forklift as supports, they were fixed to a span of $570 \mathrm{~mm}$ from the outside of one tine to the outside of the other. The fork tines supported the whole length of the pallet, being $1500 \mathrm{~mm}$ long. The unit load was centered in the forklift with the width of the pallet spanning the supports. The tines were then fully supported underneath on a wooden structure to avoid bending or any other displacement. The setup is shown in Figure 14.

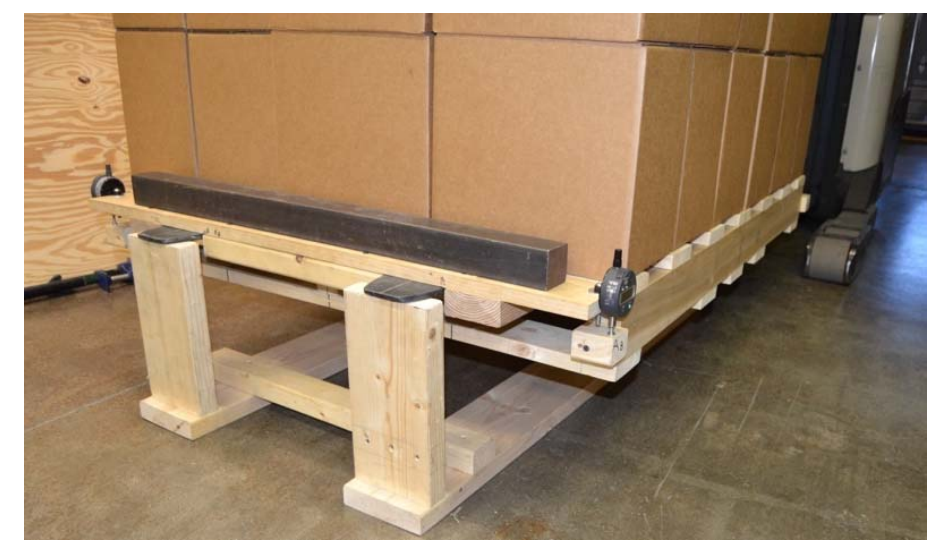

Figure 14. Experimental setup for the fork tine support across the width.

After two minutes of fully supporting the unit load on the supports, deflection was recorded at the four blocks attached at the stringers, at the mid height of the end sides of the two outside stringers. Figure 15 shows the points where deflection was recorded. Measurements were made using a custom jig which was supported on top of the fork tines to maintain a non-movable reference point. It included a Mitutoyo Digimatic Indicator Series 543 with a $12.7 \mathrm{~mm}$ range attached at each side and spacers on the bottom to assure the correct span of the supports. 


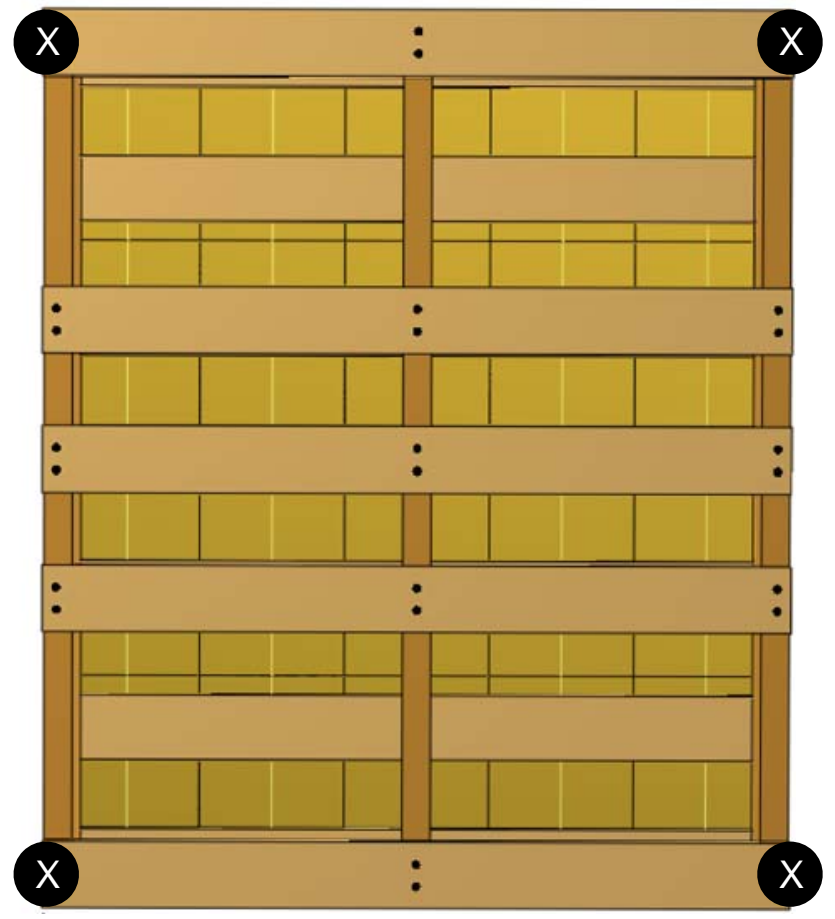

Figure 15. Identification of the pallet locations for the deflection measurements of the fork tine support across the width test.

\subsubsection{Floor Support}

In order to simulate the floor stacking condition, the pallet was fully supported using two steel I-beams $1500 \mathrm{~mm}$ long, $108 \mathrm{~mm}$ wide and $108 \mathrm{~mm}$ tall underneath each side stringer and a $54 \times 108 \mathrm{~mm}$ hollow beam under the center stringer raised with two steel scissor jacks, acting as a uniform rigid support. The setup is shown in Figure 16.

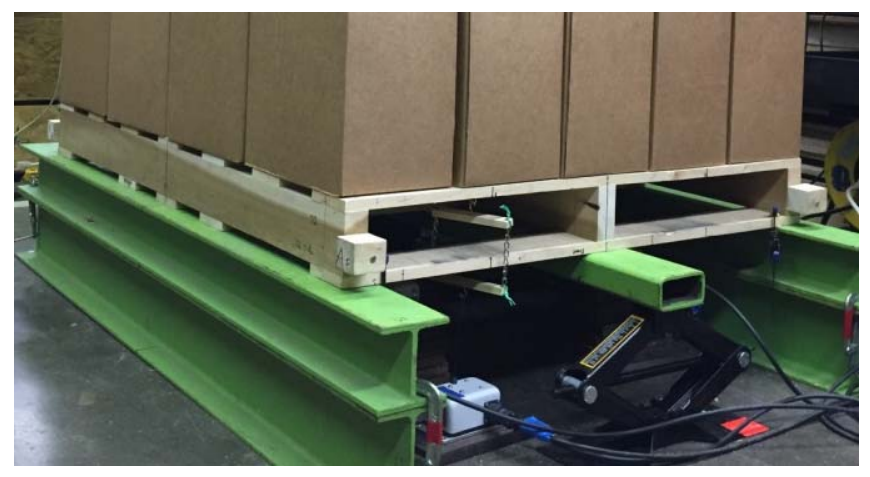

Figure 16. Experimental setup for the floor support. 
Two minutes after the application of the payload the deflection was measured using a string potentiometer connected to each pallet location using an eye hook. Figure 17 shows the points where deflection was recorded.

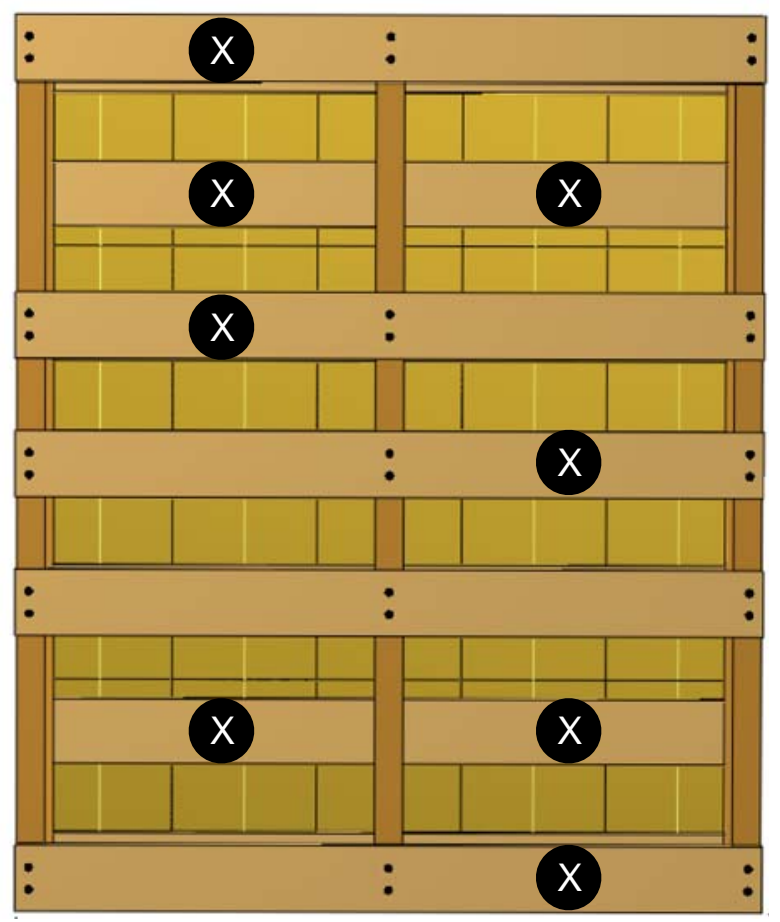

Figure 17. Identification of the pallet locations for the deflection measurements of the floor support test.

\subsection{Experimental Design}

Twelve one-way factorial experimental designs were conducted with one independent categorical variable (stacking pattern) with five levels. All treatment combinations were replicated 3 times. In order to evaluate, independently, the effect of the treatments under different support conditions and pallet design, the experimental design was run, individually, for each of four support conditions (floor stacking, fork tine support across the width, warehouse free span rack support across the length (RAL) and across the Width (RAW)) and three pallet designs (low, medium and high stiffness).

Table 12 shows the experimental designs performed. For each of the experiments a oneway analysis of variance (ANOVA) was conducted along with a multiple comparison post-hoc 
analysis using the Tukey's Honest Significant Difference (HSD) to find differences between each of the treatment levels.

Table 12. Experimental Designs for the Unit Load Deflection.

\begin{tabular}{cccccc}
\hline \multirow{3}{*}{ Pallet Design } & Stacking Pattern & \multicolumn{3}{c}{ Replicates per Support Condition } \\
\cline { 3 - 6 } & & Floor & Fork Tine & RAL & RAW \\
& Stacking & & & \\
\hline \multirow{5}{*}{ Low Stiffness } & Column (P1) & 3 & 3 & 3 & 3 \\
& Split Row IL (P2) & 3 & 3 & 3 & 3 \\
& Pinwheel IL (P3) & 3 & 3 & 3 & 3 \\
& Split Row 2-top IL (P4) & 3 & 3 & 3 & 3 \\
& Pinwheel 2 top IL (P5) & 3 & 3 & 3 & 3 \\
\hline \multirow{5}{*}{ Medium Stiffness } & Column (P1) & 3 & 3 & 3 & 3 \\
& Split Row IL (P2) & 3 & 3 & 3 & 3 \\
& Pinwheel IL (P3) & 3 & 3 & 3 & 3 \\
& Split Row 2-top IL (P4) & 3 & 3 & 3 & 3 \\
& Pinwheel 2 top IL (P5) & 3 & 3 & 3 & 3 \\
\hline \multirow{5}{*}{ High Stiffness } & Column (P1) & 3 & 3 & 3 & 3 \\
& Split Row IL (P2) & 3 & 3 & 3 & 3 \\
& Pinwheel IL (P3) & 3 & 3 & 3 & 3 \\
& Split Row 2-top IL (P4) & 3 & 3 & 3 & 3 \\
& Pinwheel 2 top IL (P5) & 3 & 3 & 3 & 3 \\
\hline Total runs & & $\mathbf{4 5}$ & $\mathbf{4 5}$ & $\mathbf{4 5}$ & $\mathbf{4 5}$ \\
\hline
\end{tabular}

The pallet deflection model used for the four experiments is shown on Equation 3.

$$
y_{i j k s}=\mu+\alpha_{i}+\beta_{j}+(\alpha \beta)_{i j}+\varepsilon_{i j k} \quad \text { [Equation 3] }
$$

Where $y_{i j k s}$ is the deflection at each of the support conditions, $\mu$ is the grand mean response, $\alpha_{i}$ the effect of the $i^{\text {th }}$ level of pallet stiffness, $\beta_{j}$ the effect of the $j^{\text {th }}$ level of stacking pattern, $(\alpha \beta)_{i j}$ the interaction effect between the $i^{\text {th }}$ level of pallet stiffness and the $j^{\text {th }}$ level of stacking pattern, $\varepsilon_{i j k}$ the random errors $\sim \operatorname{Normal}\left(0, \sigma_{\varepsilon}\right)$ and the subscript $i$ is the factor level of pallet stiffness $(1,2,3), j$ the factor level of stacking pattern $(1,2,3,4,5), k$ the replicate index $(1,2,3)$ and $s$ the support condition $(1,2,3,4)$. 


\section{Chapter 4: Results and Discussion}

\subsection{Pallet deflection when racked across the width}

Deflection measurements for warehouse racking across the width support were divided for the analysis to separate the deflection of the center points of the pallet and the deflection at the sides (or ends) of the pallet. Deflection at the pallet ends were averaged for each replicate to mirror previous research on the subject. Table 13 and Figure 18 show the deflection at the center while Table 14 shows the deflection at the ends for each pallet design tested and the comparison between the five stacking patterns.

Table 13. Average racked across the width pallet center deflection by stacking pattern and pallet design.

\begin{tabular}{lccccccccc}
\hline & \multicolumn{4}{c}{ Low Stiffness Pallet } & \multicolumn{3}{c}{ Medium Stiffness Pallet } & \multicolumn{3}{c}{ High Stiffness Pallet } \\
\cline { 2 - 9 } \multicolumn{1}{c}{ Stacking Pattern } & $\begin{array}{c}\text { Average } \\
\text { Deflection, } \\
\text { mm }\end{array}$ & $\begin{array}{c}\text { Std. } \\
\text { Dev, } \\
\text { mm }\end{array}$ & $\begin{array}{c}\text { Tukey } \\
\text { HSD }\end{array}$ & $\begin{array}{c}\text { Average } \\
\text { Deflection, } \\
\mathrm{mm}\end{array}$ & $\begin{array}{c}\text { Std. } \\
\text { Dev, } \\
\mathrm{mm}\end{array}$ & $\begin{array}{c}\text { Tukey } \\
\text { HSD }\end{array}$ & $\begin{array}{c}\text { Average } \\
\text { Deflection, } \\
\mathrm{mm}\end{array}$ & $\begin{array}{c}\text { Std. } \\
\text { Dev, } \\
\mathrm{mm}\end{array}$ & $\begin{array}{c}\text { Tukey } \\
\text { HSD }\end{array}$ \\
\hline Column (P1) & 27.21 & 0.55 & $\mathrm{~A}$ & 6.81 & 0.30 & $\mathrm{D}$ & 2.76 & 0.53 & $\mathrm{~F}$ \\
Split Row IL (P2) & 12.84 & 1.78 & $\mathrm{C}$ & 4.80 & 0.28 & $\mathrm{E}$ & 2.45 & 0.16 & $\mathrm{~F}$ \\
Pinwheel IL (P3) & 14.38 & 1.19 & $\mathrm{BC}$ & 5.16 & 0.38 & $\mathrm{E}$ & 2.23 & 0.38 & $\mathrm{~F}$ \\
Split Row mix IL (P4) & 17.18 & 0.76 & $\mathrm{~B}$ & 5.20 & 0.07 & $\mathrm{E}$ & 2.13 & 0.31 & $\mathrm{~F}$ \\
Pinwheel mix IL (P5) & 16.16 & 0.58 & $\mathrm{~B}$ & 5.10 & 0.64 & $\mathrm{E}$ & 2.10 & 0.41 & $\mathrm{~F}$ \\
\hline
\end{tabular}

Table 14. Average racked across the width pallet ends deflection by stacking pattern and pallet design.

\begin{tabular}{|c|c|c|c|c|c|c|c|c|c|}
\hline \multirow[b]{2}{*}{ Stacking Pattern } & \multicolumn{3}{|c|}{$\begin{array}{l}\text { Low Stiffness } \\
\text { Pallet }\end{array}$} & \multicolumn{3}{|c|}{$\begin{array}{l}\text { Medium Stiffness } \\
\text { Pallet }\end{array}$} & \multicolumn{3}{|c|}{$\begin{array}{l}\text { High Stiffness } \\
\text { Pallet }\end{array}$} \\
\hline & $\begin{array}{l}\text { Average } \\
\text { Deflection } \\
\text {, mm }\end{array}$ & $\begin{array}{c}\text { Std. } \\
\text { Dev } \\
, \\
\text { mm }\end{array}$ & $\begin{array}{l}\text { Tuke } \\
\text { y } \\
\text { HSD }\end{array}$ & $\begin{array}{l}\text { Average } \\
\text { Deflection, } \\
\mathrm{mm}\end{array}$ & $\begin{array}{l}\text { Std. } \\
\text { Dev, } \\
\mathrm{mm}\end{array}$ & $\begin{array}{l}\text { Tukey } \\
\text { HSD }\end{array}$ & $\begin{array}{l}\text { Average } \\
\text { Deflection, } \\
\mathrm{mm}\end{array}$ & $\begin{array}{l}\text { Std. } \\
\text { Dev, } \\
\mathrm{mm}\end{array}$ & $\begin{array}{l}\text { Tuke } \\
\text { y } \\
\text { HSD }\end{array}$ \\
\hline Column (P1) & 27.27 & 0.63 & A & 6.90 & 0.20 & $\mathrm{D}$ & 2.38 & 0.74 & $\mathrm{~F}$ \\
\hline Split Row IL (P2) & 12.80 & 1.84 & $\mathrm{C}$ & 4.95 & 0.29 & $\mathrm{E}$ & 2.28 & 0.21 & $\mathrm{~F}$ \\
\hline Pinwheel IL (P3) & 14.25 & 1.18 & $\mathrm{BC}$ & 5.27 & 0.27 & $\mathrm{E}$ & 2.09 & 0.37 & $\mathrm{~F}$ \\
\hline $\begin{array}{l}\text { Split Row mix IL } \\
\text { (P4) }\end{array}$ & 17.19 & 0.79 & B & 5.41 & 0.07 & $\mathrm{E}$ & 2.11 & 0.31 & $\mathrm{~F}$ \\
\hline $\begin{array}{l}\text { Pinwheel mix IL } \\
\text { (P5) }\end{array}$ & 16.12 & 0.50 & B & 5.24 & 0.74 & $\mathrm{E}$ & 2.03 & 0.39 & $\mathrm{~F}$ \\
\hline
\end{tabular}




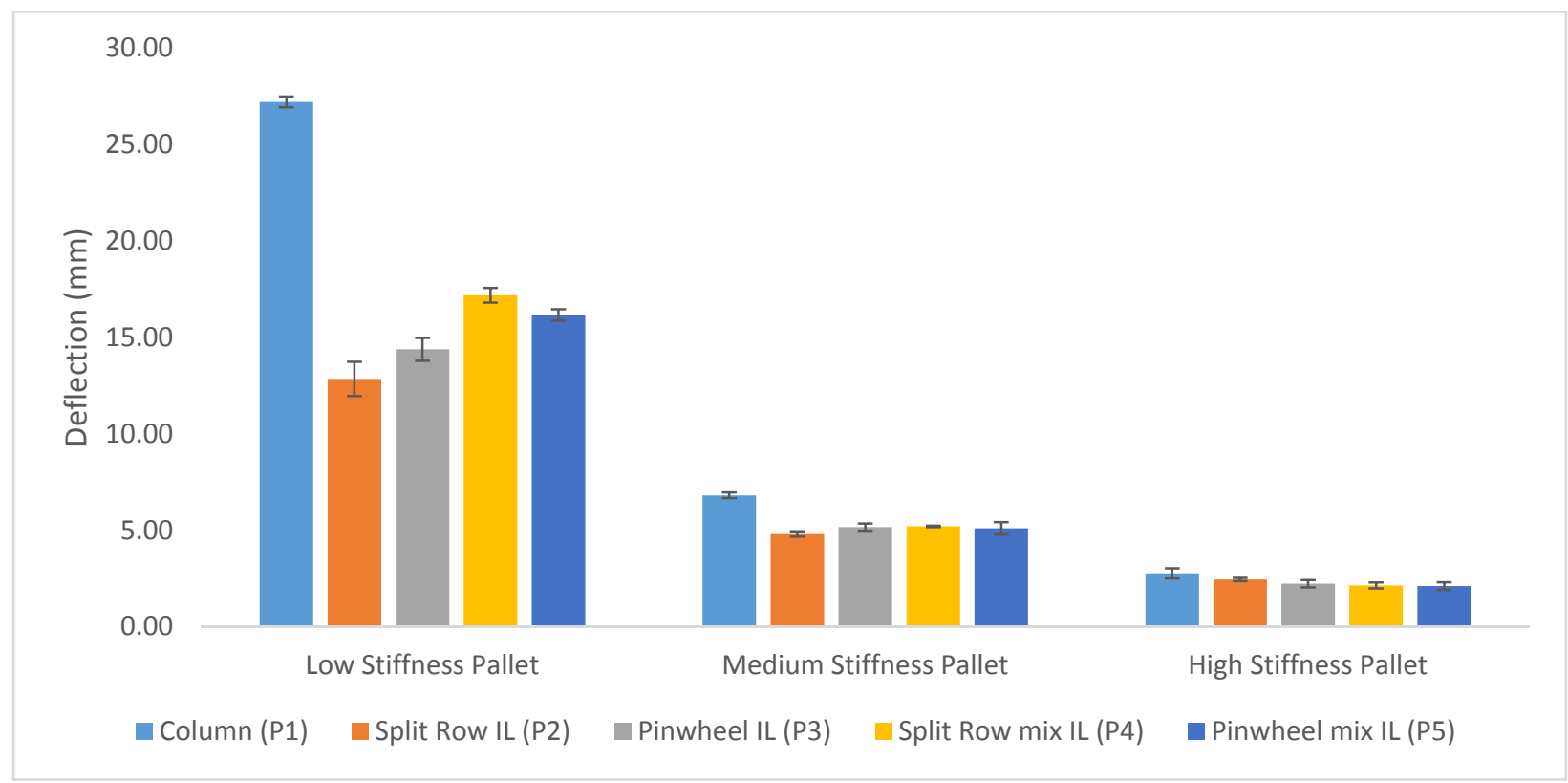

Figure 18. Average racked across the width pallet center deflection by stacking pattern and pallet design.

For the low stiffness $(17.44 \mathrm{~kg} / \mathrm{mm})$ and medium stiffness $(84.59 \mathrm{~kg} / \mathrm{mm})$ pallets, a significant difference between the column stacking, which provided the greatest pallet deflection, and the rest of the interlocking patterns was found. Specifically, in the low stiffness pallet, the greatest difference in deflection from the column stacking pattern P1 was found for the split row fully interlocking pattern P2 (53\%). The average deflection on the medium stiffness pallet showed no significant difference between the four interlocking patterns while the difference from the column stacking pattern was $30 \%$. No significant differences among the stacking patterns could be identified in the high stiffness $(175.24 \mathrm{~kg} / \mathrm{mm})$ pallet after conducting the one-way ANOVA. The results are consistent with results from previous studies, as the stiffness of the critical component is increased and no other variable changed, a reduction in the total observed load bridging occurs (Collie, 1984; Fagan, 1982; Park et al., 2017).

A difference between the two fully interlocked patterns (P2, P3) and the partial interlocked $(\mathrm{P} 4, \mathrm{P} 5)$ was found in the low stiffness pallet, and two probable explanations can be given. First, since the interlocking starts at the third layer, an asymmetric load exists for patterns P4 and P5, which could be influencing the overall results. It can also be explained from the level of interlocking presented in Table 11 in the Methods section. Since the two bottom layers are column 
stacked, the load is more evenly distributed and deflection increases. The effect is not significant in the other pallet designs.

Among the variables considered in the research conducted by Fagan (1982) for the racked across the width support condition, two stacking patterns were evaluated. Both load configurations were interlocked and no statistically significant difference between the unit load deflection was found, being consistent with the results of the two fully interlocking patterns tested (P2, P3), which showed no differences between them among the three pallet designs on either of the locations. Collie (1984) on the other hand, found a difference between two interlocking patterns, but additional variations in the load configurations were included, such as box size. Box size was determined to have a significant effect on load bridging by itself (Park et al., 2017), so the change in multiple factors prevents a direct comparison between the results.

\subsection{Pallet deflection when racked across the length}

Similarly to the racked across the width support, the deflection measurements were divided for the analysis to separate the deflection of the center points of the pallet and the deflection at the sides of the pallet. Deflection at the pallet sides were averaged for each replicate to mirror previous research on the subject. Table 15 and Figure 19 show the deflection at the center while Table 16 shows the deflection at the sides for each pallet design tested and the comparison between the five stacking patterns.

For both locations, no significant differences were identified between the stacking patterns for the three pallet stiffness levels. The critical components in this support condition are the nonnotched stringers, which have a very high stiffness overall. Consequently, statistically significant variation between the stacking patterns were not observed, given the low deflection levels. Similar results have been previously obtained when comparing different load configurations on a racked across the length support (Collie, 1984; Fagan, 1982).

The limited deflection results were such that no statistical difference was measured between the single guillotine cut design and multiple cuts design (P1), despite the two-column configuration on the interlocked patterns, that generates asymmetric loading. 
Table 15. Average racked across the length pallet center deflection by stacking pattern and pallet design.

\begin{tabular}{cccccccccc}
\hline & \multicolumn{3}{c}{ Low Stiffness Pallet } & \multicolumn{2}{c}{ Medium Stiffness Pallet } & \multicolumn{3}{c}{ High Stiffness Pallet } \\
\cline { 2 - 10 } Stacking Pattern & Average & Std. & Tukey & Average & Std. & Average & Std. & Tukey \\
& $\begin{array}{c}\text { Deflection, } \\
\text { mm }\end{array}$ & Dev, & mm & HSD & $\begin{array}{c}\text { Deflection, } \\
\text { mm }\end{array}$ & $\begin{array}{c}\text { Dev, } \\
\text { mm }\end{array}$ & $\begin{array}{c}\text { Tukey } \\
\text { HSD }\end{array}$ & $\begin{array}{c}\text { Deflection, } \\
\text { Dev, }\end{array}$ & $\begin{array}{c}\text { Dukm } \\
\text { HSD }\end{array}$ \\
\hline Column (P1) & 4.03 & 0.48 & A & 2.75 & 0.71 & B & 2.54 & 0.57 & C \\
Split Row IL (P2) & 3.75 & 0.17 & A & 2.42 & 0.51 & B & 2.13 & 0.59 & C \\
Pinwheel IL (P3) & 3.72 & 0.25 & A & 2.58 & 0.18 & B & 2.22 & 0.47 & C \\
Split Row mix IL (P4) & 3.72 & 0.38 & A & 2.65 & 0.46 & B & 2.47 & 0.42 & C \\
Pinwheel mix IL (P5) & 3.82 & 0.22 & A & 2.78 & 0.62 & B & 2.29 & 0.47 & C \\
\hline
\end{tabular}

Table 16. Average racked across the length pallet ends deflection by stacking pattern and pallet design.

\begin{tabular}{|c|c|c|c|c|c|c|c|c|c|}
\hline \multirow[b]{2}{*}{ Stacking Pattern } & \multicolumn{3}{|c|}{ Low Stiffness Pallet } & \multicolumn{3}{|c|}{ Medium Stiffness Pallet } & \multicolumn{3}{|c|}{ High Stiffness Pallet } \\
\hline & $\begin{array}{c}\text { Average } \\
\text { Deflection, } \\
\mathrm{mm}\end{array}$ & $\begin{array}{l}\text { Std. } \\
\text { Dev, } \\
\mathrm{mm}\end{array}$ & $\begin{array}{c}\text { Tukey } \\
\text { HSD }\end{array}$ & $\begin{array}{c}\text { Average } \\
\text { Deflection, } \\
\mathrm{mm}\end{array}$ & $\begin{array}{l}\text { Std. } \\
\text { Dev, } \\
\mathrm{mm}\end{array}$ & $\begin{array}{c}\text { Tukey } \\
\text { HSD }\end{array}$ & $\begin{array}{c}\text { Average } \\
\text { Deflection, } \\
\mathrm{mm}\end{array}$ & $\begin{array}{l}\text { Std. } \\
\text { Dev, } \\
\mathrm{mm}\end{array}$ & $\begin{array}{c}\text { Tukey } \\
\text { HSD }\end{array}$ \\
\hline Column (P1) & 2.94 & 0.16 & A & 2.22 & 0.57 & B & 2.27 & 0.57 & $\mathrm{C}$ \\
\hline Split Row IL (P2) & 2.87 & 0.12 & A & 2.12 & 0.26 & B & 1.77 & 0.42 & $\mathrm{C}$ \\
\hline Pinwheel IL (P3) & 2.93 & 0.25 & A & 2.37 & 0.33 & B & 1.90 & 0.33 & $\mathrm{C}$ \\
\hline Split Row mix IL (P4) & 2.80 & 0.18 & A & 2.26 & 0.47 & B & 2.12 & 0.39 & $\mathrm{C}$ \\
\hline Pinwheel mix IL (P5) & 2.96 & 0.41 & A & 2.47 & 0.40 & B & 1.84 & 0.36 & $\mathrm{C}$ \\
\hline
\end{tabular}




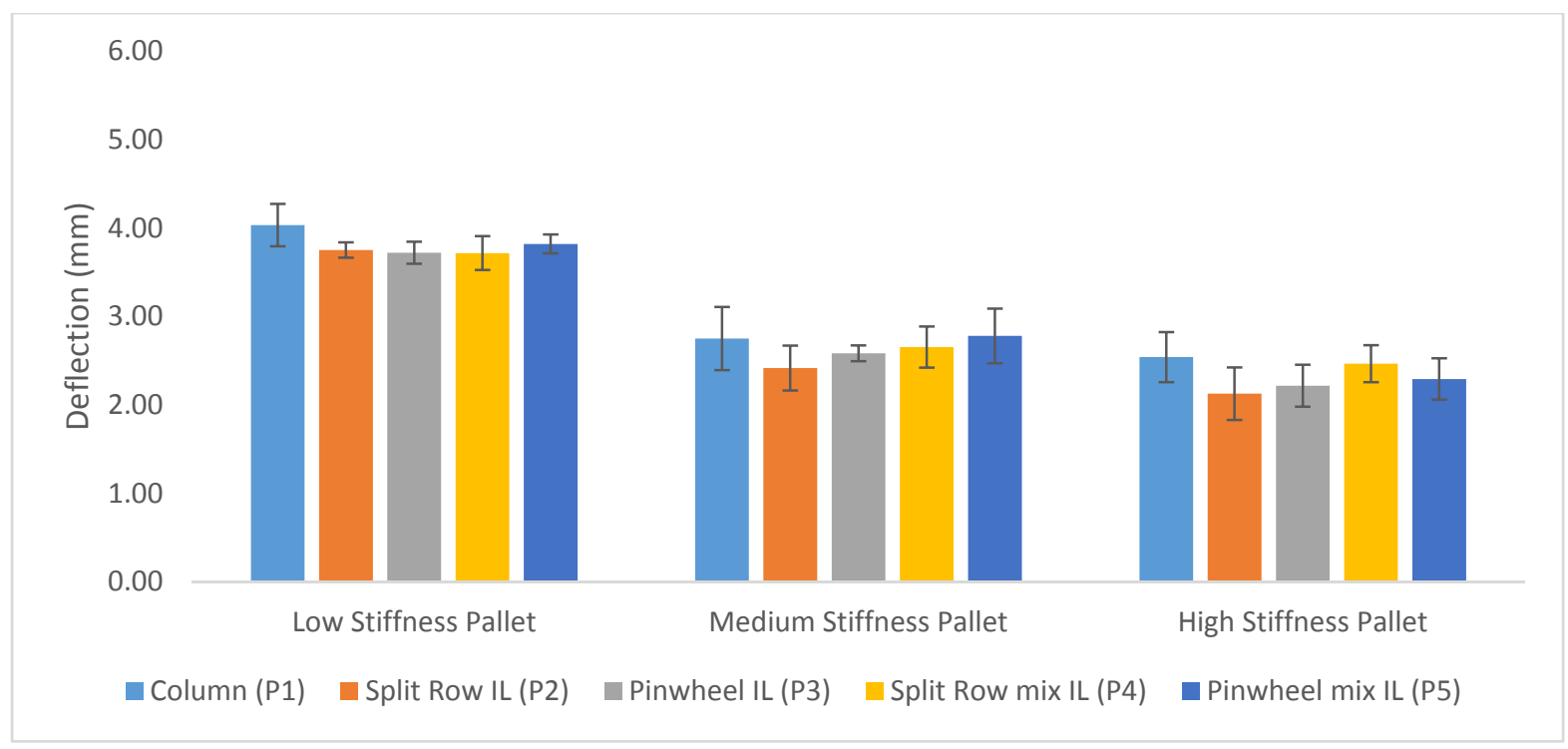

Figure 19. Average racked across the length pallet center deflection by stacking pattern and pallet design.

4.3 Pallet deflection when supported on fork tines across the width

Deflection measurements were grouped and averaged by the sides of the pallet, along the stringer length in order to account for the asymmetry present in the pallet stacking patterns.

For both sides, right side (Table 17, Figure 20) and left side (Table 18), a statistically significant difference was identified between the column stacking pattern and all the interlocking patterns for the low stiffness pallet. The medium and high stiffness pallet presented no significant difference between all the stacking patterns. Although the support condition varies significantly from racking, a similar trend is observed, where bridging is evident as long as the pallet shows high levels of deformation. There was no observable difference between the effect of stacking pattern for the two investigated sides of the pallet. 
Table 17. Average fork tine support racked across the width pallet deflection by stacking pattern and pallet design, on the right side (A) of the pallet.

\begin{tabular}{|c|c|c|c|c|c|c|c|c|c|}
\hline \multirow[b]{2}{*}{ Stacking Pattern } & \multicolumn{3}{|c|}{ Low Stiffness Pallet } & \multicolumn{3}{|c|}{ Medium Stiffness Pallet } & \multicolumn{3}{|c|}{ High Stiffness Pallet } \\
\hline & $\begin{array}{c}\text { Average } \\
\text { Deflection, } \\
\mathrm{mm}\end{array}$ & $\begin{array}{l}\text { Std. } \\
\text { Dev, } \\
\mathrm{mm}\end{array}$ & $\begin{array}{c}\text { Tukey } \\
\text { HSD }\end{array}$ & $\begin{array}{c}\text { Average } \\
\text { Deflection, } \\
\mathrm{mm}\end{array}$ & $\begin{array}{l}\text { Std. } \\
\text { Dev, } \\
\mathrm{mm}\end{array}$ & $\begin{array}{c}\text { Tukey } \\
\text { HSD }\end{array}$ & $\begin{array}{c}\text { Average } \\
\text { Deflection, } \\
\mathrm{mm}\end{array}$ & $\begin{array}{l}\text { Std. } \\
\text { Dev, } \\
\text { mm }\end{array}$ & $\begin{array}{c}\text { Tukey } \\
\text { HSD }\end{array}$ \\
\hline Column (P1) & 7.32 & 0.22 & $\mathrm{~A}$ & 1.83 & 0.48 & $\mathrm{C}$ & 0.74 & 0.10 & $\mathrm{D}$ \\
\hline Split Row IL (P2) & 4.29 & 0.45 & B & 1.88 & 0.72 & $\mathrm{C}$ & 0.45 & 0.10 & $\mathrm{D}$ \\
\hline Pinwheel IL (P3) & 4.20 & 0.43 & B & 2.12 & 0.42 & $\mathrm{C}$ & 0.60 & 0.25 & $\mathrm{D}$ \\
\hline Split Row mix IL (P4) & 4.14 & 0.59 & B & 2.39 & 0.46 & $\mathrm{C}$ & 0.98 & 0.32 & $\mathrm{D}$ \\
\hline Pinwheel mix IL (P5) & 3.89 & 0.23 & $\mathrm{~B}$ & 2.18 & 0.22 & $\mathrm{C}$ & 0.63 & 0.12 & $\mathrm{D}$ \\
\hline
\end{tabular}

Table 18. Average fork tine support racked across the width pallet deflection by stacking pattern and pallet design, on the left side (B) of the pallet.

\begin{tabular}{|c|c|c|c|c|c|c|c|c|c|}
\hline \multirow[b]{2}{*}{ Stacking Pattern } & \multicolumn{3}{|c|}{ Low Stiffness Pallet } & \multicolumn{3}{|c|}{ Medium Stiffness Pallet } & \multicolumn{3}{|c|}{ High Stiffness Pallet } \\
\hline & $\begin{array}{c}\text { Average } \\
\text { Deflection, } \\
\mathrm{mm}\end{array}$ & $\begin{array}{l}\text { Std. } \\
\text { Dev, } \\
\text { mm }\end{array}$ & $\begin{array}{c}\text { Tukey } \\
\text { HSD }\end{array}$ & $\begin{array}{c}\text { Average } \\
\text { Deflection, } \\
\mathrm{mm}\end{array}$ & $\begin{array}{l}\text { Std. } \\
\text { Dev, } \\
\mathrm{mm}\end{array}$ & $\begin{array}{c}\text { Tukey } \\
\text { HSD }\end{array}$ & $\begin{array}{c}\text { Average } \\
\text { Deflection, } \\
\mathrm{mm}\end{array}$ & $\begin{array}{l}\text { Std. } \\
\text { Dev, } \\
\mathrm{mm}\end{array}$ & $\begin{array}{c}\text { Tukey } \\
\text { HSD }\end{array}$ \\
\hline Column (P1) & 6.94 & 0.14 & A & 2.11 & 0.69 & $\mathrm{C}$ & 0.94 & 0.45 & $\mathrm{D}$ \\
\hline Split Row IL (P2) & 3.35 & 0.31 & B & 1.82 & 0.14 & $\mathrm{C}$ & 0.40 & 0.11 & $\mathrm{D}$ \\
\hline Pinwheel IL (P3) & 3.34 & 0.61 & B & 1.70 & 0.30 & $\mathrm{C}$ & 0.51 & 0.14 & $\mathrm{D}$ \\
\hline Split Row mix IL (P4) & 3.97 & 0.08 & B & 2.30 & 0.37 & $\mathrm{C}$ & 0.69 & 0.17 & $\mathrm{D}$ \\
\hline Pinwheel mix IL (P5) & 3.31 & 0.14 & B & 1.71 & 0.01 & $\mathrm{C}$ & 0.54 & 0.18 & $\mathrm{D}$ \\
\hline
\end{tabular}




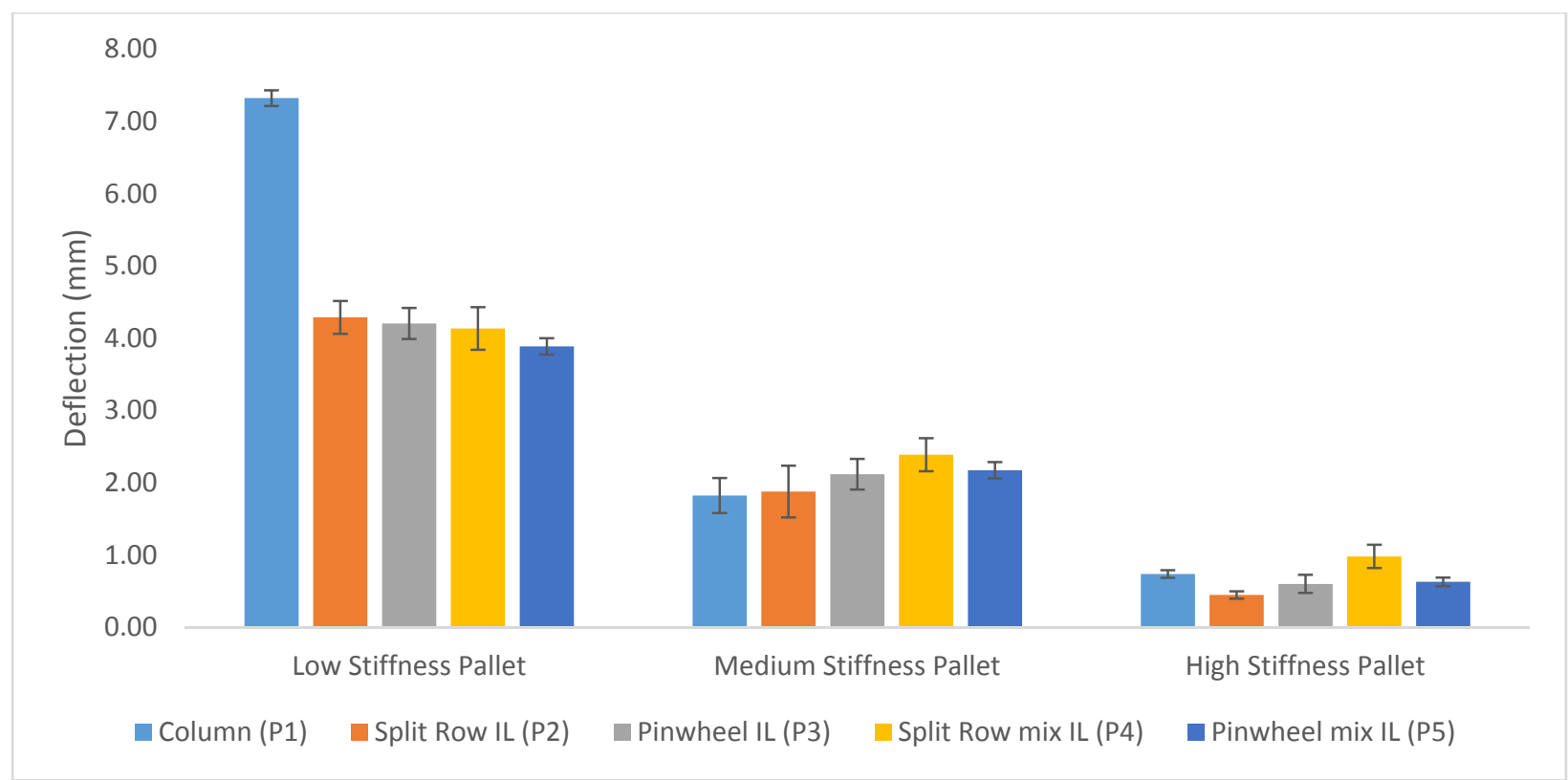

Figure 20. Average fork tine support racked across the width pallet deflection by stacking pattern and pallet design, on the right side of the pallet.

To understand the results observed, it must be noted that for the column stacking pattern, P1, on the low stiffness pallet, the outer columns where supported on the edges of the pallet without directly transferring most of the load to the fork tines, therefore showing a higher deflection under this pattern. The schematic of this load transfer is shown in Figure 21. Due to the stiffness of the components when supported on the forklift, the medium and high stiffness pallets did not show any significant difference or trend when also comparing the column and the interlocking patterns.

Additional differences between the two asymmetric and two symmetric interlocked stacking patterns, for the forklift support across the width were not observed. 


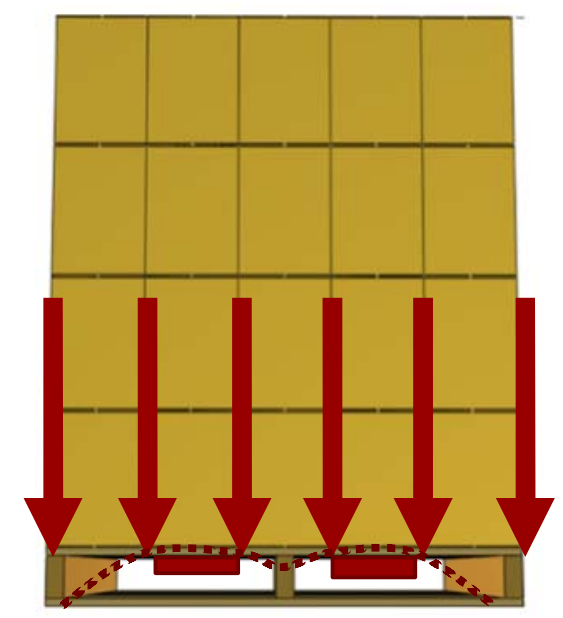

Figure 21. Load transfer schematic of a column stacked Unit Load on a fork lift support across the width.

If the bottom layer of the unit load with the low stiffness pallet is analyzed to determine its significance, it can be observed that its effect is masked by the interlocking of the layers on top. In pattern P1, boxes are oriented on the shorter side towards the outside span, thus an effective smaller dimension. The remainder of the patterns have two boxes facing the length and two on the width, but their observed behavior shows a trend where the deflection did not change significantly although the boxes orientation changed in the corners measured. The bottom layers are shown on Table 19. These results suggest that the overall interlocking of the layers is possibly redistributing the load in a more significant manner than any other effect from uneven box arrangement.

Table 19. Diagrams of pallet patterns for the bottom layers.

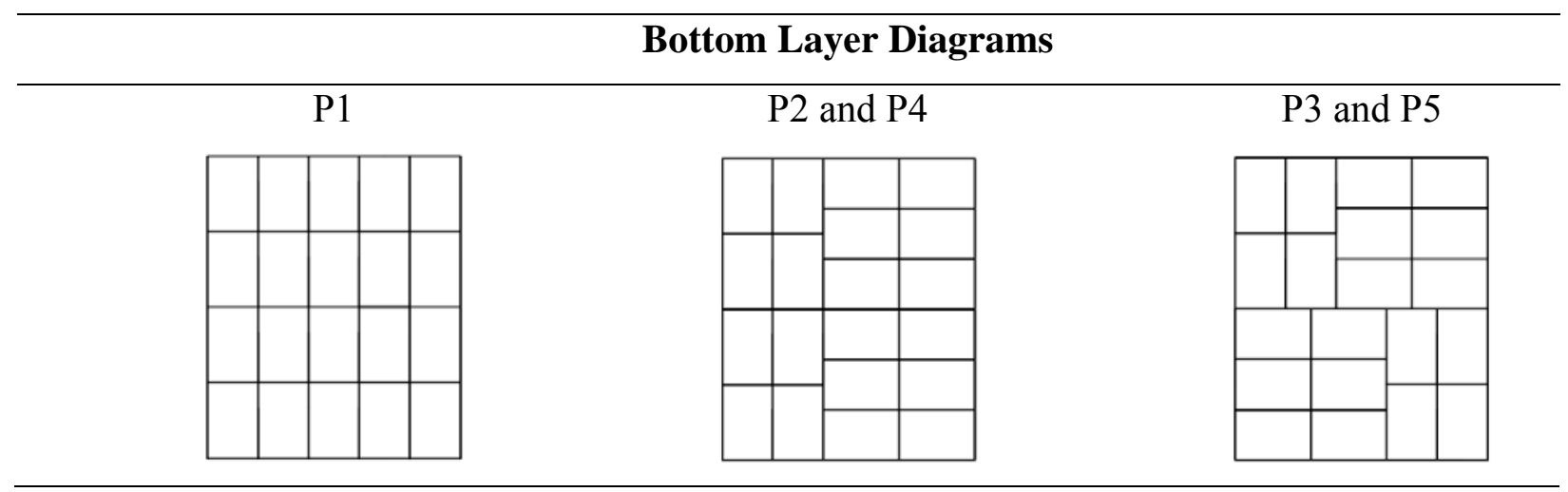




\subsection{Pallet deflection when stacked on floor}

Deflection was measured at eight locations across the top deckboards and the maximum of each replicate was selected, in order to account for the different stress distributions in relation to each stacking pattern. These results are shown in Table 20 and Figure 22.

For the load level and pallet stiffness used, no clear trend or significant difference was identified for the different pallet stacking patterns evaluated. As it was observed in the previous support conditions, if the deflection remains low in relation to the pallet capacity, differences between the stacking patterns are not significant. A difference is shown for the medium stiffness pallet between the columnar unit load (P1) and the pinwheel partially interlocked (P5). This difference is not expected from the trends already identified and the simplest justification is the power of the Tukey's HSD, where a Type-I error is detecting differences where none exists, and more replicates should be conducted to justify the difference. The ANOVA test conducted provided a p-value of 0.0428 , just slightly under the 0.05 threshold selected. Load bridging in floor stacking has not been measured in previous investigations, except for load transfer when multiple unit loads are stacked.

Table 20. Average of the maximum floor stacking pallet top deckboard deflection by stacking pattern and pallet design.

\begin{tabular}{|c|c|c|c|c|c|c|c|c|c|}
\hline \multirow[b]{2}{*}{ Stacking Pattern } & \multicolumn{3}{|c|}{ Low Stiffness Pallet } & \multicolumn{3}{|c|}{ Medium Stiffness Pallet } & \multicolumn{3}{|c|}{ High Stiffness Pallet } \\
\hline & $\begin{array}{c}\text { Average } \\
\text { Deflection, } \\
\mathrm{mm}\end{array}$ & $\begin{array}{l}\text { Std. } \\
\text { Dev, } \\
\mathrm{mm}\end{array}$ & $\begin{array}{c}\text { Tukey } \\
\text { HSD }\end{array}$ & $\begin{array}{c}\text { Average } \\
\text { Deflection, } \\
\mathrm{mm}\end{array}$ & $\begin{array}{l}\text { Std. } \\
\text { Dev, } \\
\mathrm{mm}\end{array}$ & $\begin{array}{c}\text { Tukey } \\
\text { HSD }\end{array}$ & $\begin{array}{c}\text { Average } \\
\text { Deflection, } \\
\mathrm{mm}\end{array}$ & $\begin{array}{c}\text { Std. } \\
\text { Dev, } \\
\mathrm{mm}\end{array}$ & $\begin{array}{c}\text { Tukey } \\
\text { HSD }\end{array}$ \\
\hline Column (P1) & 4.42 & 0.37 & A & 1.89 & 0.17 & B & 0.75 & 0.04 & $\mathrm{D}$ \\
\hline Split Row IL (P2) & 4.11 & 0.40 & $\mathrm{~A}$ & 1.66 & 0.07 & $\mathrm{BC}$ & 0.62 & 0.04 & $\mathrm{D}$ \\
\hline Pinwheel IL (P3) & 4.65 & 0.22 & A & 1.78 & 0.14 & $\mathrm{BC}$ & 0.71 & 0.11 & $\mathrm{D}$ \\
\hline Split Row mix IL (P4) & 4.61 & 0.09 & A & 1.65 & 0.22 & $\mathrm{BC}$ & 0.60 & 0.01 & $\mathrm{D}$ \\
\hline Pinwheel mix IL (P5) & 4.21 & 0.34 & $\mathrm{~A}$ & 1.46 & 0.05 & $\mathrm{C}$ & 0.68 & 0.01 & $\mathrm{D}$ \\
\hline
\end{tabular}




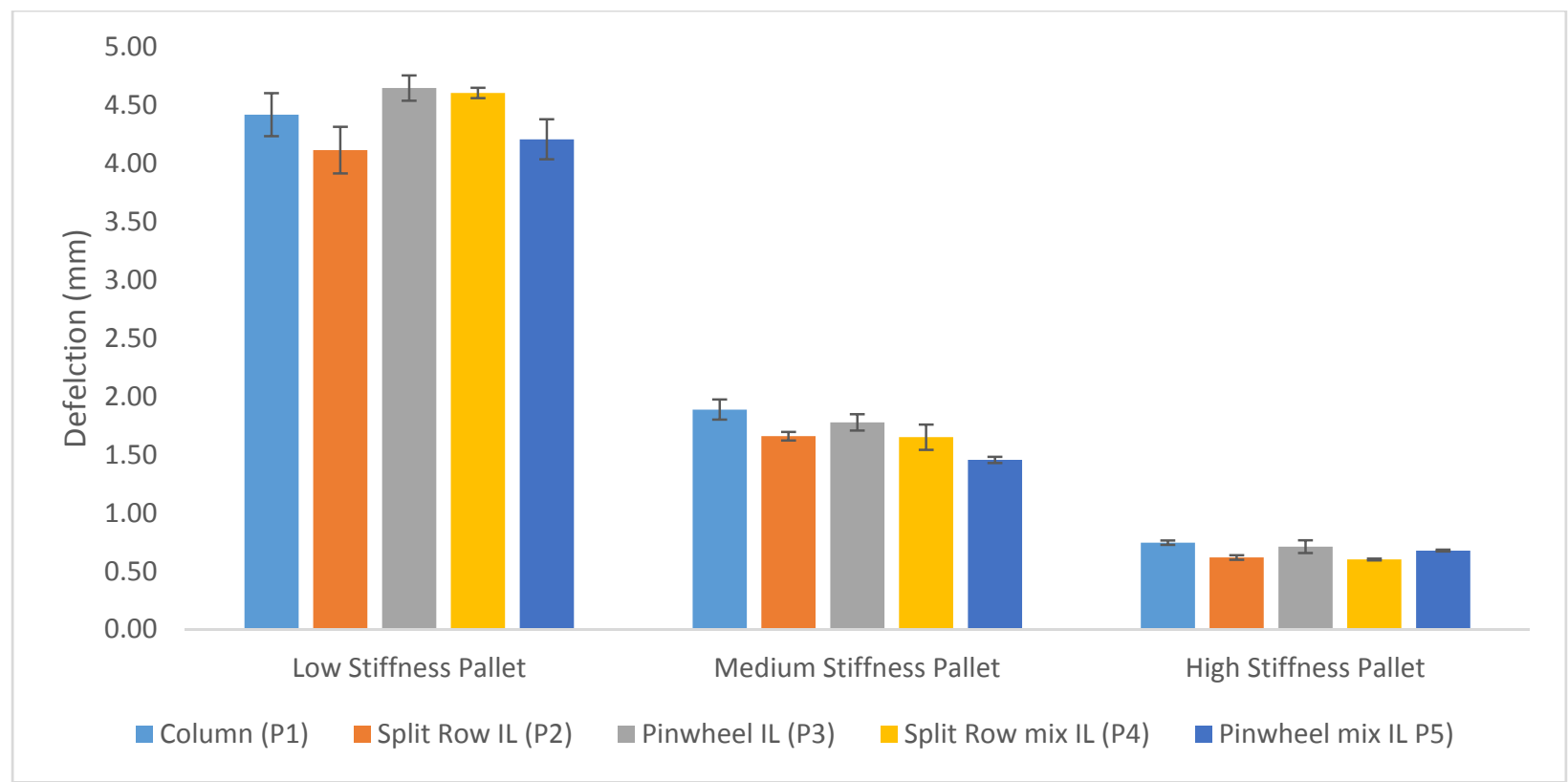

Figure 22. Average floor stacking pallet top deckboard deflection by stacking pattern and pallet design.

In order to better understand the reason why no differences where identified in this support mode, an analogy between the floor stacking and warehouse racking across the width can be made, and when analyzed as beams under load, the top deckboards have almost half of the free span between the supports (in this case, the stringers instead of the rack) with load applied through the edges of the boxes at only one or two locations depending on the pattern (Figure 23), generating an overall low deflection. Smaller boxes might have applied a more uniformly distributed load and depending on the patterns in used, would have provided higher deflection and an opportunity to identify differences, as the ones observed in the racking across the width, but actual packages for distribution are not commonly too small due to practical considerations. 


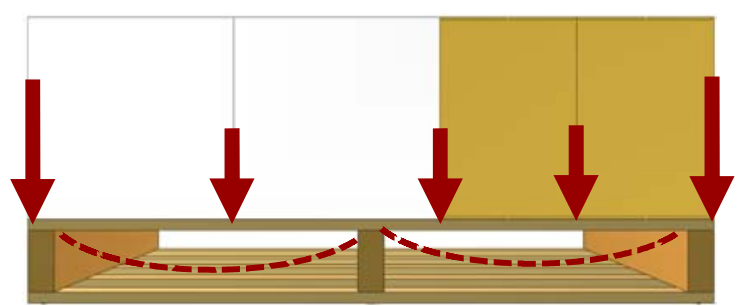

Figure 23. Schematic of load transfer in the floor stacking mode

To evaluate this, the data of four locations at the center of the top deckboards were compared to identify changes in deflection when varying the stacking pattern. That is, comparing the behavior at locations 1, 3, 5 and 6 shown on Figure 24. Data is summarized in Table 21, including the results of the independently conducted Tuckey HSD test, determining that the deflection of the boards did not present any significant change when the loading changed from 1 to 2 loading points.

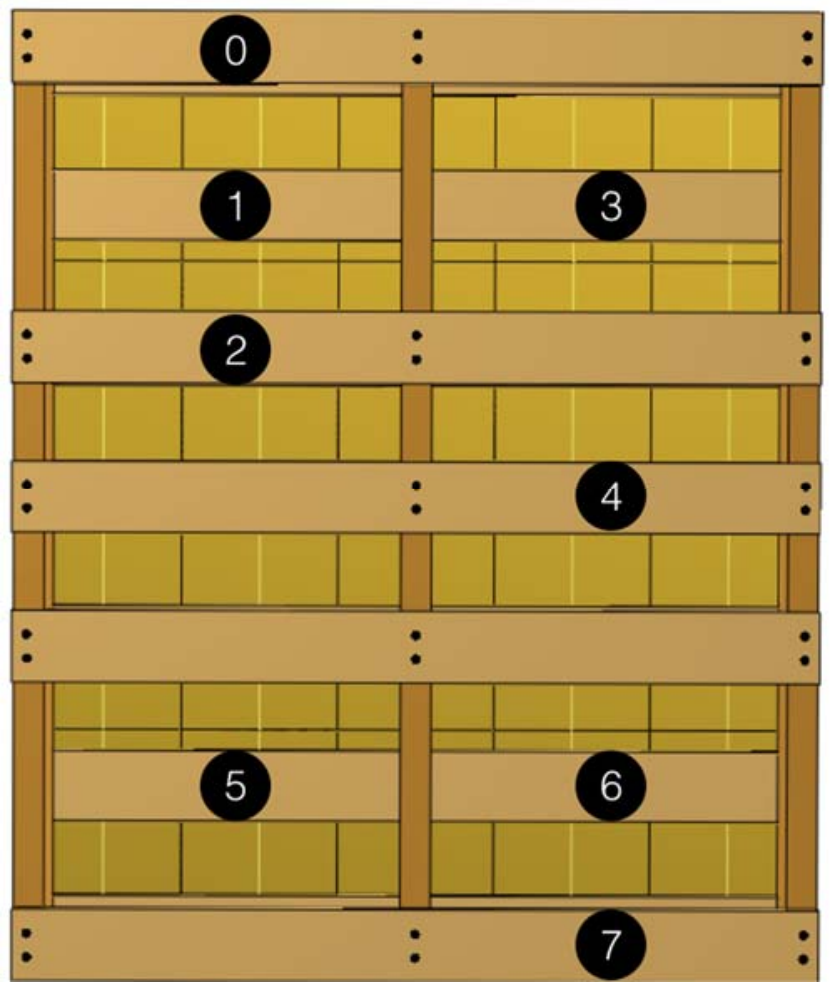

Figure 24. Top deckboard deflection measurement locations. 
Table 21. Deflection of top deckboards under a floor stacking support at four locations.

\begin{tabular}{|c|c|c|c|c|}
\hline Location & $\begin{array}{l}\text { Stacking } \\
\text { Pattern }\end{array}$ & $\begin{array}{c}\text { Average } \\
\text { Deflection, } \\
\text { mm }\end{array}$ & $\begin{array}{c}\text { Std Dev, } \\
\text { mm }\end{array}$ & Tukey HSD \\
\hline \multirow{5}{*}{1} & P1 & 4.63 & 0.10 & $\mathrm{~A}$ \\
\hline & $\mathrm{P} 2$ & 4.25 & 0.54 & A \\
\hline & P3 & 4.78 & 0.42 & A \\
\hline & $\mathrm{P} 4$ & 5.01 & 0.09 & A \\
\hline & P5 & 4.30 & 0.08 & A \\
\hline \multirow{5}{*}{3} & P1 & 3.85 & 0.29 & A \\
\hline & $\mathrm{P} 2$ & 3.22 & 0.59 & A \\
\hline & P3 & 3.16 & 0.35 & A \\
\hline & $\mathrm{P} 4$ & 3.60 & 0.01 & A \\
\hline & P5 & 3.02 & 0.51 & A \\
\hline \multirow{5}{*}{5} & P1 & 5.03 & 0.48 & $\mathrm{~A}$ \\
\hline & $\mathrm{P} 2$ & 4.42 & 0.89 & A \\
\hline & P3 & 5.33 & 0.22 & A \\
\hline & P4 & 4.01 & 0.20 & A \\
\hline & P5 & 4.56 & 0.71 & A \\
\hline \multirow{5}{*}{6} & P1 & 3.34 & 0.27 & $\mathrm{~A}$ \\
\hline & $\mathrm{P} 2$ & 3.74 & 0.11 & A \\
\hline & P3 & 3.51 & 0.34 & A \\
\hline & P4 & 3.89 & 0.16 & A \\
\hline & P5 & 3.40 & 0.78 & A \\
\hline
\end{tabular}

\subsection{Effect of pallet stiffness in load bridging}

Most of the previous investigations conducted with the objective to understand the load bridging effect, have designed specific pallets or pallet analogs, grouped them according to their stiffness and then tested with a consistent load level (Center for Unit-Load Design, 1997; Collie, 1984; Fagan, 1982; Park, 2015; Park et al., 2017; M. S. White et al., 1999). This has provided valuable information on the effect of the different factors on load bridging and was the basis for the current experimental design, but a consistent observation has been made, where the load bridging effect observed is greatest for lower stiffness pallets. 
It must be taken into consideration that by increasing pallet stiffness and keeping the payload constant, the stresses on the pallet are inherently reduced and the deflection will naturally be lower, preventing any observation of the phenomenon measured through deflection.

Calculating a ratio of the total load $(680 \mathrm{~kg})$ and the pallet stiffness measured through airbag testing (Table 8), it can be observed, in Table 22, that the support conditions where significant differences were identified, correspond to the ones with a higher load-stiffness ratios, (Low stiffness pallet design when racked across the width and on forklift support and medium stiffness pallet racked across the width).

An additional comparison can be conducted when observing the pallet load carrying capacity determined by The Pallet Design System ${ }^{\mathrm{TM}}$ (Table 9). An effect of the stacking patterns on pallet deflection was observed for most of the scenarios where the testing payload was actually higher than the safe maximum load, but not for all of these cases. As an example, it would have been expected to observe significant differences on the low stiffness pallet when racked across the length, since the payload was $680 \mathrm{~kg}$ and the design load carrying capacity $535 \mathrm{~kg}$, but when observing the load-stiffness ratio, it is on the lower range of values. It must be noted that pallet load carrying capacity is not only determined by the maximum deflection but also by the maximum strength of the individual components, so the relationship is not direct between load deflection and failure.

Ultimately, the results of this study will help us reduce the amount of materials used in pallets resulting in increased sustainability and reduced cost.

Table 22. Load-stiffness ratio for every pallet design under common support conditions with a $680 \mathrm{~kg}$ payload.

\begin{tabular}{cccc}
\hline & \multicolumn{3}{l}{ Load-Stiffness Ratio } \\
\hline & Low Stiffness & $\begin{array}{c}\text { Medium } \\
\text { Stiffness }\end{array}$ & $\begin{array}{c}\text { High } \\
\text { Stiffness }\end{array}$ \\
\cline { 2 - 4 } $\begin{array}{c}\text { Racked Across the } \\
\text { Length }\end{array}$ \\
\cline { 2 - 4 } $\begin{array}{c}\text { Racked Across the } \\
\text { Width } \\
\text { Forklift Support } \\
\text { (RAW) }\end{array}$ & 4.11 & 2.40 & 2.30 \\
\cline { 2 - 4 } & $\mathbf{3 8 . 9 9}$ & $\mathbf{8 . 0 4}$ & 3.88 \\
\cline { 2 - 4 } Floor Support & $\mathbf{9 . 8 0}$ & 6.89 & 3.19 \\
\hline
\end{tabular}




\section{Chapter 5: Conclusions}

After evaluating the effect of the interlocking of the layers, a significant reduction of unit load deflection is generated when the load changes from a columnar stacking arrangement to any of the interlocking patterns considered. This result only applies to the support conditions where pallet deflection is greater, such as warehouse racking across the width for the low and medium stiffness pallet and when supported on the fork lift across the width for the lower stiffness pallet.

After determining that the layer interlocking could have an effect under certain conditions, it is also concluded that pallets with a low stiffness and when supported across the weakest components (racked across the width), present a variation in deflection depending on the specific pallet stacking pattern used.

No observable differences were identified in scenarios where the payload to stiffness ratio was on the higher spectrum (more than 8), that is, when the pallet stiffness was high and the load not heavy enough to produce higher deflection. On most of the scenarios with no significant differences, the load used $(680 \mathrm{~kg})$ was lower than the safe maximum load obtained from software evaluation. When a pallet can safely carry a significantly higher evenly distributed load than the actual payload, the load bridging effect is not only not observable, but loses its value for practical applications.

Although the test conducted covered different stacking patterns and interlocking levels, translating the results to different scenarios with other box sizes or pallet characteristics should be done carefully, since many additional factors could influence the results and generate unaccounted interactions. When using low stiffness pallets, interlocking the layers will provide better unit load performance but the exact change in pallet stiffness and strength must be properly measured. The information obtained provides a guideline for future research and packaging design but it is not yet an adjustment factor for industry applications. When comparing the magnitude of the effect of the load bridging factors, size can generate a potential pallet deflection reduction of $75 \%$ (Park et al., 2017) when compared with uniform loading. The interlocking of the layers was observed to reduce pallet deflection up to 53\%, and when significant statistical differences where generated, the interlocking level only generated an $11.6 \%$ of deflection change. 
With this knowledge, pallet design can be improved to increase load capacity when the payload characteristics are known. This will allow for the reduction in pallet costs and the use of more lightweight pallets, which improve the sustainability of the supply chain operations. 


\section{Chapter 6: Recommendations for future research}

To further explore and validate the results obtained and trends identified on this research and with the objective to improve the understanding of the load bridging effect, the following recommendations for future research can be made:

1) Validate the relationship between load-stiffness ratio and observable load bridging, conducting studies where the payload is increased proportionally to the pallet stiffness, conserving the same ratio. This must be conducted by carefully controlling every other factor, specially box size, number of layers and unit load height. Density of the contents could be varied to obtain this.

2) Further conduct testing to analyze the effect of the stacking patterns on load bridging, but considering the interaction with additional load stabilizes, such as stretch wrap. The additional containment force could generate higher rigidity of the load, reducing overall deflection and potentially masking the differences found between the stacking patterns and/or the interlocking of the layers.

3) Previous research identified the box sizes as a very significant factor in load bridging. The interaction between the box sizes and the interlocking of the layers should be studied, since the load redistribution and containment force from the interlocking could reduce the significance of the box size effect.

4) Develop a finite element analysis model with the goal of evaluating the interactions between the unit load components and ultimately generate a model to explain the fundamental mechanism that causes load bridging. This information would provide the required knowledge to translate load configuration into actual pressure distribution on the pallet. Physical testing provides valuable knowledge for preliminary identification of factors, but the magnitude of available options (load types, package sizes, pallet designs, etc.) require computer models capable of processing multiple factors and their interactions.

5) Evaluate the load bridging effect on the pallet ultimate strength. Although attempts to achieve this have been previously conducted, physical limitations from the maximum strength of other components prevented the determination of pallet ultimate strength. Developing computer models could help towards this goal. 


\section{References}

ASTM. (2015). D198-15 Standard Test Methods of Static Tests of Lumber in Structural Sizes. West Conshohocken, PA. https://doi.org/10.1520/D0198-15

ASTM International. (2009). ASTM D1185-98a(2009) Standard test methods for pallets and related structures employed in materials handling and shipping. West Conshohocken, PA. https://doi.org/10.1520/D1185-98AR09

Baker, M., Horvath, L., \& White, M. (2016a). Effect of pallet deckboard stiffness on corrugated box compression strength. Packaging Technology and Science, 29(4-5), 263-274. https://doi.org/10.1002/pts.2201

Baker, M., Horvath, L., \& White, M. S. (2016b). Predicting the effect of gaps between pallet deckboards on the compression strength of corrugated boxes. Journal of Applied Packaging Research, 8(3), 30-42. https://doi.org/10.14448/japr.08.0017

Barnett, S., \& Kynch, G. J. (1967). Exact Solution of a Simple Cutting Problem. Operations Research, 15(6), 1051-1056.

Bisha, J. V. (2008). The effect of load stabilizer selection on load shift within unit loads (Master's Thesis). Virginia Polytechnic Institute and State University, Blacksburg, VA.

Bisha, J. V. (2012). Correlation of the elastic properties of stretch film on unit load containment. Virginia Polytechnic Institute and State University, Blacksburg, VA.

Browder, G. R. (1935). A Story of the Fibre Box and History of its Developments. Fibre Containers and Paperboard Mills, 20(8).

Bush, R. J., \& Araman, P. A. (2014). Trends in the use of wood products for distribution packaging - Cooperative Agreement No. 11-CA11330142-137. Blacksburg, VA.

Carpenter, H., \& Dowsland, W. B. (1985). Practical considerations of the pallet loading problem. The Journal of the Operational Research Society, 36(6), 489-497. https://doi.org/10.2307/2582821

Carstens, R., \& Mina, S. (1988). Lock “N” Pop And Strech Wrap: Identifying the Key Decisions In Package-Material Handling to make the best choice. Journal of Packaging Technology, 2(3), 103-105.

Center for Unit-Load Design. (1997). The effect of load bridging on unit-load deflection. Research 
Update. Blacksburg, VA.

Clarke, J. (2004). Pallets 101 : Industry overview and wood, plastic, paper \& metal options. Retrieved from http://www.ista.org/forms/Pallets_101-Clarke_2004.pdf

Collie, S. T. (1984). Laboratory verification of pallet design procedures (Master's Thesis). Virginia Polytechnic Institute and State University, Blacksburg, VA.

Dekker, A. (2013). Corrugated fibreboard packaging. In M. J. Kirwan (Ed.), Handbook of Paper and Paperboard Packaging Technology (2nd ed., pp. 313-339). London: John Wiley \& Sons, Ltd. https://doi.org/10.1002/9781118470930

DiSalvo, M. H. (1999). Interactive effects of palletizing factors on fiberboard packing strength (Master's Thesis). San Jose State University, San Jose, CA.

Fagan, B. (1982). Load-support conditions and computerized test apparatus for wood pallets (Master's Thesis). Virginia Polytechnic Institute and State University, Blacksburg, VA.

FEFCO-ESBO. (2007). International fibreboard case code. Belgium: FEFCO. https://doi.org/10.1017/CBO9781107415324.004

Fibre Box Association. (2005). Fibre Box Handbook (22nd ed.). Elk Grove Village, IL.

Fibre Box Association. (2015). Fibre Box Handbook (75th Anniv). Elk Grove Village, IL.

Foster, G. A. (2010). Boxes, Corrugated. In K. L. Yam (Ed.), The Wiley Encyclopedia of Packaging Technology (3rd., pp. 162-170). New York: John Wiley \& Sons, Ltd.

Frank, B. (2014). Corrugated box compression-A literature survey. Packaging Technology and Science, 27(2), 105-128. https://doi.org/10.1002/pts.2019

Frank, B., Gilgenbach, M., \& Maltenfort, M. (2010). Compression testing to simulate real-world stresses. Packaging Technology and Science, 23(5), 275-282. https://doi.org/10.1002/pts.898

Goertz, J. (1976). Unitization in Distribution. In P. M. Van Buytenen (Ed.), Business Logistics (pp. 200-217). Belgium: H.E. Stenfert Kroese B.V.

Han, J., White, M., \& Hamner, P. (2007). Development of a Finite Element Model of Pallet Deformation and Compressive Stresses on Packaging within Pallet Loads. Journal of Applied Packaging Research, 1(3), 149-162.

Heskett, J. L., Ivie, R. M., \& Glaskowsky, N. A. (1964). Business Logistics (1st.). New York: The Ronald Press Company.

Hodgson, T. J. (1982). A combined approach to the pallet loading problem. A I I E Transactions, 14(3), 175-182. https://doi.org/10.1080/05695558208975057 
Ievans, U. I. (1975). The effect of warehouse mishandling and stacking patterns on the compression strength of corrugated boxes. TAPPI Journal, 58(8), 108-111.

ISO. (2003). ISO 6780:2003(E) Flat pallets for intercontinental materials handling - Principal dimensions and tolerances. Geneva.

ISO. (2012). ISO 3394:2012 Packaging - Complete, filled transport packages and unit loads Dimensions of rigid rectangular packages. Geneva, Switzerland.

ISO/FDIS. (2011). ISO/FDIS 8611-1:2011(E) Pallets for materials handling — Flat pallets. Geneva, Switzerland.

Jones, A. L. (1871). Improvement in Paper for Packing. USA: United States Patent Office.

Kellicut, K. Q. (1963). Effect of contents and load bearing surface on compressive strength and stacking life of corrugated containers. Tappi, 46(1), 151A-154 A.

Kellicut, K. Q., \& Landt, E. F. (1951). Safe stacking life of corrugated boxes. Fibre Containers, 36(9), 28-38.

Kocjan, W., \& Holmström, K. (2010). Computing stable loads for pallets. European Journal of Operational Research, 207(2), 980-985. https://doi.org/10.1016/j.ejor.2010.05.005

Koning, J. W. (1983). Corrugated Fiberboard. In R. E. Mark (Ed.), Handbook of Physical and Mechanical Testing of Paper and Paperboard (pp. 385-408). New York: Marcel Dekker, Inc.

Lacefield, S. K. (2015). Paper or plastic? (or maybe metal). Retrieved from http://www.dcvelocity.com/articles/20150325-paper-or-plastic-or-maybe-metal/

LeBlanc, R., \& Richardson, S. (2003). Pallets: A North American perspective (1ed.). Ontario, Canada, Canada: PACTS Management Inc.

Loferski, J. R., Mclain, T. E., \& Collie, S. T. (1988). Analysis of racked wood pallets. Wood and Fiber Science, 20(3), 304-319.

Maltenfort, G. G. (1988). Corrugated Shipping Containers. New York: Jelmar Publishing Co., Inc.

Mazeika Bilbao, A., Carrano, A. L., Hewitt, M., \& Thorn, B. K. (2011). On the environmental impacts of pallet management operations. Management Research Review, 34(11), 12221236. https://doi.org/10.1108/01409171111178765

McCrea, B. (2016). Pallet usage report: Pallets remain critical in the modern-day warehouse. $\begin{array}{llll}\text { Retrieved } \quad \text { March } & 6, & \text { 2017, from }\end{array}$ 
http://www.mmh.com/article/pallets_remain_critical_in_the_modern_day_warehouse

McGinley, D. (2016). Wood pallets \& skids production in the US (IBISWorld Industry Report 32192). Melbourne, Australia.

McKee, R. C., \& Gander, J. W. (1957). Top-load compression. TAPPI, 40(1), 57-64.

McKee, R. C., Ganer, J. W., \& Wachuta, J. R. (1963). Compression strenght formula for corrugated boxes. In G. G. Maltenfort (Ed.), Performance and Evaluation of Shipping Containers (1st ed., pp. 62-73). New York: Jelmar Publishing Co., Inc.

MH1 Committee. (2016). MH1-2016 Pallets, Slip Sheets, and Other Bases for Unit Loads. Charlotte, NC: MH1 Secretariat.

Monaghan, J., \& Marcondes, J. (1992). Technical notes: Overhang and pallet gap effects on the performance of corrugated fiberboard boxes. Transactions of the ASAE, 35(6), 1945-1947. https://doi.org/10.13031/2013.28820

National Wooden Pallet and Container Association. (2014). Uniform standard for wood pallets. Alexandria, VA: NWPCA.

Park, J. (2015). Investigation of fundamental relationships to improve the sustainability of unit loads (Doctoral dissertation). Virginia Polytechnic Institute and State University.

Park, J., Horvath, L., White, M. S., Phanthanousy, S., Araman, P., \& Bush, R. J. (2017). The influence of package size and flute type of corrugated boxes on load bridging in unit loads. Packaging Technology and Science, 30(1-2), 33-43. https://doi.org/10.1002/pts.2279

Peleg, K., \& Peleg, E. (1976). Container dimensions for optimal utilization of storage and transportation space. Computer-Aided Design, 8(3), 175-180. https://doi.org/10.1016/00104485(76)90031-2

Raballand, G., \& Aldaz-Carroll, E. (2007). How do differing standards increase trade costs? The case of pallets. The World Economy, 30(4), 685-702. https://doi.org/10.1111/j.14679701.2007.01009.x

Ram, B. (1992). The pallet loading problem: A survey. International Journal of Production Economics, 28(2), 217-225. https://doi.org/10.1016/0925-5273(92)90034-5

Rogers, L. K. (2011). Keeping it together. Modern Materials Handling, 66(7), 32-35.

Samarasinghe, S. (1987). Predicting rotation modulus for block pallet joints (Master's Thesis). Virginia Tech, Blacksburg, VA.

Schuster, M., Bormann, R., Steidl, D., Reynolds-Haertle, S., \& Stilman, M. (2010). Stable stacking 
for the distributor's pallet packing problem. In 2010 IEEE/RSJ International Conference on Intelligent Robots and Systems (pp. 3646-3651). Taipei, Taiwan: IEEE. https://doi.org/10.1109/IROS.2010.5650217

Silva, E., Oliveira, J. F., \& Wäscher, G. (2016). The pallet loading problem: A review of solution methods and computational experiments. International Transactions in Operational Research, 23(1-2), 147-172. https://doi.org/10.1111/itor.12099

Singh, J., Cernokus, E., Saha, K., \& Roy, S. (2014). The Effect of Stretch Wrap Prestretch on Unitized Load Containment. Packaging Technology and Science, 27(12), 944-961. https://doi.org/10.1002/pts.2083

Singh, J., \& Singh, S. P. (2011). Effect of Palletized Box Offset on Compression Strength of Unitized and Stacked Empty Corrugated Fiberboard Boxes. Journal of Applied Packaging Research, 5(3), 157-167.

Steadman, R. (2002). Corrugated Board. In R. E. Mark, C. C. Habeger, J. Borch, \& M. B. Lyne (Eds.), Handbook of Physical Testing of Paper (2nd ed., pp. 563-660). New York.

The Freedonia Group, I. (2008). Pallets. Cleveland, Ohio.

The Freedonia Group, I. (2015). Pallets. Cleveland, Ohio.

Twede, D. (2007). The History of Corrugated Fiberboard Shipping Containers. CHARM, 241-246.

Twede, D., Selke, S. E. M., Kamdem, D.-P., \& Shires, D. (2014). Cartons, crates and corrugated board: handbook of paper and wood packaging technology (2nd.). DEStech Publications, Inc.

Urbanik, T. J. (1985a). A method for determining the effect of fasteners on the stiffness and strength of wood drive-in-rack pallets. Journal of Testing and Evaluation, 13(5), 379-386. https://doi.org/10.1520/JTE10967J

Urbanik, T. J. (1985b). Deckboard bending theory for 3-stringer wood pallets in drive-in racks. Journal of Testing and Evaluation, 13(1), 3-8. https://doi.org/10.1520/JTE10754J

Urbanik, T. J., \& Frank, B. (2006). Box compression analysis of world-wide data spanning 46 years. Wood And Fiber Science, 38(3), 399-416.

Weigel, B. T. G., \& White, M. S. (1999). The Effect of Pallet Connection Stiffness, Deck Stiffness and Static Load Level on the Resonant Response of Pallet Decks to Vibration Frequencies Occurring in the Distribution Environment. Packaging Technology and Science, 12, 47-55.

White, B. S. (2008). Measurement of wood pallet performance subjected to uniform loading in 
racked, fork tine, and floor stacked support conditions (Master's Thesis). Virginia Polytechnic Institute and State University, Blacksburg, VA.

White, M. S. (2015). The Effect of Pallet Deck Design on Package Compression. In ISTA TransPack Forum. Orlando, Florida.

White, M. S., Dibling, W., Rupert, R., \& Mcleod, J. (1999). Determining pallet maximum working loads from nominal load measurements. Blacksburg, VA.

White, M. S., \& Hamner, P. (2005). Pallets move the world: the case for developing system-based designs for unit loads. Forest Products Journal, 55(3), 8-16.

Yoo, J. (2011). Modeling compressive stress distributions at the interface between a pallet deck and distribution packaging (Doctoral dissertation). Virginia Tech. 


\section{Appendix A: Modulus of Elasticity (MOE) measurements for pallet components}

The Modulus of Elasticity (MOE) was calculated for each wood component of the pallets, conducting a center-point loading test to determine flexural properties following the standard ASTM D198 (ASTM, 2015) Static Tests of Lumber in Structural Sizes. With the load and bending data obtained, the MOE was calculated using Equation 2.

$$
\text { Modulus of Elasticity }(M O E)=\frac{P l^{3}}{4 b d^{3} \Delta} \quad \text { [Equation 2] }
$$

Where $P$ is the increment of applied load on flexure specimen below proportional limit, $(\mathrm{N}), l$ is the span of flexure $(\mathrm{mm}), b$ is the width of flexure specimen $(\mathrm{mm}), d$ is the depth of rectangular flexure specimen $(\mathrm{mm})$ and $\Delta$ is the increment of deflection of neutral axis of flexure specimen measured at midspan over distance $l$ and corresponding load $P(\mathrm{~mm})$.

Every test conducted for the stringer components had a span, $l$, of $1100 \mathrm{~mm}$ and deckboard components of $900 \mathrm{~mm}$. The following tables show the data for each component, by pallet design. 
Table A 1. Modulus of Elasticity (MOE) data for the low stiffness pallet design.

\begin{tabular}{|c|c|c|c|c|c|c|c|}
\hline Component Type & Specimen ID & $\begin{array}{l}\text { Deflection } \\
\Delta(\mathbf{m m})\end{array}$ & $\begin{array}{l}\text { Load } \\
P(\mathbf{N})\end{array}$ & $\begin{array}{c}\text { Component } \\
\text { Thickness } \\
d(\mathrm{~mm})\end{array}$ & $\begin{array}{l}\text { Component Width } \\
\qquad b(\mathbf{m m})\end{array}$ & $\begin{array}{l}\text { Component Length } \\
\text { (mm) }\end{array}$ & MOE (MPa) \\
\hline Stringer & $\mathrm{S} 2$ & 2.359 & 1,450 & 88.66 & 25.65 & 1,202 & 11,397 \\
\hline Stringer & S8 & 2.127 & 1,291 & 88.84 & 25.61 & 1,202 & 11,205 \\
\hline Stringer & S12 & 2.101 & 1,242 & 88.96 & 25.60 & 1,200 & 10,870 \\
\hline Deckboard & D1-1 & 15.765 & 54 & 9.80 & 88.24 & 1,002 & 7,482 \\
\hline Deckboard & D1-2 & 15.636 & 50 & 9.62 & 88.00 & 1,000 & 7,438 \\
\hline Deckboard & D1-3 & 14.759 & 48 & 9.72 & 88.26 & 1,002 & 7,341 \\
\hline Deckboard & D1-5 & 15.250 & 48 & 9.76 & 88.08 & 1,000 & 7,036 \\
\hline Deckboard & D1-6 & 16.004 & 54 & 9.67 & 88.22 & 1,000 & 7,661 \\
\hline Deckboard & D1-7 & 16.643 & 46 & 9.73 & 88.58 & 1,002 & 6,198 \\
\hline Deckboard & D1-9 & 16.494 & 44 & 9.71 & 88.45 & 1,000 & 6,033 \\
\hline Deckboard & D1-11 & 13.503 & 40 & 9.75 & 88.48 & 1,000 & 6,542 \\
\hline Deckboard & D1-12 & 14.598 & 46 & 9.74 & 88.57 & 1,000 & 6,985 \\
\hline Deckboard & D1-13 & 13.784 & 48 & 9.75 & 87.89 & 1,000 & 7,807 \\
\hline Deckboard & D1-15 & 12.457 & 29 & 9.88 & 88.40 & 1,000 & 4,990 \\
\hline Deckboard & D1-16 & 13.368 & 24 & 9.75 & 88.65 & 999 & 3,905 \\
\hline Deckboard & D1-17 & 12.115 & 25 & 9.78 & 88.45 & 1,000 & 4,598 \\
\hline Deckboard & D1-21 & 8.915 & 52 & 9.81 & 87.88 & 1,000 & 12,640 \\
\hline
\end{tabular}


Table A 2. Modulus of Elasticity (MOE) data for the medium stiffness pallet design.

\begin{tabular}{|c|c|c|c|c|c|c|c|c|}
\hline $\begin{array}{c}\text { Component } \\
\text { Type }\end{array}$ & $\begin{array}{c}\text { Specimen } \\
\text { ID }\end{array}$ & $\begin{array}{c}\text { Deflection } \\
\Delta(\mathbf{m m})\end{array}$ & $\begin{array}{l}\text { Load } \\
P(\mathrm{~N})\end{array}$ & $\begin{array}{c}\text { Component } \\
\text { Thickness } \\
d(\mathrm{~mm})\end{array}$ & $\begin{array}{c}\text { Component } \\
\text { Width } \\
b(\mathrm{~mm})\end{array}$ & $\begin{array}{c}\text { Component } \\
\text { Length } \\
(\mathbf{m m})\end{array}$ & $\begin{array}{l}\text { MOE } \\
\text { (MPa) }\end{array}$ & $\begin{array}{c}\text { Component } \\
\text { Type }\end{array}$ \\
\hline Stringer & S5 & EM-D2 & 2.011 & 1,788 & 88.46 & 38.40 & 1,200 & 11,088 \\
\hline Stringer & $\mathrm{S} 10$ & EM-D2 & 1.425 & 1,443 & 88.75 & 38.26 & 1,200 & 12,546 \\
\hline Stringer & S11 & EM-D2 & 1.536 & 1,399 & 88.79 & 38.29 & 1,202 & 11,261 \\
\hline Deckboard & D2-1 & EM-D2 & 6.267 & 116 & 16.09 & 88.18 & 1,002 & 9,154 \\
\hline Deckboard & D2-2 & EM-D2 & 5.332 & 101 & 16.08 & 87.47 & 1,002 & 9,471 \\
\hline Deckboard & D2-3 & EM-D2 & 6.669 & 115 & 16.13 & 88.33 & 1,000 & 8,426 \\
\hline Deckboard & $\mathrm{D} 2-5$ & EM-D2 & 7.402 & 119 & 16.07 & 88.33 & 1,000 & 7,945 \\
\hline Deckboard & D2-6 & EM-D2 & 8.615 & 143 & 16.07 & 87.45 & 1,000 & 8,295 \\
\hline Deckboard & D2-8 & EM-D2 & 6.575 & 123 & 16.08 & 88.08 & 1,002 & 9,290 \\
\hline Deckboard & $\mathrm{D} 2-10$ & EM-D2 & 6.260 & 118 & 16.09 & 88.07 & 1,002 & 9,348 \\
\hline Deckboard & $\mathrm{D} 2-12$ & EM-D2 & 4.821 & 127 & 16.11 & 86.67 & 1,000 & 13,157 \\
\hline Deckboard & $\mathrm{D} 2-13$ & EM-D2 & 6.859 & 128 & 16.09 & 87.70 & 1,000 & 9,260 \\
\hline Deckboard & D2-17 & EM-D2 & 5.975 & 127 & 16.22 & 88.67 & 1,000 & 10,173 \\
\hline Deckboard & D2-18 & EM-D2 & 4.646 & 130 & 16.25 & 87.58 & 999 & 13,528 \\
\hline Deckboard & D2-19 & EM-D2 & 6.626 & 122 & 16.19 & 88.67 & 999 & 8,914 \\
\hline Deckboard & D2-20 & EM-D2 & 5.436 & 139 & 16.18 & 87.82 & 999 & 12,505 \\
\hline Deckboard & D2-21 & EM-D2 & 6.306 & 123 & 16.17 & 88.73 & 999 & 9,404 \\
\hline
\end{tabular}


Table A 3. Modulus of Elasticity (MOE) data for the high stiffness pallet design.

\begin{tabular}{|c|c|c|c|c|c|c|c|c|}
\hline $\begin{array}{l}\text { Component } \\
\text { Type }\end{array}$ & $\begin{array}{l}\text { Specimen } \\
\text { ID }\end{array}$ & $\begin{array}{l}\text { Deflection } \Delta \\
(\mathrm{mm})\end{array}$ & $\begin{array}{l}\text { Load } \\
P(\mathrm{~N})\end{array}$ & $\begin{array}{l}\text { Component } \\
\text { Thickness } \\
d(\mathrm{~mm})\end{array}$ & $\begin{array}{l}\text { Component } \\
\text { Width } \\
b(\mathrm{~mm})\end{array}$ & $\begin{array}{l}\text { Component } \\
\text { Length } \\
(\mathrm{mm})\end{array}$ & $\begin{array}{l}\text { MOE } \\
\text { (MPa) }\end{array}$ & $\begin{array}{l}\text { Component } \\
\text { Type }\end{array}$ \\
\hline Stringer & S3 & EM-D3 & 1.541 & 1,635 & 88.72 & 44.72 & 1,202 & 11,261 \\
\hline Stringer & S4 & EM-D3 & 1.444 & 1,630 & 88.82 & 44.75 & 1,200 & 11,938 \\
\hline Stringer & S6 & EM-D3 & 3.332 & 4,277 & 89.31 & 44.75 & 1,202 & 13,344 \\
\hline Deckboard & D3-3 & EM-D3 & 3.537 & 210 & 22.31 & 87.41 & 1,002 & 11,079 \\
\hline Deckboard & D3-4 & EM-D3 & 3.438 & 247 & 22.31 & 88.02 & 1,000 & 13,300 \\
\hline Deckboard & D3-6 & EM-D3 & 3.546 & 223 & 22.22 & 87.77 & 1,000 & 11,860 \\
\hline Deckboard & D3-7 & EM-D3 & 4.128 & 206 & 22.27 & 87.62 & 1,000 & 9,343 \\
\hline Deckboard & D3-9 & EM-D3 & 4.051 & 209 & 22.26 & 87.85 & 1,002 & 9,659 \\
\hline Deckboard & D3-10 & EM-D3 & 3.520 & 224 & 22.28 & 88.45 & 1,000 & 11,771 \\
\hline Deckboard & D3-11 & EM-D3 & 3.578 & 197 & 22.17 & 87.29 & 1,000 & 10,499 \\
\hline Deckboard & D3-12 & EM-D3 & 3.147 & 193 & 22.38 & 88.05 & 1,002 & 11,294 \\
\hline Deckboard & D3-15 & EM-D3 & 4.605 & 231 & 22.55 & 88.79 & 1,000 & 8,921 \\
\hline Deckboard & D3-17 & EM-D3 & 3.531 & 259 & 22.50 & 88.43 & 1,000 & 13,191 \\
\hline Deckboard & D3-18 & EM-D3 & 4.593 & 207 & 22.55 & 88.84 & 999 & 8,037 \\
\hline Deckboard & D3-19 & EM-D3 & 3.990 & 204 & 22.51 & 86.76 & 1,000 & 9,391 \\
\hline Deckboard & D3-20 & EM-D3 & 3.744 & 248 & 22.52 & 88.17 & 999 & 11,944 \\
\hline Deckboard & D3-22 & EM-D3 & 4.658 & 254 & 22.50 & 88.52 & 1,000 & 9,819 \\
\hline
\end{tabular}




\section{Appendix B: Statistical analysis results for the effect of pallet stacking patterns on pallet deflection}

ANOVA tables for the effect of the pallet stacking pattern when floor stacked.

Table B 1. ANOVA results for the effect of the stacking pattern on the low stiffness pallet when floor stacked.

\begin{tabular}{lrrrrr}
\hline Source & DF & Sum of Squares & Mean Square & F Ratio & Prob > F \\
\hline Stacking Pattern & 4 & 0.6606267 & 0.165157 & 1.7735 & 0.2107 \\
Error & 10 & 0.9312667 & 0.093127 & & \\
C. Total & 14 & 1.5918933 & & & \\
\hline
\end{tabular}

Table B 2. ANOVA results for the effect of the stacking pattern on the medium stiffness pallet when floor stacked.

\begin{tabular}{lrrrrr}
\hline Source & DF & Sum of Squares & Mean Square & F Ratio & Prob > F \\
\hline Stacking Pattern & 4 & 0.30902667 & 0.077257 & 3.6906 & $0.0428^{*}$ \\
Error & 10 & 0.20933333 & 0.020933 & & \\
C. Total & 14 & 0.51836 & & & \\
\hline
\end{tabular}

Table B 3. ANOVA results for the effect of the stacking pattern on the high stiffness pallet when floor stacked.

\begin{tabular}{lrrrrr}
\hline Source & DF & Sum of Squares & Mean Square & F Ratio & Prob > F \\
\hline Stacking Pattern & 4 & 0.04596 & 0.01149 & 3.4264 & 0.052 \\
Error & 10 & 0.03353333 & 0.003353 & & \\
C. Total & 14 & 0.07949333 & & & \\
\hline
\end{tabular}


Table B 4. ANOVA results for the effect of the stacking pattern on the center of the low stiffness pallet when racked across the width.

\begin{tabular}{lrrrrr}
\hline Source & DF & Sum of Squares & Mean Square & F Ratio & Prob > F \\
\hline Stacking Pattern & 4 & 382.6084 & 95.6521 & 82.4251 & $<.0001^{*}$ \\
Error & 10 & 11.60473 & 1.1605 & & \\
C. Total & 14 & 394.21313 & & & \\
\hline
\end{tabular}

Table B 5. ANOVA results for the effect of the stacking pattern on the sides of the low stiffness pallet when racked across the width.

\begin{tabular}{lrrrrr}
\hline Source & DF & Sum of Squares & Mean Square & F Ratio & Prob > F \\
\hline Stacking Pattern & 4 & 390.20971 & 97.5524 & 80.721 & $<.0001^{*}$ \\
Error & 10 & 12.08513 & 1.2085 & & \\
C. Total & 14 & 402.29484 & & & \\
\hline
\end{tabular}

Table B 6. ANOVA results for the effect of the stacking pattern on the center of the medium stiffness pallet when racked across the width.

\begin{tabular}{lrrrrr}
\hline Source & DF & Sum of Squares & Mean Square & F Ratio & Prob > F \\
\hline Stacking Pattern & 4 & 7.5762667 & 1.89407 & 12.9938 & $0.0006^{*}$ \\
Error & 10 & 1.4576667 & 0.14577 & & \\
C. Total & 14 & 9.0339333 & & & \\
\hline
\end{tabular}

Table B 7. ANOVA results for the effect of the stacking pattern on the sides of the medium stiffness pallet when racked across the width.

\begin{tabular}{lrrrrr}
\hline Source & DF & Sum of Squares & Mean Square & F Ratio & Prob > F \\
\hline Stacking Pattern & 4 & 7.12484 & 1.78121 & 11.923 & $0.0008^{*}$ \\
Error & 10 & 1.4939333 & 0.14939 & & \\
C. Total & 14 & 8.6187733 & & & \\
\hline
\end{tabular}


Table B 8. ANOVA results for the effect of the stacking pattern on the center of the high stiffness pallet when racked across the width.

\begin{tabular}{lrrrrr}
\hline Source & DF & Sum of Squares & Mean Square & F Ratio & Prob > F \\
\hline Stacking Pattern & 4 & 0.9021333 & 0.225533 & 1.5787 & 0.2539 \\
Error & 10 & 1.4286 & 0.14286 & & \\
C. Total & 14 & 2.3307333 & & & \\
\hline
\end{tabular}

Table B 9. ANOVA results for the effect of the stacking pattern on the sides of the high stiffness pallet when racked across the width.

\begin{tabular}{lrrrrr}
\hline Source & DF & Sum of Squares & Mean Square & F Ratio & Prob > F \\
\hline Stacking Pattern & 4 & 0.2622233 & 0.065556 & 0.3384 & 0.8461 \\
Error & 10 & 1.93745 & 0.193745 & & \\
C. Total & 14 & 2.1996733 & & & \\
\hline
\end{tabular}

ANOVA tables for the effect of the pallet stacking pattern when racked across the length.

Table B 10. ANOVA results for the effect of the stacking pattern on the center of the low stiffness pallet when racked across the length.

\begin{tabular}{lrrrrr}
\hline Source & DF & Sum of Squares & Mean Square & F Ratio & Prob > F \\
\hline Stacking Pattern & 4 & 0.2111067 & 0.052777 & 0.5111 & 0.7293 \\
Error & 10 & 1.0325333 & 0.103253 & & \\
C. Total & 14 & 1.24364 & & & \\
\hline
\end{tabular}

Table B 11. ANOVA results for the effect of the stacking pattern on the sides of the low stiffness pallet when racked across the length.

\begin{tabular}{lrrrrr}
\hline Source & DF & Sum of Squares & Mean Square & F Ratio & Prob > F \\
\hline Stacking Pattern & 4 & 0.04986 & 0.012465 & 0.2036 & 0.9306 \\
Error & 10 & 0.61223333 & 0.061223 & & \\
C. Total & 14 & 0.66209333 & & & \\
\hline
\end{tabular}


Table B 12. ANOVA results for the effect of the stacking pattern on the center of the medium stiffness pallet when racked across the length.

\begin{tabular}{lrrrrr}
\hline Source & DF & Sum of Squares & Mean Square & F Ratio & Prob > F \\
\hline Stacking Pattern & 4 & 0.2547333 & 0.063683 & 0.2286 & 0.9161 \\
Error & 10 & 2.7864 & 0.27864 & & \\
C. Total & 14 & 3.0411333 & & & \\
\hline
\end{tabular}

Table B 13. ANOVA results for the effect of the stacking pattern on the sides of the medium stiffness pallet when racked across the length.

\begin{tabular}{lrrrrr}
\hline Source & DF & Sum of Squares & Mean Square & F Ratio & Prob > F \\
\hline Stacking Pattern & 4 & 0.2238767 & 0.055969 & 0.321 & 0.8576 \\
Error & 10 & 1.7435167 & 0.174352 & & \\
C. Total & 14 & 1.9673933 & & & \\
\hline
\end{tabular}

Table B 14. ANOVA results for the effect of the stacking pattern on the center of the high stiffness pallet when racked across the length.

\begin{tabular}{lrrrrr}
\hline Source & DF & Sum of Squares & Mean Square & F Ratio & Prob > F \\
\hline Stacking Pattern & 4 & 0.3549067 & 0.088727 & 0.3428 & 0.8431 \\
Error & 10 & 2.5884667 & 0.258847 & & \\
C. Total & 14 & 2.9433733 & & & \\
\hline
\end{tabular}

Table B 15. ANOVA results for the effect of the stacking pattern on the sides of the high stiffness pallet when racked across the length.

\begin{tabular}{lrrrrr}
\hline Source & DF & Sum of Squares & Mean Square & F Ratio & Prob > F \\
\hline Stacking Pattern & 4 & 0.53146 & 0.132865 & 0.7491 & 0.5806 \\
Error & 10 & 1.7737 & 0.17737 & & \\
C. Total & 14 & 2.30516 & & & \\
\hline
\end{tabular}


Table B 16. ANOVA results for the effect of the stacking pattern on the right side (A) of the low stiffness pallet when supported on forklift across the width.

\begin{tabular}{lrrrrr}
\hline Source & DF & Sum of Squares & Mean Square & F Ratio & Prob > F \\
\hline Stacking Pattern & 4 & 24.728293 & 6.18207 & 37.1608 & $<.0001^{*}$ \\
Error & 10 & 1.6636 & 0.16636 & & \\
C. Total & 14 & 26.391893 & & & \\
\hline
\end{tabular}

Table B 17. ANOVA results for the effect of the stacking pattern on the left side (B) of the low stiffness pallet when supported on forklift across the width.

\begin{tabular}{lrrrrr}
\hline Source & DF & Sum of Squares & Mean Square & F Ratio & Prob > F \\
\hline Stacking Pattern & 4 & 29.46036 & 7.36509 & 72.0091 & $<.0001^{*}$ \\
Error & 10 & 1.0228 & 0.10228 & & \\
C. Total & 14 & 30.48316 & & & \\
\hline
\end{tabular}

Table B 18. ANOVA results for the effect of the stacking pattern on the right side (A) of the medium stiffness pallet when supported on forklift across the width.

\begin{tabular}{lrrrrr}
\hline Source & DF & Sum of Squares & Mean Square & F Ratio & Prob > F \\
\hline Stacking Pattern & 4 & 0.6407333 & 0.160183 & 0.6787 & 0.6222 \\
Error & 10 & 2.3600667 & 0.236007 & & \\
C. Total & 14 & 3.0008 & & & \\
\hline
\end{tabular}

Table B 19. ANOVA results for the effect of the stacking pattern on the left side (B) of the medium stiffness pallet when supported on forklift across the width.

\begin{tabular}{lrrrrr}
\hline Source & DF & Sum of Squares & Mean Square & F Ratio & Prob > F \\
\hline Stacking Pattern & 4 & 0.8650933 & 0.216273 & 1.5036 & 0.2732 \\
Error & 10 & 1.4384 & 0.14384 & & \\
C. Total & 14 & 2.3034933 & & & \\
\hline
\end{tabular}


Table B 20. ANOVA results for the effect of the stacking pattern on the right side (A) of the high stiffness pallet when supported on forklift across the width.

\begin{tabular}{lrrrrr}
\hline Source & DF & Sum of Squares & Mean Square & F Ratio & Prob > F \\
\hline Stacking Pattern & 4 & 0.47413333 & 0.118533 & 2.9081 & 0.0779 \\
Error & 10 & 0.4076 & 0.04076 & & \\
C. Total & 14 & 0.88173333 & & & \\
\hline
\end{tabular}

Table B 21. ANOVA results for the effect of the stacking pattern on the left side (B) of the high stiffness pallet when supported on forklift across the width.

\begin{tabular}{lrrrrr}
\hline Source & DF & Sum of Squares & Mean Square & F Ratio & Prob $>$ F \\
\hline Stacking Pattern & 4 & 0.5159067 & 0.128977 & 2.1895 & 0.1436 \\
Error & 10 & 0.5890667 & 0.058907 & & \\
C. Total & 14 & 1.1049733 & & & \\
\hline
\end{tabular}




\section{Appendix C: Data collected for the evaluation of the effect of pallet stacking patterns on pallet deflection}

Pallet deflection measurement tables when floor stacked.

Table C 1. Absolute deflection measurements in millimeters by stacking pattern for the low stiffness pallet when floor stacked.

\begin{tabular}{llllllllll}
\hline Stacking & \multirow{2}{*}{ Pattenn } & Replicate & \multicolumn{7}{l}{ Measurement Location } \\
\cline { 2 - 10 } & & $\mathbf{0}$ & $\mathbf{1}$ & $\mathbf{2}$ & $\mathbf{3}$ & $\mathbf{4}$ & $\mathbf{5}$ & $\mathbf{6}$ & $\mathbf{7}$ \\
\hline P1 & 1 & 3.63 & 3.89 & 4.01 & 2.97 & 3.68 & 4.39 & 2.41 & 3.02 \\
P1 & 2 & 3.38 & 3.89 & 4.06 & 3.02 & 3.53 & 3.84 & 2.95 & 3.94 \\
P1 & 3 & 4.65 & 4.06 & 4.75 & 3.51 & 3.40 & 4.80 & 2.59 & 2.95 \\
P2 & 1 & 3.86 & 3.81 & 3.56 & 1.88 & 1.85 & 4.57 & 2.95 & 2.31 \\
P2 & 2 & 3.84 & 2.95 & 3.07 & 2.69 & 2.59 & 3.84 & 3.05 & 3.43 \\
P2 & 3 & 3.86 & 3.94 & 2.29 & 3.02 & 2.36 & 2.79 & 3.18 & 3.91 \\
P3 & 1 & 3.63 & 3.61 & 2.72 & 2.21 & 2.49 & 4.42 & 2.44 & 2.84 \\
P3 & 2 & 4.67 & 4.37 & 2.84 & 2.34 & 2.59 & 4.85 & 3.07 & 4.22 \\
P3 & 3 & 3.96 & 4.29 & 3.63 & 2.87 & 2.90 & 4.67 & 2.95 & 2.72 \\
P4 & 1 & 4.39 & 4.60 & 3.35 & 2.92 & 2.84 & 3.12 & 3.38 & 3.91 \\
P4 & 2 & 4.50 & 4.52 & 3.48 & 2.92 & 2.21 & 3.33 & 3.18 & 3.91 \\
P4 & 3 & 4.52 & 4.70 & 3.18 & 2.90 & 2.72 & 3.53 & 3.07 & 3.86 \\
P5 & 1 & 3.94 & 3.63 & 2.72 & 1.75 & 2.62 & 4.57 & 2.03 & 2.41 \\
P5 & 2 & 3.48 & 3.53 & 2.54 & 2.57 & 2.92 & 3.15 & 3.56 & 4.17 \\
P5 & 3 & 3.66 & 3.68 & 2.69 & 2.69 & 2.95 & 3.89 & 2.54 & 3.33 \\
\hline
\end{tabular}


Table C 2. Absolute deflection measurements in millimeters by stacking pattern for the medium stiffness pallet when floor stacked.

\begin{tabular}{llllllllll}
\hline Stacking & \multirow{2}{*}{ Pattern } & Replicate & \multicolumn{7}{l}{ Measurement Location } \\
\cline { 3 - 10 } & & $\mathbf{0}$ & $\mathbf{1}$ & $\mathbf{2}$ & $\mathbf{3}$ & $\mathbf{4}$ & $\mathbf{5}$ & $\mathbf{6}$ & $\mathbf{7}$ \\
\hline P1 & 1 & 1.22 & 1.14 & 2.08 & 0.81 & 1.04 & 1.19 & 0.86 & 1.47 \\
P1 & 2 & 1.09 & 0.97 & 1.75 & 0.91 & 1.40 & 1.09 & 0.89 & 1.32 \\
P1 & 3 & 1.12 & 0.89 & 1.83 & 0.89 & 1.32 & 1.17 & 0.81 & 1.42 \\
P2 & 1 & 1.70 & 0.84 & 1.47 & 1.17 & 0.91 & 1.27 & 0.89 & 0.97 \\
P2 & 2 & 1.12 & 1.04 & 1.70 & 1.19 & 1.07 & 1.07 & 0.84 & 1.14 \\
P2 & 3 & 1.35 & 0.94 & 1.57 & 1.27 & 1.09 & 1.30 & 0.89 & 1.22 \\
P3 & 1 & 1.22 & 1.02 & 1.52 & 1.27 & 1.30 & 1.50 & 0.81 & 1.93 \\
P3 & 2 & 0.97 & 0.76 & 1.75 & 1.07 & 1.19 & 1.35 & 1.07 & 1.32 \\
P3 & 3 & 1.42 & 0.99 & 1.65 & 1.27 & 1.22 & 1.45 & 1.07 & 1.17 \\
P4 & 1 & 1.45 & 0.99 & 1.45 & 1.09 & 1.07 & 0.89 & 0.89 & 1.07 \\
P4 & 2 & 1.42 & 0.84 & 1.63 & 1.45 & 1.37 & 1.27 & 1.09 & 1.19 \\
P4 & 3 & 1.04 & 0.76 & 1.88 & 1.40 & 1.19 & 1.32 & 1.04 & 0.99 \\
P5 & 1 & 1.24 & 0.79 & 1.50 & 1.35 & 1.14 & 1.40 & 0.46 & 1.22 \\
P5 & 2 & 1.40 & 0.91 & 1.35 & 1.09 & 1.19 & 1.37 & 0.69 & 1.19 \\
P5 & 3 & 1.32 & 0.99 & 1.47 & 1.27 & 1.09 & 1.47 & 0.64 & 1.35 \\
\hline
\end{tabular}


Table C 3. Absolute deflection measurements in millimeters by stacking pattern for the high stiffness pallet when floor stacked.

\begin{tabular}{llllllllll}
\hline Stacking & \multirow{2}{*}{ Pattern } & Replicate & \multicolumn{7}{l}{ Measurement Location } \\
\cline { 3 - 10 } & & $\mathbf{0}$ & $\mathbf{1}$ & $\mathbf{2}$ & $\mathbf{3}$ & $\mathbf{4}$ & $\mathbf{5}$ & $\mathbf{6}$ & $\mathbf{7}$ \\
\hline P1 & 1 & 0.46 & 0.43 & 0.71 & 0.38 & 0.61 & 0.46 & 0.33 & 0.53 \\
P1 & 2 & 0.46 & 0.56 & 0.79 & 0.28 & 0.48 & 0.36 & 0.20 & 0.33 \\
P1 & 3 & 0.38 & 0.51 & 0.74 & 0.48 & 0.58 & 0.48 & 0.36 & 0.41 \\
P2 & 1 & 0.43 & 0.36 & 0.56 & 0.66 & 0.41 & 0.48 & 0.41 & 0.38 \\
P2 & 2 & 0.46 & 0.51 & 0.58 & 0.53 & 0.51 & 0.41 & 0.48 & 0.30 \\
P2 & 3 & 0.43 & 0.61 & 0.56 & 0.48 & 0.61 & 0.36 & 0.58 & 0.36 \\
P3 & 1 & 0.51 & 0.51 & 0.58 & 0.64 & 0.66 & 0.76 & 0.38 & 0.51 \\
P3 & 2 & 0.38 & 0.53 & 0.51 & 0.58 & 0.46 & 0.38 & 0.25 & 0.20 \\
P3 & 3 & 0.51 & 0.48 & 0.76 & 0.71 & 0.61 & 0.79 & 0.36 & 0.43 \\
P4 & 1 & 0.36 & 0.46 & 0.58 & 0.61 & 0.48 & 0.51 & 0.41 & 0.43 \\
P4 & 2 & 0.23 & 0.41 & 0.53 & 0.61 & 0.53 & 0.51 & 0.43 & 0.53 \\
P4 & 3 & 0.33 & 0.41 & 0.56 & 0.58 & 0.51 & 0.53 & 0.46 & 0.36 \\
P5 & 1 & 0.15 & 0.51 & 0.69 & 0.69 & 0.41 & 0.56 & 0.36 & 0.43 \\
P5 & 2 & 0.41 & 0.46 & 0.69 & 0.61 & 0.61 & 0.58 & 0.41 & 0.46 \\
P5 & 3 & 0.33 & 0.56 & 0.66 & 0.53 & 0.61 & 0.64 & 0.30 & 0.38 \\
\hline
\end{tabular}


Pallet deflection measurement tables when racked across the width.

Table C 4. Absolute deflection measurements in millimeters by stacking pattern for the low stiffness pallet when racked across the width.

\begin{tabular}{lllll}
\hline $\begin{array}{l}\text { Stacking } \\
\text { Pattern }\end{array}$ & Replicate & Back & Center & Front \\
\hline P1 & 1 & 26.63 & 27.18 & 28.52 \\
P1 & 2 & 25.27 & 26.67 & 27.81 \\
P1 & 3 & 24.16 & 27.77 & 31.2 \\
P2 & 1 & 9.65 & 10.88 & 11.87 \\
P2 & 2 & 10.94 & 14.34 & 17.75 \\
P2 & 3 & 11.46 & 13.31 & 15.12 \\
P3 & 1 & 13.16 & 15.62 & 17.78 \\
P3 & 2 & 11.34 & 14.27 & 16.94 \\
P3 & 3 & 12.92 & 13.24 & 13.33 \\
P4 & 1 & 14.77 & 17.36 & 19.93 \\
P4 & 2 & 13.65 & 16.34 & 19.01 \\
P4 & 3 & 16.38 & 17.83 & 19.38 \\
P5 & 1 & 14.62 & 15.9 & 17.38 \\
P5 & 2 & 14.17 & 15.76 & 17.2 \\
P5 & 3 & 15.52 & 16.83 & 17.8 \\
\hline
\end{tabular}


Table C 5. Absolute deflection measurements in millimeters by stacking pattern for the medium stiffness pallet when racked across the width.

\begin{tabular}{lllll}
\hline $\begin{array}{l}\text { Stacking } \\
\text { Pattern }\end{array}$ & Replicate & Back & Center & Front \\
\hline P1 & 1 & 6.29 & 6.59 & 7.16 \\
P1 & 2 & 6.15 & 6.68 & 7.57 \\
P1 & 3 & 6.56 & 7.15 & 7.66 \\
P2 & 1 & 4.2 & 4.5 & 5.02 \\
P2 & 2 & 4.32 & 5.05 & 5.97 \\
P2 & 3 & 4.75 & 4.85 & 5.42 \\
P3 & 1 & 4.71 & 5.59 & 6.42 \\
P3 & 2 & 4.15 & 4.89 & 5.95 \\
P3 & 3 & 5.02 & 5 & 5.35 \\
P4 & 1 & 5.31 & 5.28 & 5.65 \\
P4 & 2 & 5.13 & 5.17 & 5.55 \\
P4 & 3 & 4.43 & 5.15 & 6.41 \\
P5 & 1 & 4.04 & 4.79 & 5.79 \\
P5 & 2 & 4.28 & 4.67 & 5.17 \\
P5 & 3 & 5.35 & 5.84 & 6.83 \\
\hline
\end{tabular}


Table C 6. Absolute deflection measurements in millimeters by stacking pattern for the high stiffness pallet when racked across the width.

\begin{tabular}{lllll}
\hline $\begin{array}{l}\text { Stacking } \\
\text { Pattern }\end{array}$ & Replicate & Back & Center & Front \\
\hline P1 & 1 & 2.73 & 3.33 & 3.67 \\
P1 & 2 & 1.26 & 2.66 & 2.28 \\
P1 & 3 & 1.85 & 2.29 & 2.51 \\
P2 & 1 & 2.43 & 2.55 & 2.55 \\
P2 & 2 & 1.92 & 2.53 & 2.63 \\
P2 & 3 & 1.96 & 2.26 & 2.2 \\
P3 & 1 & 2.37 & 2.49 & 2.44 \\
P3 & 2 & 1.54 & 2.4 & 2.81 \\
P3 & 3 & 1.39 & 1.79 & 1.99 \\
P4 & 1 & 2.11 & 2.47 & 2.71 \\
P4 & 2 & 1.75 & 2.08 & 2.5 \\
P4 & 3 & 1.84 & 1.85 & 1.74 \\
P5 & 1 & 2.53 & 2.57 & 2.43 \\
P5 & 2 & 2.01 & 1.83 & 1.49 \\
P5 & 3 & 1.75 & 1.9 & 1.97 \\
\hline
\end{tabular}


Pallet deflection measurement tables when racked across the length.

Table C 7. Absolute deflection measurements in millimeters by stacking pattern for the low stiffness pallet when racked across the length.

\begin{tabular}{lllll}
\hline $\begin{array}{l}\text { Stacking } \\
\text { Pattern }\end{array}$ & Replicate & Back & Center & Front \\
\hline P1 & 1 & 2.89 & 3.52 & 2.68 \\
P1 & 2 & 2.86 & 4.11 & 2.99 \\
P1 & 3 & 2.87 & 4.47 & 3.32 \\
P2 & 1 & 2.65 & 3.64 & 2.84 \\
P2 & 2 & 2.81 & 3.66 & 2.92 \\
P2 & 3 & 2.93 & 3.95 & 3.05 \\
P3 & 1 & 2.55 & 3.44 & 2.88 \\
P3 & 2 & 2.90 & 3.80 & 2.82 \\
P3 & 3 & 3.35 & 3.92 & 3.06 \\
P4 & 1 & 2.62 & 3.50 & 2.73 \\
P4 & 2 & 2.82 & 3.49 & 2.61 \\
P4 & 3 & 3.00 & 4.16 & 3.02 \\
P5 & 1 & 2.48 & 3.60 & 2.61 \\
P5 & 2 & 3.41 & 4.03 & 3.33 \\
P5 & 3 & 2.79 & 3.83 & 3.14 \\
\hline
\end{tabular}


Table C 8. Absolute deflection measurements in millimeters by stacking pattern for the medium stiffness pallet when racked across the length.

\begin{tabular}{lllll}
\hline Ptacking & Replicate & Back & Center & Front \\
\hline P1 & 1 & 1.72 & 1.93 & 1.49 \\
P1 & 2 & 2.68 & 3.10 & 2.00 \\
P1 & 3 & 3.13 & 3.22 & 2.31 \\
P2 & 1 & 2.12 & 2.08 & 1.78 \\
P2 & 2 & 2.29 & 2.17 & 1.69 \\
P2 & 3 & 2.70 & 3.00 & 2.13 \\
P3 & 1 & 2.39 & 2.47 & 1.71 \\
P3 & 2 & 2.56 & 2.49 & 2.14 \\
P3 & 3 & 3.16 & 2.79 & 2.26 \\
P4 & 1 & 2.38 & 2.12 & 1.06 \\
P4 & 2 & 3.08 & 2.97 & 2.06 \\
P4 & 3 & 2.80 & 2.87 & 2.16 \\
P5 & 1 & 2.30 & 2.07 & 1.73 \\
P5 & 2 & 3.00 & 3.09 & 2.36 \\
P5 & 3 & 3.04 & 3.18 & 2.40 \\
\hline
\end{tabular}


Table C 9. Absolute deflection measurements in millimeters by stacking pattern for the high stiffness pallet when racked across the width.

\begin{tabular}{lllll}
\hline $\begin{array}{l}\text { Stacking } \\
\text { Pattern }\end{array}$ & Replicate & Back & Center & Front \\
\hline P1 & 1 & 1.86 & 2.01 & 1.38 \\
P1 & 2 & 2.88 & 2.47 & 2.12 \\
P1 & 3 & 3.20 & 3.14 & 2.20 \\
P2 & 1 & 1.35 & 1.45 & 1.23 \\
P2 & 2 & 2.07 & 2.37 & 1.94 \\
P2 & 3 & 2.18 & 2.56 & 1.85 \\
P3 & 1 & 2.09 & 2.00 & 1.37 \\
P3 & 2 & 2.00 & 1.89 & 1.39 \\
P3 & 3 & 2.57 & 2.76 & 1.98 \\
P4 & 1 & 1.99 & 2.22 & 1.47 \\
P4 & 2 & 2.43 & 2.23 & 1.84 \\
P4 & 3 & 2.92 & 2.95 & 2.09 \\
P5 & 1 & 1.62 & 1.86 & 1.35 \\
P5 & 2 & 2.13 & 2.23 & 1.53 \\
P5 & 3 & 2.40 & 2.79 & 2.00 \\
\hline
\end{tabular}


Pallet deflection measurement tables when supported on forklift across the width.

Table C 10. Absolute deflection measurements in millimeters by stacking pattern for the low stiffness pallet when supported on forklift across the width.

\begin{tabular}{|c|c|c|c|c|c|}
\hline $\begin{array}{l}\text { Stacking } \\
\text { Pattern }\end{array}$ & Replicate & $\begin{array}{l}\text { Back - A } \\
\text { (Ab) }\end{array}$ & $\begin{array}{l}\text { Back - B } \\
\text { (Bb) }\end{array}$ & $\begin{array}{l}\text { Front - A } \\
\text { (Af) }\end{array}$ & $\begin{array}{l}\text { Front - B } \\
\text { (Bf) }\end{array}$ \\
\hline P1 & 1 & 8.83 & 5.83 & 5.96 & 7.75 \\
\hline P1 & 2 & 7.95 & 6.48 & 6.20 & 7.66 \\
\hline P1 & 3 & 8.29 & 6.69 & 6.69 & 7.24 \\
\hline $\mathbf{P 2}$ & 1 & 5.40 & 4.24 & 3.58 & 3.18 \\
\hline P2 & 2 & 6.20 & 3.25 & 3.01 & 3.11 \\
\hline $\mathbf{P} 2$ & 3 & 5.02 & 3.40 & 2.52 & 2.93 \\
\hline P3 & 1 & 5.22 & 2.62 & 3.97 & 3.08 \\
\hline P3 & 2 & 4.61 & 3.69 & 3.93 & 4.34 \\
\hline P3 & 3 & 4.69 & 2.45 & 2.80 & 3.84 \\
\hline P4 & 1 & 4.31 & 3.08 & 2.60 & 5.04 \\
\hline P4 & 2 & 5.63 & 3.50 & 3.41 & 4.33 \\
\hline P4 & 3 & 6.90 & 3.13 & 1.96 & 4.72 \\
\hline P5 & 1 & 3.81 & 3.35 & 3.60 & 3.02 \\
\hline P5 & 2 & 4.87 & 3.46 & 3.41 & 3.10 \\
\hline P5 & 3 & 5.72 & 3.68 & 1.91 & 3.25 \\
\hline
\end{tabular}


Table C 11. Absolute deflection measurements in millimeters by stacking pattern for the medium stiffness pallet when supported on forklift across the width.

\begin{tabular}{|c|c|c|c|c|c|}
\hline $\begin{array}{l}\text { Stacking } \\
\text { Pattern }\end{array}$ & Replicate & $\begin{array}{l}\text { Back - A } \\
\text { (Ab) }\end{array}$ & $\begin{array}{l}\text { Back - B } \\
\text { (Bb) }\end{array}$ & $\begin{array}{l}\text { Front - A } \\
\text { (Af) }\end{array}$ & $\begin{array}{l}\text { Front - B } \\
\text { (Bf) }\end{array}$ \\
\hline P1 & 1 & 1.62 & 1.91 & 1.09 & 1.40 \\
\hline P1 & 2 & 2.08 & 2.17 & 1.52 & 1.38 \\
\hline P1 & 3 & 2.43 & 3.28 & 2.21 & 2.53 \\
\hline $\mathbf{P} 2$ & 1 & 1.85 & 2.00 & 0.29 & 1.88 \\
\hline P2 & 2 & 3.45 & 1.52 & 1.41 & 1.82 \\
\hline P2 & 3 & 2.34 & 1.63 & 1.94 & 2.05 \\
\hline P3 & 1 & 3.42 & 1.63 & 1.18 & 1.06 \\
\hline P3 & 2 & 3.61 & 1.17 & 1.24 & 2.56 \\
\hline P3 & 3 & 1.45 & 1.82 & 1.82 & 1.93 \\
\hline P4 & 1 & 3.45 & 2.32 & 2.33 & 2.41 \\
\hline P4 & 2 & 2.16 & 2.84 & 1.83 & 2.42 \\
\hline P4 & 3 & 3.09 & 2.08 & 1.48 & 1.73 \\
\hline P5 & 1 & 2.68 & 2.33 & 1.77 & 1.06 \\
\hline P5 & 2 & 3.04 & 1.89 & 0.82 & 1.55 \\
\hline P5 & 3 & 3.56 & 1.42 & 1.18 & 2.00 \\
\hline
\end{tabular}


Table C 12. Absolute deflection measurements in millimeters by stacking pattern for the high stiffness pallet when supported on forklift across the width.

\begin{tabular}{|c|c|c|c|c|c|}
\hline $\begin{array}{l}\text { Stacking } \\
\text { Pattern }\end{array}$ & Replicate & $\begin{array}{l}\text { Back - A } \\
\text { (Ab) }\end{array}$ & $\begin{array}{l}\text { Back - B } \\
\text { (Bb) }\end{array}$ & $\begin{array}{l}\text { Front - A } \\
\text { (Af) }\end{array}$ & $\begin{array}{l}\text { Front - B } \\
\text { (Bf) }\end{array}$ \\
\hline P1 & 1 & 0.84 & 2.33 & 0.78 & 0.58 \\
\hline P1 & 2 & 0.48 & 0.63 & 0.76 & 0.77 \\
\hline P1 & 3 & 0.82 & 1.24 & 0.76 & 0.07 \\
\hline $\mathbf{P 2}$ & 1 & 0.50 & 0.50 & 0.60 & 0.05 \\
\hline $\mathbf{P 2}$ & 2 & 0.27 & 0.29 & 0.43 & 0.67 \\
\hline $\mathbf{P 2}$ & 3 & 0.30 & 0.67 & 0.60 & 0.23 \\
\hline P3 & 1 & 0.09 & 0.37 & 1.50 & 0.59 \\
\hline P3 & 2 & 0.13 & 0.81 & 0.51 & 0.53 \\
\hline P3 & 3 & 0.56 & 0.65 & 0.83 & 0.13 \\
\hline P4 & 1 & 0.72 & 0.84 & 0.56 & 0.21 \\
\hline $\mathbf{P 4}$ & 2 & 1.60 & 1.07 & 0.47 & 0.67 \\
\hline P4 & 3 & 1.75 & 0.71 & 0.80 & 0.65 \\
\hline P5 & 1 & 0.67 & 0.57 & 0.79 & 0.24 \\
\hline P5 & 2 & 0.81 & 0.91 & 0.19 & 0.57 \\
\hline P5 & 3 & 0.68 & 0.03 & 0.65 & 0.93 \\
\hline
\end{tabular}

